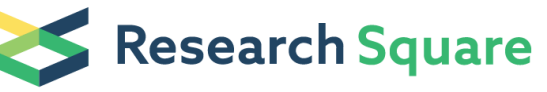 \\ Preprints are preliminary reports that have not undergone peer review. \\ They should not be considered conclusive, used to inform clinical practice, or referenced by the media as validated information.
}

\section{Tyrosine Inhibits TyrRS-mediated DNA Repair and Induces Neuronal Oxidative DNA Damage}

\section{Megha Jhanji}

University of South Carolina https://orcid.org/0000-0002-4796-8209

\section{Chintada Nageswara Rao}

University of South Carolina https://orcid.org/0000-0003-2451-0139

\section{Xueyan Zhou}

Wake Forest School of Medicine

\section{Keene}

University of Washington https://orcid.org/0000-0002-5291-1469

\section{Tao Ma}

Wake Forest University School of Medicine https://orcid.org/0000-0002-0763-7261

\section{Jason Stewart}

University of South Carolina

Mathew Sajish ( $\sim$ mathew2@cop.sc.edu )

University of South Carolina https://orcid.org/0000-0001-6715-5953

\section{Article}

Keywords: circadian-regulated tyrosine, Tyrosyl-tRNA synthetase, oxidative DNA damage

Posted Date: August 13th, 2021

DOI: https://doi.org/10.21203/rs.3.rs-785404/v1

License: (c) (1) This work is licensed under a Creative Commons Attribution 4.0 International License. Read Full License

Version of Record: A version of this preprint was published at Nature Communications on June 10th, 2022. See the published version at https://doi.org/10.1038/s41467-022-30785-8. 


\title{
Tyrosine Inhibits TyrRS-mediated DNA Repair and Induces Neuronal Oxidative DNA Damage
}

\author{
Megha Jhanji ${ }^{1}$, Chintada Nageswara Rao ${ }^{1}$, Xueyan Zhou ${ }^{2}$, C. Dirk Keene ${ }^{3}$, Tao Ma ${ }^{2,4}$, Jason A. Stewart ${ }^{5}$, \\ and Mathew Sajish ${ }^{1 *}$
}

\author{
${ }^{1}$ Department of Drug Discovery and Biomedical Sciences, College of Pharmacy, \\ University of South Carolina, SC 29208 \\ ${ }^{2}$ Department of Internal Medicine, Gerontology and Geriatric Medicine, Wake Forest School of \\ Medicine, Winston-Salem, North Carolina, USA \\ ${ }^{3}$ Department of Laboratory Medicine and Pathology, University of Washington School of Medicine, \\ Seattle, Washington, USA \\ ${ }^{4}$ Department of Neurobiology and Anatomy, Wake Forest School of Medicine, Winston-Salem, North \\ Carolina, USA \\ ${ }^{5}$ Department of Biological Sciences, College of Arts and Sciences, \\ University of South Carolina, SC 29208 \\ *Correspondence: mathew2@cop.sc.edu
}




\begin{abstract}
Human aging and neurodegenerative diseases accumulate oxidative DNA damage-associated mutations in neurons. Circadian-regulated tyrosine (Tyr) is increased during aging and in Alzheimer's Disease (AD). Tyr exacerbates the cognitive decline in the elderly and AD patients. Tyrosyl-tRNA synthetase (TyrRS) that activates Tyr for protein synthesis and participates in DNA repair is depleted in the affected brain regions of AD patients through an unknown mechanism. Here, we found that increased Tyr levels decrease the nuclear and neurite levels of TyrRS in neurons and cause oxidative DNA damage. Although Tyr inhibits protein synthesis at the elongation step, dopamine (DA)- a neurotransmitter derived from Tyr increases TyrRS levels. We previously showed that Tyr inhibits TyrRS-mediated activation of poly-ADP-ribose polymerase 1 (PARP1), a modulator of DNA repair. We now found that trans-resveratrol (transRSV) that binds to TyrRS mimicking 'Tyr conformation' decreases TyrRS, inhibits DNA repair and induces neurotoxicity. Conversely, cis-RSV binds to TyrRS mimicking a 'Tyr-free conformation,' increases TyrRS, facilitates DNA repair, and protects neurons against multiple neurotoxic agents in a TyrRS-dependent manner. Our results suggest that increased Tyr levels may have causal effects in human aging and neurocognitive disorders and offer a plausible explanation to divergent results obtained in clinical trials using RSV.
\end{abstract}




\section{Introduction}

TyrRS is a member of the evolutionarily conserved family of aminoacyl-tRNA synthetases (aaRSs) that activates the aromatic amino acid (AAA) Tyr for protein synthesis ${ }^{1}$. TyrRS has a moonlighting function in DNA repair as well ${ }^{2,3}$ and is essential for cell survival ${ }^{4}$. In neurons, brainderived neurotrophic factor (BDNF) stimulates the de novo synthesis of TyrRS ${ }^{5}$. Protein synthesis is required for long-term memory formation ${ }^{6,7}$, and consistently, the brain protein level of TyrRS is depleted in the affected brain regions of $\mathrm{AD}$ patients ${ }^{8}$ through an unknown mechanism. Tyr is circadian-regulated with the highest serum levels in the morning and lowest at midnight (sleep time $)^{9,10}$. Sleep stimulates human brain protein synthesis ${ }^{11}$, memory formation ${ }^{12,13}$, and neuronal DNA repair ${ }^{14}$. Beyond feeding and protein synthesis ${ }^{15}$, Tyr level is modulated by the circadian activities of tyrosine hydroxylase $(\mathrm{TH})^{16}$, tyrosine aminotransferases (TAT) $)^{17,18}$, and gut microbiota $^{19}$. However, serum levels of Tyr increase during human aging ${ }^{20-22}$, and increased Tyr level is a biomarker for the development of type 2 diabetes (T2D) in humans ${ }^{23}$, a major risk factor for dementia ${ }^{24}$ and $\mathrm{AD}^{25}$. Genetic mutations that increase the levels of Tyr (tyrosinemia) ${ }^{26-29}$ or its precursor L-phenylalanine (Phe, phenylketonuria $[\mathrm{PKU}])^{30}$ cause multiple health problems, including cognitive deficits in children. Moreover, treatment with Tyr exacerbates the cognitive decline in the elderly ${ }^{31-33}$ and AD patients ${ }^{34}$, and dysregulated Tyr metabolism shortens lifespan in tyrosinemia patients ${ }^{35}$ through unknown mechanisms.

We previously showed that Tyr inhibits TyrRS-dependent activation of PARP1 ${ }^{36}$, a major modulator of DNA repair ${ }^{37,38}$. Here, we found that increased Tyr levels decrease the nuclear and neurite levels of TyrRS and cause neuronal oxidative DNA damage, potentially through the inhibition of protein synthesis at the elongation step. However, the neurotransmitter derived from 
Tyr (dopamine) stimulates the de novo synthesis of neuronal TyrRS. Furthermore, consistent with our previous findings that $c i s-\mathrm{RSV}$ evokes a 'Tyr-free conformation' ${ }^{39}$, and trans-RSV mimics a 'Tyr conformation' ${ }^{36}$ in TyrRS, we now show that cis-and trans-RSV have opposite effects on TyrRS levels and neuronal DNA repair. cis-RSV protects the neurons against Tyr and other neurotoxic agents-induced depletion of TyrRS and DNA damage. Therefore, our results provide a potential molecular basis for the age-associated accumulation of neuronal oxidative DNA damage ${ }^{40-43}$ and Tyr-induced cognitive impairments in elderly and AD patients ${ }^{31-34}$.

\section{Results}

TyrRS is decreased in the hippocampal tissue samples of human AD patients.

$\mathrm{AD}$ decreases brain protein synthesis at the elongation step in humans ${ }^{44-47}$ through an unknown mechanism. Recently published human brain proteome showed decreased TyrRS and phenylalanyl-tRNA synthetase beta (PheRS $\beta$ ) levels in AD-affected brain regions ${ }^{8}$ (Supplementary Fig. 1a and b). We validated the depletion of TyrRS and PheRS $\beta$ in the hippocampal region of AD patients. However, the level of PheRS $\alpha$ was not affected (Fig. 1a and Supplementary Table 1). Our re-analysis of a second brain proteome ${ }^{48}$ showed that the protein levels of TyrRS and PheRS $\beta$ correlate with cognitive performance in humans (Supplementary Fig. 1c) ${ }^{48}$. Conversely, their decrease correlates with AD status and Braak stages (Supplementary Fig. 1d $)^{48}$. Intriguingly, a meta-analysis of human brain transcriptomic data from AD patients did not show any changes in the mRNA levels of TyrRS or PheRS $\beta^{49,50}$. While PheRS $\beta$ translation declines in an age-dependent manner (Supplementary Fig. 1e) ${ }^{51}$, TyrRS did not correlate with any known biomarkers of AD or other neurodegenerative diseases (Supplementary Fig. 1f $)^{48}$, indicating that TyrRS protein level might be modulated by hitherto unknown factors. 


\section{Tyrosine is increased during aging and in neurocognitive disorders in humans.}

Aging is the highest risk factor for neurodegenerative diseases ${ }^{52}$ and intriguingly, the incidence of $\mathrm{AD}$ and other dementias is higher in women than in men ${ }^{53}$. Tyr level increases during human aging $^{20-22}$ and consistently, Tyr levels are also increased in human AD brain tissues ${ }^{54-56}$. Although there is no sex difference in Tyr levels in children ${ }^{57}$ or $\mathrm{AD}$ patients ${ }^{58}$, interestingly, young women have lower serum Tyr levels than young men ${ }^{21,57,59}$. However, menopause increases Tyr levels ${ }^{60}$, resulting in a significant increase in Tyr levels in older women from $\sim 60-70 \mathrm{yr}^{20}($ Supplementary Fig. 2a and Supplementary Table 2). Beyond neurodegenerative diseases ${ }^{52}$, aging in humans is associated with increased incidents of other diseases as well ${ }^{61}$. Consistently, our literature analysis showed that Tyr and/or Phe are increased during delirium, heart failure (HF), Parkinson's Disease (PD), autism spectrum disorders (ASD), cardiovascular diseases (CVD), and other metabolic disorders in humans (Supplementary Fig. 2b and Supplementary Table 3). Interestingly, increased levels of Tyr and/or Phe inhibit aminoacyl-tRNA synthesis in the brain ex vivo ${ }^{62,63}$ and inhibit protein synthesis ${ }^{64}$ and induce DNA damage ${ }^{65,66}$ and promote oxidative stress in brain ${ }^{67}$ in vivo in rat. Because human $\mathrm{AD}$ brain has decreased levels of TyrRS (Fig. 1a), and AD decreases brain protein synthesis at the elongation step ${ }^{44-47}$, and aged neurons ${ }^{40}$ and $\mathrm{AD}$ brain $^{42}$ accumulate increased levels of oxidative DNA damage, and Tyr inhibits brain protein synthesis ${ }^{64}$, we hypothesized that increased levels of Tyr negatively regulate the protein levels of TyrRS and might cause neuronal oxidative DNA damage.

\section{Tyrosine decreases and dopamine increases neuronal TyrRS protein.}

As expected, treatment with Tyr in rat cortical neurons (DIV 9/10) decreased TyrRS (Fig. 1b) with preferential effects in the nucleus and the neurites (Fig. 1b). Although Tyr depleted PheRS $\beta$, it did 
not affect the levels of PheRS $\alpha$ (Fig. 1c). Similarly, Phe, 3,4-dihydroxy-L-phenylalanine (LDOPA), and 6-hydroxydopamine (6-OHDA) also decreased the levels of TyrRS and PheRS $\beta$ (Fig. 1c and Supplementary Fig. 3a-c). We previously showed that $~ 75 \%$ knockdown of TyrRS using siRNA ( siRNA $^{\text {TyrRS }}$ ) does not affect cell viability ${ }^{36}$. However, siRNA ${ }^{\text {TyrRS }}$ in cortical neurons ( 50\% knockdown) resulted in robust neurite degeneration (Fig. 1d and Supplementary Fig. 3d), indicating a critical role of TyrRS in maintaining neurite stability. Despite a significant decrease in the neurite levels of TyrRS, surprisingly, Tyr did not induce neurite degeneration (Fig. 1b). Moreover, the levels of TyrRS were restored in 16-24 hr (Fig. 1e and Supplementary Fig. 3e), suggesting that the effect of Tyr on TyrRS protein levels is reversible. The neurotransmitter dopamine (DA), which is decreased during aging ${ }^{68}$, and in the affected brain regions of $\mathrm{AD}$ patients $^{54}$, is generated from Tyr (L-Tyr $\rightarrow$ L-DOPA $\rightarrow$ DA). DA dephosphorylates eukaryotic elongation factor $2(\mathrm{eEF} 2)^{69}$ and activates neuronal protein synthesis ${ }^{70}$. Because BDNF activates $\mathrm{eEF}^{71}$ and stimulates the de novo synthesis of neuronal TyrRS ${ }^{5}$ (Supplementary Fig. 3f and g), we tested if DA would also increase neuronal TyrRS levels. As expected, DA increased the protein levels of TyrRS (Fig. 1f and Supplementary Fig. 3h), and the effects of DA were abrogated by rapamycin (rapa) (Fig. 1g). Unlike DA ${ }^{69}$, treatment with Tyr inhibited eEF2 (Fig. 1h). This data suggests that while Tyr decreases TyrRS protein levels, BDNF and DA increase it (Fig. 1i).

\section{cis-RSV and trans-RSV have opposite effects on TyrRS levels in neurons.}

We previously showed that trans-RSV competes with Tyr to bind TyrRS ${ }^{36}$. More importantly, we showed that low concentration trans-RSV adapts its cis conformation (cis-RSV) and increases the protein levels of TyrRS ${ }^{36}$. Furthermore, we found that cis-RSV binding to TyrRS alters its normal function and mediates a PARP1-dependent stress response, whereas trans-RSV mimics Tyr 
binding. Although cis-RSV and trans-RSV exist in mixtures ${ }^{72,73}$ and are stable for at least six weeks at $4^{\circ} \mathrm{C}^{72,73}$, and in the cell for $24 \mathrm{hr}^{74}$, the sulfate metabolites of RSV that provide an intracellular pool ${ }^{75}$ mainly generate $c i s-\mathrm{RSV}^{74}$. Clinical studies using a daily dose of $1,000 \mathrm{mg} / \mathrm{day}$ trans-RSV (>99\% pure) reported a peak trans-RSV plasma concentration of $137 \mu \mathrm{M}^{76}$ and 50 $640 \mu \mathrm{M}$ trans-RSV accumulation in human tissues ${ }^{75}$. Recent clinical studies using low-dose transRSV (75mg/dose) reported cognitive benefits in postmenopausal women ${ }^{77-79}$, who have higher Tyr levels ${ }^{60}$. In contrast, clinical studies with $1,000 \mathrm{mg} / \mathrm{dose}$ trans-RSV resulted in brain volume loss in $\mathrm{AD}$ patients ${ }^{80}$ through unknown mechanisms. Because the brain protein level of TyrRS correlates with cognitive performance in humans (Supplementary Fig. 1c) ${ }^{48}$ and is essential for survival $^{1,4}$, we hypothesized that cis-RSV and trans-RSV would have differential effects on neuronal TyrRS levels. Consistent with the results in clinical trials, a low dose of trans-RSV $(10 \mu \mathrm{M})$ increased TyrRS and the high dose $(50 \mu \mathrm{M})$ decreased it, whereas cis-RSV $(10-50 \mu \mathrm{M})$ increased TyrRS protein levels (Fig. 2a and Supplementary Fig. 4a). cis-RSV rescued the effects of trans-RSV and Tyr-mediated decrease in TyrRS levels in a dose-dependent manner (Fig. 2b and c). High concentration trans-RSV decreased PheRS $\beta$, not PheRS $\alpha$ levels, while low concentration cis-RSV increased their levels (Fig. 2d). Further, cis-RSV-mediated increase in TyrRS level was abrogated by adding cycloheximide (CHX) (Fig. 2e). Ser51 phosphorylation of eukaryotic initiation factor 2 alpha (p-eIF2 $\alpha$ ) and Thr56 phosphorylation of eEF2 (p-eEF2) inhibit protein synthesis at the initiation and elongation steps, respectively. While cis-RSV triggered a transient increase in the levels of p-eIF2 $\alpha$ (Supplementary Fig. $\mathbf{4 b}$ and $\mathbf{c}$ ), trans-RSV sustained the inhibition of eIF2 $\alpha$ (Supplementary Fig. 4b and c). Consistent with a previous report ${ }^{81}$, trans- $^{-}$ RSV inhibited eEF2 (Fig. 2f), but in contrast, cis-RSV activated eEF2 through dephosphorylation (Fig. 2f). Similarly, treatment with an eEF2K activator (nelfinavir) ${ }^{82}$ depleted neuronal TyrRS 
which was rescued by cis-RSV (Fig. 2g and Supplementary Fig. 4d). We previously showed that genetic reduction of eEF2K attenuates age-related memory deficits in mice ${ }^{83}$. Consistently, we found that TyrRS and PheRS $\beta$ were increased in the brain tissue samples of eEF2 $\mathrm{K}^{+/-}$mice $($Fig. 2h). To determine the mechanism of $c i s-\mathrm{RSV}$-mediated activation of eEF2, we tested if cis- and trans-RSV modulate the interaction of TyrRS with eEF2. We found that cis-RSV facilitated the interaction of eEF2 with TyrRS and protein phosphatase 2 (PP2A), whereas trans-RSV and Tyr decreased their interactions (Fig. 2i). These data suggest that cis-RSV and Tyr modulate the de novo synthesis of TyrRS at the elongation step, similar to $\mathrm{BDNF}^{71}$ and $\mathrm{DA}^{69}$. Furthermore, similar to 6-OHDA (Supplementary Fig. 3c), other neurotoxic agents such as the N-Methyl-D-aspartate (NMDA), and the mitochondrial toxin 1-methyl-4-phenylpyridinium ( $\mathrm{MPP}^{+}$) also decreased the levels of neuronal TyrRS after $4 \mathrm{hr}$ of treatment (Supplementary Fig. 4e and f); cis-RSV suppressed this effect, whereas trans-RSV exacerbated it (Supplementary Fig. 4e and f), suggesting that neuronal TyrRS is a potential target of multiple neurotoxic agents.

\section{Pharmacological activation of protein synthesis increases TyrRS levels in neurons.}

Phosphorylation of eIF2 $\alpha$ modulates motor and cognitive function ${ }^{84-88}$, and neuronal survival ${ }^{89}$. Pharmacological activation of mRNA translation using integrated stress response inhibitor (ISRIB) protects against age-related memory deficits ${ }^{90}$. Consistently, treatment with ISRIB (550nM) increased the protein levels of TyrRS and PheRS $\beta$ (Supplementary Fig. 5a) and rescued trans-RSV-mediated depletion of TyrRS (Supplementary Fig. 5b). Interestingly, ISRIB stimulated the dephosphorylation of eEF2 (Supplementary Fig. 5a), potentially mediated through increased levels of TyrRS. However, higher doses of ISRIB (250-500nM) decreased TyrRS levels (Supplementary Fig. 5c), consistent with some reported adverse effects of ISRIB ${ }^{91,92}$. Because 
circadian-regulated Tyr ${ }^{9} 10$ decreased neurite TyrRS (Fig. 1b), and sleep regulates synaptic protein synthesis ${ }^{93}$, we wondered if the synaptic protein level of TyrRS is circadian-regulated. Our reanalysis of the mouse circadian proteomic ${ }^{93}$ and metabolomic ${ }^{94}$ data showed that synaptic protein level of only TyrRS (among the aaRSs) is circadian-regulated and is inversely correlated with Tyr levels (Supplementary Fig. 5d). Further, re-analysis of the human metabolome ${ }^{95,96}$ showed that sleep deprivation increases the serum levels of Tyr (Supplementary Fig. S5e). Collectively, these data suggest that Tyr is a potential endogenous modulator of synaptic and nuclear TyrRS.

\section{Tyrosine induces oxidative DNA damage in neurons and cis-RSV protects against it.}

Human aging and neurodegenerative diseases accumulate oxidative DNA damage-associated mutations in neurons through unknown mechanisms ${ }^{40-43}$. While sleep deprivation causes oxidative DNA damage ${ }^{97,98}$, sleep stimulates neuronal DNA repair ${ }^{14}$ through an unknown mechanism. Because TyrRS has a moonlighting function in DNA repair ${ }^{2,3}$, we hypothesized that decreased levels of Tyr in the night ${ }^{9,10}$ may switch the function of a fraction of TyrRS from protein synthesis to DNA repair, and conversely, aging and neurodegenerative diseases that increase Tyr levels (Supplementary Fig. 2) may inhibit TyrRS-mediated DNA repair. Therefore, increased Tyr levels and compounds that mimic 'Tyr conformation' in TyrRS may induce neuronal oxidative DNA damage. Conversely, compounds that mimic a 'Tyr-free conformation' in TyrRS may shift its function to facilitate neuronal DNA repair. To test this possibility, we treated neuronal cultures with cis-RSV, which evokes a 'Tyr-free conformation'39, or trans-RSV, which mimics a 'Tyr conformation' in TyrRS ${ }^{36}$. Treatment with Tyr resulted in the accumulation of $\gamma-\mathrm{H} 2 \mathrm{AX}$ foci (a marker of DNA damage) and 8-oxo-2'-deoxyguanosine (8-oxo-dG, a marker of oxidative DNA damage) (Fig. 3a and b). While cis-RSV rescued Tyr-induced accumulation of $\gamma-\mathrm{H} 2 \mathrm{AX}$, and 8- 
oxo-dG, trans-RSV itself caused the accumulation of $\gamma-\mathrm{H} 2 \mathrm{AX}$ and 8-oxo-dG (Fig. 3a and b). Tyr also decreased the levels of 8-oxoguanine-DNA glycosylase (OGG1) (Fig. 3c), analogous to the reported decrease in the levels of OGG1 in sleep-deprived humans ${ }^{98}$ and in the AD brain tissues ${ }^{99}$. cis-RSV rescued Tyr-mediated depletion of OGG1 (Supplementary Fig. 6a). 8-oxo-dG is highly mutagenic, driving a G.C $\rightarrow$ A.T transversion ${ }^{100}$, and mutagenic frequency is reported to increase in aged neurons ${ }^{40}$ and $\mathrm{AD}$ brain tissues ${ }^{43}$. Consistently, $\gamma$-H2 $\mathrm{AX}^{101,102}$ and 8 -oxo- $\mathrm{dG}^{42}$ are accumulated in AD neurons. Further, D-Tyr, which does not get converted to $\mathrm{DA}^{103}$ but is activated by TyrRS ${ }^{104}$, induced neurotoxicity, whereas D-Phe and D-Trp had no effects (Fig. 3d, and e and Supplementary Fig. 6b and c). cis-RSV protected against D-Tyr-mediated neurotoxicity but not trans-RSV (Fig. 3f). Emerging works show a critical role of histone poly-ADP-ribosylation factor (HPF1) in DNA repair ${ }^{105}$. Although cis-RSV did not affect the HPF1 levels, treatment with Tyr and trans-RSV decreased the levels of HPF1 (Fig. 3g and Supplementary Fig. 6d and e), indicating multiple mechanisms for Tyr-mediated accumulation of oxidative DNA damage in neurons. Consistently, we found that HPF1 is decreased in the hippocampal tissues from AD patients (Fig. 3h).

\section{cis-RSV is neuroprotective and trans-RSV is neurotoxic.}

Because cis- and trans-RSV have opposite effects on neuronal oxidative DNA damage, we hypothesized that they would have differential effects on neuronal survival under stress conditions. We analyzed cis- and trans-RSV effects on the survival of rat primary cortical neurons exposed to different stress agents to test this hypothesis. As expected, the effect of trans-RSV on NMDAmediated neurotoxicity showed a concentration-dependent dual response, where low concentrations of trans-RSV $(\leq 10 \mu \mathrm{M})$ evoked protective effects, but the higher concentrations 
$(\geq 25 \mu \mathrm{M})$ exacerbated the toxicity (Fig. 4a). In contrast, cis-RSV protected against NMDAmediated toxicity in a concentration-dependent manner (Fig. 4b). Hence, the concentrationdependent dual response of trans-RSV on neuroprotection is consistent with trans to cis conversion at low concentrations ${ }^{36,74}$, increasing TyrRS levels (Fig. 2a), and the retention of 'trans/Tyr conformation' at high concentrations ${ }^{36,39}$, causing TyrRS depletion (Fig. 2a). We also found that cis-RSV $(50 \mu \mathrm{M})$ suppressed the neurotoxicity induced by a DNA-damaging agent (etoposide, ETO) (Supplementary Fig. 7a), oxidative stress $\left(\mathrm{H}_{2} \mathrm{O}_{2}\right)$ (Supplementary Fig. 7b), and mitochondrial inhibition $\left(\mathrm{MPP}^{+}\right)($Supplementary Fig. 7c) but trans-RSV $(50 \mu \mathrm{M})$ did not protect against these neurotoxic agents (Supplementary Fig. 7a-c). To test if the observed effects of $c i s$ - and trans-RSV on neurotoxicity are mediated via TyrRS, we carried out siRNA knockdown of TyrRS (siRNA ${ }^{\text {TyrRS }}$ ) in rat cortical neurons. TyrRS knockdown (Supplementary Fig. 3d) blunted the neuroprotective effects of cis-RSV but did not diminish the toxicity of trans-RSV $(50 \mu \mathrm{M})$ upon NMDA treatment $(\mathbf{F i g} .4 \mathbf{c})$. These results suggest that the neuroprotective effect of cis-RSV (and low-dose trans-RSV) is TyrRS dependent, but the neurotoxic effect of trans-RSV is TyrRS independent. Moreover, we found that trans-RSV $(50 \mu \mathrm{M})$ by itself was neurotoxic in the rat primary cortical neuron cultures (Fig. 4c), whereas cis-RSV protected against the neurotoxicity induced by trans-RSV in a dose-dependent manner (Fig. 4d). Furthermore, a high concentration of trans-RSV and D-Tyr increased the levels of cleaved caspase-3 (a marker of apoptosis) in rat primary cortical neurons (Supplementary Fig. 7d and e). In contrast, cis-RSV decreased the levels of caspase-3 cleavage (Supplementary Fig. 7d). As expected, treatment with either ISRIB, eEF2K inhibitor or DA protected against neurotoxic effects of trans-RSV (Supplementary Fig. 7f-h), indicating a critical role of protein synthesis in neuronal survival. 


\section{cis-RSV and trans-RSV have opposite effects on the auto-PARylation of PARP1.}

We previously showed that Tyr inhibits the auto-poly-ADP-ribose(PAR)ylation of PARP1 ${ }^{36}$ while cis-RSV induced a 'Tyr-free conformation' in TyrRS ${ }^{39}$ to stimulate the auto-PARylation ${ }^{36}$. Consistent with the circadian regulation of Tyr (Supplementary Fig. 5d), auto-PARylation of PARP1 is also circadian-regulated ${ }^{106}$. Because trans-RSV mimics the 'Tyr conformation' in TyrRS ${ }^{36}$, we analyzed the effects of $c i s-$ and trans-RSV on the auto-PARylation of PARP1 ${ }^{36}$. As expected, a low concentration of trans-RSV $(5 \mu \mathrm{M})$, which converts to cis-RSV in solution $^{36,74}$, and cis-RSV stimulated the auto-PARylation of PARP1 (Fig. 4e and f) whereas higher concentrations of trans-RSV $(\geq 25 \mu \mathrm{M})$ inhibited the auto-PARylation of PARP1 (Fig. 4f). It is interesting to note that the apparent $\mathrm{Ki}$ value of trans-RSV-mediated inhibition of Tyr activation by TyrRS in an ATP-PPi exchange assay (Tyr + ATP $\rightarrow$ Tyr-AMP + PPi) was $\sim 25 \mu \mathrm{M}^{36}$ which is the lowest concentration of trans-RSV that significantly inhibits the auto-PARylation of PARP1 (Fig. 4f). We previously showed that Tyr inhibits auto-PARylation-dependent acetylation of proteins $^{36}$. Further, $500 \mathrm{mg} /$ day dosing of trans-RSV $(68.5 \mu \mathrm{M}$ peak plasma concentration) inhibited the acetylation of $\mathrm{H} 3$ at lysine 56 (Ac-K56-H3) in humans ${ }^{107}$. Consistently, trans-RSV $(\geq 25 \mu \mathrm{M})$ inhibited H3 acetylation at lysines 9 and 56 (Ac-K9-H3 and Ac-K56-H3) (Fig. 4e and f), whereas cis-RSV increased the acetylation of H3 lysine 9 (Ac-K9-H3). Furthermore, TyrRS knockdown diminished the effects of low-concentration $(5 \mu \mathrm{M})$ trans-RSV and cis-RSV $(25 \mu \mathrm{M})$ on the auto-PARylation of PARP1 (Fig. 4g and Supplementary Fig. 7i).

\section{cis-RSV stimulates the deADP-ribosylation of neuronal chromatin.}

DNA damage activates PARP1/HPF1-dependent serine ADP-ribosylation of histones ${ }^{108}$, and removal of these 'ADP-ribose chromatin scar' is essential for neuronal survival ${ }^{109,110}$. Importantly, 
the brain samples of AD patients have increased levels of nuclear ADP-ribosylation ${ }^{111}$, suggesting a potential role of 'ADP-ribose chromatin scar' in AD-related neurodegeneration. Although autoPARylation dissociates PARP1 from the chromatin ${ }^{112}$, HPF1 inhibits the auto-PARylation ${ }^{113}$, and increases trans-PARylation of chromatin ${ }^{113,114}$. Because trans-RSV inhibited the auto-PARylation (Fig. 4f), we hypothesized that trans-RSV would increase PARP1-dependent trans-PARylation of the chromatin. As expected, trans-RSV increased the association of PARP1 with chromatin and increased the levels of PARylated proteins in the chromatin fraction (Fig. 5a). Further, low concentrations of trans-RSV $(\leq 10 \mu \mathrm{M})$ and cis-RSV prevented the interaction of PARP1 with histone H3 while the higher concentrations $(\geq 25 \mu \mathrm{M})$ of trans-RSV increased it (Supplementary Fig. 8a). Although cis-RSV-mediated auto-PARylation of PARP1 resulted in its removal from the chromatin, unexpectedly, we found that cis-RSV activated the deADP-ribosylation of the chromatin fraction along with higher levels of TyrRS (Fig. 5a and Supplementary Fig. 8b). ADP-

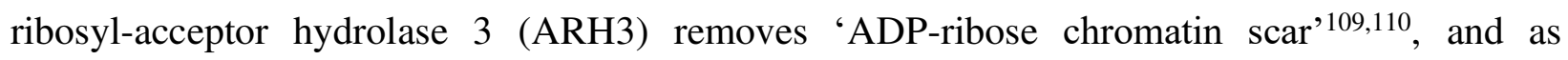
expected, cis- and trans-RSV had differential effects on the recruitment of ARH3 to the chromatin (Fig. 5a and Supplementary Fig. 8c). Despite having increased levels of nuclear ADPribosylation ${ }^{111}$, the levels of ARH3 remained unchanged in the hippocampal region of human AD patients (Supplementary Fig. 8d), indicating that ARH3 may not be functional in human AD brain tissues in the absence of TyrRS. Consistently, we found that TyrRS interacted with ARH3 (Fig. 5b), suggesting a potential novel role of TyrRS in the removal of 'ADP-ribose chromatin scar' (Fig. 5a) that enhances neuronal DNA repair and survival. 


\section{'Trapped' PARP1 inhibits DNA repair and mediates the neurotoxic effects of trans-RSV.}

Suicidal crosslinking of PARP1 to the damaged DNA ${ }^{115}$ causes cytotoxicity ${ }^{116}$, and therefore, cell survival depends on removing 'trapped' PARP1 on the broken DNA by either ablation ${ }^{38,117}$ or auto-PARylation ${ }^{112,118,119}$. Because trans-RSV caused DNA damage (Fig. 3a and b) and inhibited the auto-PARylation of PARP1 (Fig. 4f), and ablation of PARP1 rescues 'trapped' PARP1mediated neurotoxicity ${ }^{120-122}$, we hypothesized that trans-RSV-mediated neurotoxicity is exerted through 'trapped' PARP1 on the damaged DNA. Consistently, small interfering RNA (siRNA) knockdown of PARP1 (siRNA ${ }^{\text {PARP1}}$ ) protected against trans-RSV-mediated neurotoxicity but did not interfere with the effect of cis-RSV (Fig. 5c), indicating that 'trapped' PARP1 mediates the neurotoxic effects of trans-RSV. On the other hand, we found that cis-RSV facilitated the recruitment of DNA repair factors such as HPF1 and OGG1 to the chromatin (PARP2 and XRCC1 were not affected) while trans-RSV prevented their recruitment (Supplementary Fig. 8e). PARP1 inhibits flap endonuclease (FEN1)-dependent long patch base excision repair (LP-BER) ${ }^{123}$, and consistently, cis-RSV decreased the recruitment of FEN1 (Supplementary Fig. 8e), indicating a potential role of TyrRS/ARH3-dependent deADP-ribosylation of PARP1 in limiting long patch BER. As further evidence of DNA repair, we assessed whether DNA synthesis occurred following cis- or trans-RSV treatment. The incorporation of nucleoside analogs into DNA from neurons was previously used as a readout of neuronal DNA repair ${ }^{37,102}$ and depletion of PARP1 or inhibitors of PARP1 increases the incorporation of nucleoside analogs ${ }^{37}$. In agreement with the observation that 'trapped' PARP1 on the DNA impairs base excision repair (BER) ${ }^{124,125}$, trans-RSV prevented the incorporation of the nucleoside analog CldU into DNA fibers isolated from neurons (Fig. 5d and Supplementary Fig. 8f). However, cis-RSV reduced the CldU incorporation (Fig. 5d and Supplementary Fig. 8f), suggesting the activation of PARP1-dependent short patch BER (SP- 
$\mathrm{BER})^{37}$, potentially through the displacement of FEN1 (Supplementary Fig. 8e) ${ }^{123}$ and/or increased recruitment of unmodified PARP1 to the chromatin (Fig. 5a) ${ }^{125}$ that limits DNA resection $^{38}$. This decrease also indicates that $c i s-\mathrm{RSV}$ might activate other DNA repair pathways that enhance discrimination against the incorporation of nucleoside analogs into the genome, which requires future explorations. Together these results show that cis-and trans-RSV may have opposite effects on TyrRS-regulated auto-PARylation ${ }^{36,39}$ and DNA repair ${ }^{2,3}$.

Taken together, our results explain the opposite effects of low and high doses of trans-RSV in clinical trials ${ }^{39}$. Our data suggest that the observed beneficial effects of RSV result from its cis conformation. The mechanism for opposite effects of cis- and trans-RSV on neuronal survival emerging from our studies are illustrated in Figure 5e. In this model, different forms of stress facilitate the interaction of TyrRS with PARP1 leading to its auto-PARylation ${ }^{36}$ and subsequent removal from the damaged DNA allowing recruitment of DNA repair factors such as HPF1, ARH3, and OGG1 to repair the damage efficiently. cis-RSV-bound TyrRS facilitates removing auto-PARylated PARP1 from chromatin while activating ARH3-mediated removal of 'ADPribose chromatin scar' to achieve efficient neuronal DNA repair. In contrast, treatment with transRSV decreases TyrRS in the absence of which PARP1 gets 'trapped' on the damaged DNA and impedes DNA repair. This inefficient repair process results in the accumulation of 'ADP-ribose chromatin scars' which drives the subsequent induction of neurodegeneration.

\section{Discussion}

This study shows that circadian-regulated Tyr ${ }^{9,10}$ is a negative regulator of neuronal TyrRS, providing a potential molecular basis for circadian modulation of synaptic TyrRS 
(Supplementary Fig. 5d) ${ }^{93}$, accumulation of oxidative DNA damage in aged neurons and AD brain tissues ${ }^{40-43}$, Tyr-mediated cognitive impairments ${ }^{26-29,31-34}$, and the decreased protein synthesis at the elongation step in human AD brain tissue samples ${ }^{44-47}$. Interestingly, mutant amino acid transporter that accumulates Tyr in Neurospora crassa is sensitive to $\mathrm{Tyr}^{126}$, and $\mathrm{Tyr}$ detoxification is essential for the survival of hematophagous insects ${ }^{127}$. Therefore, Tyr-mediated regulation of TyrRS might be an evolutionary conserved negative feedback regulatory mechanism of protein synthesis exploited by neurons to enhance plasticity. Interestingly, calorie restriction (CR) significantly lowers only Tyr levels among the AAAs ${ }^{128,129}$, and improves memory ${ }^{130,131}$ in humans. Similarly, sleep that decreases Tyr levels stimulates human brain protein synthesis ${ }^{11}$, memory formation ${ }^{12,13}$, and neuronal DNA repair ${ }^{14}$, potentially through the circadian regulation of TyrRS-mediated auto-PARylation of PARP1 ${ }^{36,106}$. Interestingly, exercise stimulates the production of BDNF, and DA is also known to activate PARP1-dependent DNA repair $^{132}$ and stimulates protein synthesis through activation of eEF2 in humans ${ }^{133}$. Consistently, PARylation is required for long-term memory formation ${ }^{134,135}$ and contributes to spatial and fear memory acquisition ${ }^{136,137}$. Not surprisingly, centenarians retain high levels of PARylation ${ }^{138,139}$ and nuclear PARP1 is decreased in the brains of $\mathrm{PD}^{140}$ and $\mathrm{AD}^{141,142}$ patients. Moreover, inflammatory conditions trigger proteolytic cleavage of TyrRS ${ }^{143}$ and inhibit PARP1-dependent DNA repair ${ }^{144}$. Although aging is the single most important contributing factor to the development of $\mathrm{AD}^{52}$, intriguingly, $\mathrm{AD}$ does not occur naturally in naked mole-rats (NMR), which are the longest-lived of rodents resistant to $\mathrm{AD}^{145,146}$. Because NMR maintains lower levels of Tyr ${ }^{147}$ and higher levels of auto-PARylation of PARP1 ${ }^{148,149}$, whether decreased levels of Tyr in NMR contribute to its longevity and protection against AD through enhanced TyrRS/PARP1-dependent DNA repair ${ }^{148,149}$ need to be explored in the future. Although 
increased levels of branched-chain amino acids (BCAAs) are associated with metabolic disorders ${ }^{23,150}$, in this context, it is interesting to note that the levels of BCAAs are decreased in $\mathrm{AD}^{151,152}$ as well as in $\mathrm{ASD}^{153-155}$. However, an increased level of Tyr is associated with both neurocognitive and metabolic disorders (Supplementary Fig. 2b and Supplementary Table 3). Although there is no sex differences in Tyr levels in children ${ }^{57}$, whether increased levels of Tyr in children with $\mathrm{ASD}^{156,157}$ or mutations of amino acid transporter (LAT1) that increase the levels of Tyr/Phe in the brain ${ }^{153,154}$ contribute to the increased incidence of mutations ${ }^{158}$ and dysregulated protein synthesis in $\mathrm{ASD}^{154}$ will be of future research interest. Therefore, Tyrmediated induction of 8-oxo-dG and $\gamma \mathrm{H} 2 \mathrm{AX}$ (Fig. 3a-c), and Tyr-mediated depletion of TyrRS shown here may have causal effects in human aging, motor, cognitive, and metabolic disorders (Supplementary Fig. 9).

Most recent clinical trials showed that low-dose trans-RSV $(50 \mathrm{mg} / \mathrm{dose}, 6 \mu \mathrm{M}$ peak plasma concentration) that gets converted to $c i s-\mathrm{RSV}^{36,74}$ and induces a 'Tyr-free conformation' in TyrRS $^{39}$ protected against human heart failure ${ }^{159}$ where high Tyr levels negatively correlate with survival $^{160,161}$. In contrast, high-dose trans-RSV $(500 \mathrm{mg} / \mathrm{dose}, 68.5 \mu \mathrm{M}$ peak plasma concentration ${ }^{76}$ ) that maintains 'trans/Tyr conformation' in TyrRS and induces oxidative DNA damage (Fig. 3a and $\mathbf{b}$ ) increased the CVD risk ${ }^{162}$. Consistently, oxidative DNA damage is elevated in $\mathrm{CVD}^{163}$ and patients with heart failure ${ }^{164}$. Therefore, in addition to a plausible explanation for the apparent benefits of low doses of trans-RSV ${ }^{76}$, our study suggests that cis- $^{-}$ RSV or compounds that use cis-RSV conformation as a pharmacophore may help in the chronotherapy of age-associated neurological disorders and potentially degenerative and metabolic diseases of other tissues. 


\section{References}

1 Ibba, M. \& Soll, D. Aminoacyl-tRNA synthesis. Annu Rev Biochem 69, 617-650, doi:10.1146/annurev.biochem.69.1.617 (2000).

2 Cao, X. et al. Acetylation promotes TyrRS nuclear translocation to prevent oxidative damage. Proc Natl Acad Sci U S A 114, 687-692, doi:10.1073/pnas.1608488114 (2017).

3 Wei, N. et al. Oxidative stress diverts tRNA synthetase to nucleus for protection against DNA damage. Mol Cell 56, 323-332, doi:10.1016/j.molcel.2014.09.006 (2014).

4 Schimmel, P. The endless frontier of tRNA synthetases. Enzymes 48, 1-10, doi:10.1016/bs.enz.2020.09.001 (2020).

5 Liao, L. et al. BDNF induces widespread changes in synaptic protein content and upregulates components of the translation machinery: An analysis using high-throughput proteomics. J Proteome Res 6, 1059-1071, doi:10.1021/pr060358f (2007).

6 Flexner, J. B., Flexner, L. B. \& Stellar, E. Memory in Mice as Affected by Intracerebral Puromycin. Science 141, 57-\&, doi:DOI 10.1126/science.141.3575.57 (1963).

7 Costa-Mattioli, M., Sossin, W. S., Klann, E. \& Sonenberg, N. Translational control of long-lasting synaptic plasticity and memory. Neuron 61, 10-26, doi:10.1016/j.neuron.2008.10.055 (2009).

$8 \mathrm{Xu}$, J. et al. Regional protein expression in human Alzheimer's brain correlates with disease severity. Commun Biol 2, 43, doi:10.1038/s42003-018-0254-9 (2019).

9 Wurtman, R. J., Chou, C. \& Rose, C. M. Daily rhythm in tyrosine concentration in human plasma: persistence on low-protein diets. Science 158, 660-662, doi:10.1126/science.158.3801.660 (1967). 
10 Wurtman, R. J., Rose, C. M., Chou, C. \& Larin, F. F. Daily rhythms in the concentrations of various amino acids in human plasma. N Engl J Med 279, 171-175, doi:10.1056/NEJM196807252790401 (1968).

11 Picchioni, D. et al. Rates of cerebral protein synthesis in primary visual cortex during sleep-dependent memory consolidation, a study in human subjects. Sleep $\mathbf{4 1}$, doi:10.1093/sleep/zsy088 (2018).

12 Marshall, L., Helgadottir, H., Molle, M. \& Born, J. Boosting slow oscillations during sleep potentiates memory. Nature 444, 610-613, doi:10.1038/nature05278 (2006).

13 Huber, R., Ghilardi, M. F., Massimini, M. \& Tononi, G. Local sleep and learning. Nature 430, 78-81, doi:10.1038/nature02663 (2004).

14 Zada, D., Bronshtein, I., Lerer-Goldshtein, T., Garini, Y. \& Appelbaum, L. Sleep increases chromosome dynamics to enable reduction of accumulating DNA damage in single neurons. Nature Communications 10, doi:ARTN 89510.1038/s41467-019-08806w (2019).

15 Moja, E. A. et al. Cycloheximide blocks the fall of plasma and tissue tryptophan levels after tryptophan-free amino acid mixtures. Life Sci 49, 1121-1128, doi:10.1016/00243205(91)90600-g (1991).

16 McGeer, E. G. \& McGeer, P. L. Circadian rhythm in pineal tyrosine hydroxylase. Science 153, 73-74, doi:10.1126/science.153.3731.73 (1966).

17 Fishman, B., Wurtman, R. J. \& Munro, H. N. Daily rhythms in hepatic polysome profiles and tyrosine transaminase activity: role of dietary protein. Proc Natl Acad Sci U S A 64, 677-682, doi:10.1073/pnas.64.2.677 (1969). 
18 Wurtman, R. J., Shoemaker, W. J. \& Larin, F. Mechanism of the daily rhythm in hepatic tyrosine transaminase activity: role of dietary tryptophan. Proc Natl Acad Sci U S A 59, 800-807, doi:10.1073/pnas.59.3.800 (1968).

19 Dodd, D. et al. A gut bacterial pathway metabolizes aromatic amino acids into nine circulating metabolites. Nature 551, 648-+, doi:10.1038/nature24661 (2017).

20 Chak, C. M. et al. Ageing Investigation Using Two-Time-Point Metabolomics Data from KORA and CARLA Studies. Metabolites 9, doi:ARTN 4410.3390/metabo9030044 (2019).

21 Darst, B. F., Koscik, R. L., Hogan, K. J., Johnson, S. C. \& Engelman, C. D. Longitudinal plasma metabolomics of aging and sex. Aging (Albany NY) 11, 1262-1282, doi:10.18632/aging.101837 (2019).

22 Hwangbo, N. et al. An aging clock using metabolomic CSF. bioRxiv, 2021.2004.2004.438397, doi:10.1101/2021.04.04.438397 (2021).

23 Wang, T. J. et al. Metabolite profiles and the risk of developing diabetes. Nat Med 17, 448-453, doi:10.1038/nm.2307 (2011).

24 Amidei, C. B. et al. Association Between Age at Diabetes Onset and Subsequent Risk of Dementia. Jama-J Am Med Assoc 325, 1640-1649, doi:10.1001/jama.2021.4001 (2021).

25 Janson, J. et al. Increased risk of type 2 diabetes in Alzheimer disease. Diabetes 53, 474481, doi:10.2337/diabetes.53.2.474 (2004).

26 Huhn, R. et al. Novel and recurrent tyrosine aminotransferase gene mutations in tyrosinemia type II. Human Genetics 102, 305-313, doi:DOI 10.1007/s004390050696 (1998). 
27 Ellaway, C. J. et al. Outcome of tyrosinaemia type III. Journal of Inherited Metabolic Disease 24, 824-832, doi:Doi 10.1023/A:1013936107064 (2001).

28 Bendadi, F. et al. Impaired cognitive functioning in patients with tyrosinemia type I receiving nitisinone. J Pediatr 164, 398-401, doi:10.1016/j.jpeds.2013.10.001 (2014).

29 van Vliet, K. et al. Emotional and behavioral problems, quality of life and metabolic control in NTBC-treated Tyrosinemia type 1 patients. Orphanet J Rare Dis 14, 285, doi:10.1186/s13023-019-1259-2 (2019).

30 Blau, N., van Spronsen, F. J. \& Levy, H. L. Phenylketonuria. Lancet 376, 1417-1427, doi:Doi 10.1016/S0140-6736(10)60961-0 (2010).

31 van de Rest, O., Bloemendaal, M., de Heus, R. \& Aarts, E. Dose-Dependent Effects of Oral Tyrosine Administration on Plasma Tyrosine Levels and Cognition in Aging. Nutrients 9, doi:10.3390/nu9121279 (2017).

32 Bloemendaal, M. et al. Neuro-Cognitive Effects of Acute Tyrosine Administration on Reactive and Proactive Response Inhibition in Healthy Older Adults. eNeuro 5, doi:10.1523/ENEURO.0035-17.2018 (2018).

33 Frobose, M. I., Westbrook, A., Bloemendaal, M., Aarts, E. \& Cools, R. Catecholaminergic modulation of the cost of cognitive control in healthy older adults. Plos One 15, e0229294, doi:10.1371/journal.pone.0229294 (2020).

34 Meyer, J. S. et al. Neurotransmitter precursor amino acids in the treatment of multiinfarct dementia and Alzheimer's disease. J Am Geriatr Soc 25, 289-298, doi:10.1111/j.1532-5415.1977.tb00640.x (1977).

35 van Spronsen, F. J. et al. Hereditary tyrosinemia type I: a new clinical classification with difference in prognosis on dietary treatment. Hepatology 20, 1187-1191 (1994). 
36 Sajish, M. \& Schimmel, P. A human tRNA synthetase is a potent PARP1-activating effector target for resveratrol. Nature 519, 370-373, doi:10.1038/nature14028 (2015).

$37 \mathrm{Wu}, \mathrm{W}$. et al. Neuronal enhancers are hotspots for DNA single-strand break repair. Nature, doi:10.1038/s41586-021-03468-5 (2021).

38 Caron, M. C. et al. Poly(ADP-ribose) polymerase-1 antagonizes DNA resection at double-strand breaks. Nature Communications 10, doi:ARTN 295410.1038/s41467-01910741-9 (2019).

39 Jhanji, M., Rao, C. N. \& Sajish, M. Towards resolving the enigma of the dichotomy of resveratrol: cis- and trans-resveratrol have opposite effects on TyrRS-regulated PARP1 activation. Geroscience, doi:10.1007/s11357-020-00295-w (2020).

40 Lodato, M. A. et al. Aging and neurodegeneration are associated with increased mutations in single human neurons. Science 359, 555-559, doi:10.1126/science.aao4426 (2018).

$41 \mathrm{Lu}, \mathrm{T}$. et al. Gene regulation and DNA damage in the ageing human brain. Nature 429, 883-891, doi:10.1038/nature02661 (2004).

42 Gabbita, S. P., Lovell, M. A. \& Markesbery, W. R. Increased nuclear DNA oxidation in the brain in Alzheimer's disease. J Neurochem 71, 2034-2040 (1998).

43 Park, J. S. et al. Brain somatic mutations observed in Alzheimer's disease associated with aging and dysregulation of tau phosphorylation. Nat Commun 10, 3090, doi:10.1038/s41467-019-11000-7 (2019).

44 Mann, D. M. et al. Alterations in protein synthetic capability of nerve cells in Alzheimer's disease. J Neurol Neurosurg Psychiatry 44, 97-102, doi:10.1136/jnnp.44.2.97 (1981). 
45 Bustany, P. et al. Local Brain Protein Metabolism in Dementia and Schizophrenia: In Vivo Studies with ${ }^{11} \mathrm{C}-\mathrm{L}-\mathrm{Methionine}$ and Positron Emission Tomography. (Positron Emission Tomography of the Brain, p208-211, Springer, Berlin, Heidelberg, 1983).

46 Langstrom, N. S., Anderson, J. P., Lindroos, H. G., Winblad, B. \& Wallace, W. C. Alzheimer's disease-associated reduction of polysomal mRNA translation. Brain Res Mol Brain Res 5, 259-269 (1989).

47 Ding, Q. X., Markesbery, W. R., Chen, Q. H., Li, F. \& Keller, J. N. Ribosome dysfunction is an early event in Alzheimer's disease. J Neurosci 25, 9171-9175, doi:10.1523/Jneurosci.3040-05.2005 (2005).

48 Johnson, E. C. B. et al. Large-scale proteomic analysis of Alzheimer's disease brain and cerebrospinal fluid reveals early changes in energy metabolism associated with microglia and astrocyte activation. Nat Med 26, 769-780, doi:10.1038/s41591-020-0815-6 (2020).

49 Noori, A., Mezlini, A. M., Hyman, B. T., Serrano-Pozo, A. \& Das, S. Systematic review and meta-analysis of human transcriptomics reveals neuroinflammation, deficient energy metabolism, and proteostasis failure across neurodegeneration. Neurobiology of Disease 149, doi:ARTN 10522510.1016/j.nbd.2020.105225 (2021).

50 Patel, H., Dobson, R. J. B. \& Newhouse, S. J. A Meta-Analysis of Alzheimer's Disease Brain Transcriptomic Data. J Alzheimers Dis 68, 1635-1656, doi:10.3233/JAD-181085 (2019).

51 Anisimova, A. S. et al. Multifaceted deregulation of gene expression and protein synthesis with age. Proc Natl Acad Sci U S A 117, 15581-15590, doi:10.1073/pnas.2001788117 (2020). 
52 Hou, Y. J. et al. Ageing as a risk factor for neurodegenerative disease. Nature Reviews Neurology 15, 565-581, doi:10.1038/s41582-019-0244-7 (2019).

53 Winblad, B. et al. Defeating Alzheimer's disease and other dementias: a priority for European science and society. Lancet Neurol 15, 455-532, doi:10.1016/S14744422(16)00062-4 (2016).

54 Storga, D., Vrecko, K., Birkmayer, J. G. D. \& Reibnegger, G. Monoaminergic neurotransmitters, their precursors and metabolites in brains of Alzheimer patients. Neuroscience Letters 203, 29-32, doi:Doi 10.1016/0304-3940(95)12256-7 (1996).

55 Kim, Y. H. et al. Metabolomic Analysis Identifies Alterations of Amino Acid Metabolome Signatures in the Postmortem Brain of Alzheimer's Disease. Exp Neurobiol 28, 376-389, doi:10.5607/en.2019.28.3.376 (2019).

56 Huo, Z. et al. Brain and blood metabolome for Alzheimer's dementia: findings from a targeted metabolomics analysis. Neurobiol Aging 86, 123-133, doi:10.1016/j.neurobiolaging.2019.10.014 (2020).

57 Andraos, S. et al. Population epidemiology and concordance for plasma amino acids and precursors in 11-12-year-old children and their parents. Sci Rep-Uk 11, doi:ARTN 361910.1038/s41598-020-80923-9 (2021).

58 Arnold, M. et al. Sex and APOE epsilon4 genotype modify the Alzheimer's disease serum metabolome. Nat Commun 11, 1148, doi:10.1038/s41467-020-14959-w (2020).

59 Caballero, B., Gleason, R. E. \& Wurtman, R. J. Plasma amino acid concentrations in healthy elderly men and women. Am J Clin Nutr 53, 1249-1252, doi:10.1093/ajcn/53.5.1249 (1991). 
60 Auro, K. et al. A metabolic view on menopause and ageing. Nature Communications $\mathbf{5}$, doi:ARTN 470810.1038/ncomms5708 (2014).

61 Lopez-Otin, C., Blasco, M. A., Partridge, L., Serrano, M. \& Kroemer, G. The hallmarks of aging. Cell 153, 1194-1217, doi:10.1016/j.cell.2013.05.039 (2013).

62 Lahdesmaki, P. Inhibition of protein and aminoacyl-tRNA synthesis, and binding and transport sites for aromatic amino acids in the brain in vitro with aromatic acids. Int $J$ Neurosci 23, 1-13, doi:10.3109/00207458408985341 (1984).

63 Lahdesmaki, P. \& Oja, S. S. Effect of aromatic acids on protein synthesis in subcellular preparations from the rat brain. J Neurobiol 6, 313-320, doi:10.1002/neu.480060307 (1975).

64 Lindroos, O. F. \& Oja, S. S. Hyperphenylalanaemia and the exchange of tyrosine in adult rat brain. Exp Brain Res 14, 48-60, doi:10.1007/BF00234910 (1971).

65 De Pra, S. D. et al. L-tyrosine induces DNA damage in brain and blood of rats. Neurochem Res 39, 202-207, doi:10.1007/s11064-013-1207-9 (2014).

66 Streck, E. L. et al. Role of antioxidant treatment on DNA and lipid damage in the brain of rats subjected to a chemically induced chronic model of tyrosinemia type II. Mol Cell Biochem 435, 207-214, doi:10.1007/s11010-017-3070-5 (2017).

67 Sgaravatti, A. M. et al. Tyrosine promotes oxidative stress in cerebral cortex of young rats. Int J Dev Neurosci 26, 551-559, doi:10.1016/j.ijdevneu.2008.05.007 (2008).

68 Haycock, J. W. et al. Marked disparity between age-related changes in dopamine and other presynaptic dopaminergic markers in human striatum. J Neurochem 87, 574-585, doi:10.1046/j.1471-4159.2003.02017.x (2003). 
69 David, O., Barrera, I., Gould, N., Gal-Ben-Ari, S. \& Rosenblum, K. D1 Dopamine Receptor Activation Induces Neuronal eEF2 Pathway-Dependent Protein Synthesis. Front Mol Neurosci 13, 67, doi:10.3389/fnmol.2020.00067 (2020).

70 Smith, W. B., Starck, S. R., Roberts, R. W. \& Schuman, E. M. Dopaminergic stimulation of local protein synthesis enhances surface expression of GluR1 and synaptic transmission in hippocampal neurons. Neuron 45, 765-779, doi:10.1016/j.neuron.2005.01.015 (2005).

71 Takei, N. et al. Brain-derived neurotrophic factor enhances the basal rate of protein synthesis by increasing active eukaryotic elongation factor 2 levels and promoting translation elongation in cortical neurons. J Biol Chem 284, 26340-26348, doi:10.1074/jbc.M109.023010 (2009).

72 Goldberg, D. M. et al. Direct Gas-Chromatographic Mass-Spectrometric Method to Assay Cis-Resveratrol in Wines - Preliminary Survey of Its Concentration in Commercial Wines. J Agr Food Chem 43, 1245-1250, doi:DOI 10.1021/jf00053a023 (1995).

73 RomeroPerez, A. I., LamuelaRaventos, R. M., Waterhouse, A. L. \& delaTorreBoronat, M. C. Levels of cis- and trans-resveratrol and their glucosides in white and rose Vitis vinifera wines from Spain. J Agr Food Chem 44, 2124-2128, doi:DOI 10.1021/jf9507654 (1996).

74 Fernandez-Castillejo, S., Macia, A., Motilva, M. J., Catalan, U. \& Sola, R. Endothelial Cells Deconjugate Resveratrol Metabolites to Free Resveratrol: A Possible Role in Tissue Factor Modulation. Mol Nutr Food Res 63, e1800715, doi:10.1002/mnfr.201800715 (2019). 
75 Patel, K. R. et al. Sulfate metabolites provide an intracellular pool for resveratrol generation and induce autophagy with senescence. Sci Transl Med 5, 205ra133, doi:10.1126/scitranslmed.3005870 (2013).

76 Cai, H. et al. Cancer chemoprevention: Evidence of a nonlinear dose response for the protective effects of resveratrol in humans and mice. Sci Transl Med 7, 298ra117, doi:10.1126/scitranslmed.aaa7619 (2015).

77 Thaung Zaw, J. J., Howe, P. R. C. \& Wong, R. H. X. Sustained Cerebrovascular and Cognitive Benefits of Resveratrol in Postmenopausal Women. Nutrients 12, doi:10.3390/nu12030828 (2020).

78 Thaung Zaw, J. J., Howe, P. R. \& Wong, R. H. Long-term effects of resveratrol on cognition, cerebrovascular function and cardio-metabolic markers in postmenopausal women: A 24-month randomised, double-blind, placebo-controlled, crossover study. Clin Nutr, doi:10.1016/j.clnu.2020.08.025 (2020).

79 Evans, H. M., Howe, P. R. C. \& Wong, R. H. X. Effects of Resveratrol on Cognitive Performance, Mood and Cerebrovascular Function in Post-Menopausal Women; A 14Week Randomised Placebo-Controlled Intervention Trial. Nutrients 9, doi:ARTN 2710.3390/nu9010027 (2017).

80 Turner, R. S. et al. A randomized, double-blind, placebo-controlled trial of resveratrol for Alzheimer disease. Neurology 85, 1383-1391, doi:10.1212/WNL.0000000000002035 (2015).

81 Khan, A. A., Dace, D. S., Ryazanov, A. G., Kelly, J. \& Apte, R. S. Resveratrol regulates pathologic angiogenesis by a eukaryotic elongation factor-2 kinase-regulated pathway. Am J Pathol 177, 481-492, doi:10.2353/ajpath.2010.090836 (2010). 
82 De Gassart, A. et al. Pharmacological eEF2K activation promotes cell death and inhibits cancer progression. Embo Reports 17, 1471-1484, doi:10.15252/embr.201642194 (2016).

83 Gosrani, S. P., Jester, H. M., Zhou, X. Y., Ryazanov, A. G. \& Ma, T. Repression of eEF2 kinase improves deficits in novel object recognition memory in aged mice. Neurobiol Aging 95, 154-160, doi:10.1016/j.neurobiolaging.2020.07.016 (2020).

84 Longo, F. et al. Cell-type-specific disruption of PERK-eIF2alpha signaling in dopaminergic neurons alters motor and cognitive function. Mol Psychiatry, doi:10.1038/s41380-021-01099-w (2021).

85 Costa-Mattioli, M. et al. Translational control of hippocampal synaptic plasticity and memory by the eIF2alpha kinase GCN2. Nature 436, 1166-1173, doi:10.1038/nature03897 (2005).

86 Costa-Mattioli, M. et al. eIF2alpha phosphorylation bidirectionally regulates the switch from short- to long-term synaptic plasticity and memory. Cell 129, 195-206, doi:10.1016/j.cell.2007.01.050 (2007).

87 Di Prisco, G. V. et al. Translational control of mGluR-dependent long-term depression and object-place learning by eIF2alpha. Nat Neurosci 17, 1073-1082, doi:10.1038/nn.3754 (2014).

88 Yang, W., Zhou, X., Zimmermann, H. R. \& Ma, T. Brain-specific suppression of AMPKalpha2 isoform impairs cognition and hippocampal LTP by PERK-mediated eIF2alpha phosphorylation. Mol Psychiatry, doi:10.1038/s41380-020-0739-z (2020).

89 Moreno, J. A. et al. Sustained translational repression by eIF2alpha-P mediates prion neurodegeneration. Nature 485, 507-511, doi:10.1038/nature11058 (2012). 
90 Krukowski, K. et al. Small molecule cognitive enhancer reverses age-related memory decline in mice. Elife 9, doi:ARTN e6204810.7554/eLife.62048 (2020).

91 Johnson, E. C. B. \& Kang, J. A small molecule targeting protein translation does not rescue spatial learning and memory deficits in the hAPP-J20 mouse model of Alzheimer's disease. Peerj 4, doi:ARTN e256510.7717/peerj.2565 (2016).

92 Briggs, D. I. et al. Role of Endoplasmic Reticulum Stress in Learning and Memory Impairment and Alzheimer's Disease-Like Neuropathology in the PS19 and APPSwe Mouse Models of Tauopathy and Amyloidosis. Eneuro 4, doi:ARTN e002510.1523/ENEURO.0025-17.2017 (2017).

93 Noya, S. B. et al. The forebrain synaptic transcriptome is organized by clocks but its proteome is driven by sleep. Science 366, doi:10.1126/science.aav2642 (2019).

94 Eckel-Mahan, K. L. et al. Coordination of the transcriptome and metabolome by the circadian clock. Proc Natl Acad Sci U S A 109, 5541-5546, doi:10.1073/pnas.1118726109 (2012).

95 Grant, L. K. et al. Circadian and wake-dependent changes in human plasma polar metabolites during prolonged wakefulness: A preliminary analysis. Sci Rep 9, 4428, doi:10.1038/s41598-019-40353-8 (2019).

96 Kervezee, L., Cermakian, N. \& Boivin, D. B. Individual metabolomic signatures of circadian misalignment during simulated night shifts in humans. PLoS Biol 17, e3000303, doi:10.1371/journal.pbio.3000303 (2019).

97 Carroll, J. E. et al. Partial sleep deprivation activates the DNA damage response (DDR) and the senescence-associated secretory phenotype (SASP) in aged adult humans. Brain Behavior and Immunity 51, 223-229, doi:10.1016/j.bbi.2015.08.024 (2016). 
98 Cheung, V., Yuen, V. M., Wong, G. T. C. \& Choi, S. W. The effect of sleep deprivation and disruption on DNA damage and health of doctors. Anaesthesia 74, 434-440, doi:10.1111/anae.14533 (2019).

99 Iida, T., Furuta, A., Nishioka, K., Nakabeppu, Y. \& Iwaki, T. Expression of 8oxoguanine DNA glycosylase is reduced and associated with neurofibrillary tangles in Alzheimer's disease brain. Acta Neuropathol 103, 20-25, doi:DOI $10.1007 / \mathrm{s} 004010100418$ (2002).

100 Shibutani, S., Takeshita, M. \& Grollman, A. P. Insertion of specific bases during DNA synthesis past the oxidation-damaged base 8-oxodG. Nature 349, 431-434, doi:10.1038/349431a0 (1991).

101 Shanbhag, N. M. et al. Early neuronal accumulation of DNA double strand breaks in Alzheimer's disease. Acta Neuropathol Commun 7, 77, doi:10.1186/s40478-019-0723-5 (2019).

102 Reid, D. A. et al. Incorporation of a nucleoside analog maps genome repair sites in postmitotic human neurons. Science 372, 91-94, doi:10.1126/science.abb9032 (2021).

103 Nagatsu, T., Levitt, M. \& Udenfriend, S. Tyrosine Hydroxylase. The Initial Step in Norepinephrine Biosynthesis. J Biol Chem 239, 2910-2917 (1964).

104 Calendar, R. \& Berg, P. D-Tyrosyl RNA: formation, hydrolysis and utilization for protein synthesis. J Mol Biol 26, 39-54, doi:10.1016/0022-2836(67)90259-8 (1967).

105 Palazzo, L. et al. Serine is the major residue for ADP-ribosylation upon DNA damage. Elife 7, doi:ARTN e3433410.7554/eLife.34334 (2018).

106 Asher, G. et al. Poly(ADP-ribose) polymerase 1 participates in the phase entrainment of circadian clocks to feeding. Cell 142, 943-953, doi:10.1016/j.cell.2010.08.016 (2010). 
107 Bo, S. et al. Impact of sirtuin-1 expression on H3K56 acetylation and oxidative stress: a double-blind randomized controlled trial with resveratrol supplementation. Acta Diabetol 55, 331-340, doi:10.1007/s00592-017-1097-4 (2018).

108 Bonfiglio, J. J. et al. Serine ADP-Ribosylation Depends on HPF1. Mol Cell 65, 932-940 e936, doi:10.1016/j.molcel.2017.01.003 (2017).

109 Hanzlikova, H. et al. Pathogenic ARH3 mutations result in ADP-ribose chromatin scars during DNA strand break repair. Nature Communications 11, doi:ARTN 339110.1038/s41467-020-17069-9 (2020).

110 Mashimo, M., Kato, J. \& Moss, J. ADP-ribosyl-acceptor hydrolase 3 regulates poly (ADP-ribose) degradation and cell death during oxidative stress. P Natl Acad Sci USA 110, 18964-18969, doi:10.1073/pnas.1312783110 (2013).

111 Love, S., Barber, R. \& Wilcock, G. K. Increased poly(ADP-ribosyl)ation of nuclear proteins in Alzheimer's disease. Brain 122 ( Pt 2), 247-253 (1999).

112 Kim, M. Y., Mauro, S., Gevry, N., Lis, J. T. \& Kraus, W. L. NAD+-dependent modulation of chromatin structure and transcription by nucleosome binding properties of PARP-1. Cell 119, 803-814, doi:10.1016/j.cell.2004.11.002 (2004).

113 Rudolph, J., Roberts, G., Muthurajan, U. M. \& Luger, K. HPF1 and nucleosomes mediate a dramatic switch in activity of PARP1 from polymerase to hydrolase. Elife 10, doi:10.7554/eLife.65773 (2021).

114 Gibbs-Seymour, I., Fontana, P., Rack, J. G. M. \& Ahel, I. HPF1/C4orf27 Is a PARP-1Interacting Protein that Regulates PARP-1 ADP-Ribosylation Activity. Molecular Cell 62, 432-442, doi:10.1016/j.molcel.2016.03.008 (2016). 
115 Prasad, R. et al. Suicidal cross-linking of PARP-1 to AP site intermediates in cells undergoing base excision repair. Nucleic Acids Res 42, 6337-6351, doi:10.1093/nar/gku288 (2014).

116 Hopkins, T. A. et al. PARP1 Trapping by PARP Inhibitors Drives Cytotoxicity in Both Cancer Cells and Healthy Bone Marrow. Molecular Cancer Research 17, 409-419, doi:10.1158/1541-7786.Mcr-18-0138 (2019).

117 Yang, Y. G., Cortes, U., Patnaik, S., Jasin, M. \& Wang, Z. Q. Ablation of PARP-1 does not interfere with the repair of DNA double-strand breaks, but compromises the reactivation of stalled replication forks. Oncogene 23, 3872-3882, doi:10.1038/sj.onc.1207491 (2004).

118 Zahradka, P. \& Ebisuzaki, K. A shuttle mechanism for DNA-protein interactions. The regulation of poly(ADP-ribose) polymerase. Eur J Biochem 127, 579-585 (1982).

119 Satoh, M. S. \& Lindahl, T. Role of poly(ADP-ribose) formation in DNA repair. Nature 356, 356-358, doi:10.1038/356356a0 (1992).

120 Hoch, N. C. et al. XRCC1 mutation is associated with PARP1 hyperactivation and cerebellar ataxia. Nature 541, 87-+, doi:10.1038/nature20790 (2017).

121 Eliasson, M. J. et al. Poly(ADP-ribose) polymerase gene disruption renders mice resistant to cerebral ischemia. Nat Med 3, 1089-1095 (1997).

122 Komulainen, E. et al. Parp1 hyperactivity couples DNA breaks to aberrant neuronal calcium signalling and lethal seizures. Embo Reports 22, doi:ARTN e5185110.15252/embr.202051851 (2021). 
123 Sukhanova, M., Khodyreva, S. \& Lavrik, O. Poly(ADP-ribose) polymerase 1 regulates activity of DNA polymerase beta in long patch base excision repair. Mutat Res $\mathbf{6 8 5}, 80$ 89, doi:10.1016/j.mrfmmm.2009.08.009 (2010).

124 Demin, A. A. et al. XRCC1 prevents toxic PARP1 trapping during DNA base excision repair. Mol Cell, doi:10.1016/j.molcel.2021.05.009 (2021).

125 Sukhanova, M. V. et al. Human base excision repair enzymes apurinic/apyrimidinic endonuclease1 (APE1), DNA polymerase beta and poly(ADP-ribose) polymerase 1: interplay between strand-displacement DNA synthesis and proofreading exonuclease activity. Nucleic Acids Res 33, 1222-1229, doi:10.1093/nar/gki266 (2005).

126 Wolfinbarger, L. \& Marzluf, G. A. Characterization of a Mutant of Neurospora-Crassa Sensitive to L-Tyrosine. J Gen Microbiol 93, 189-193, doi:Doi 10.1099/00221287-93-1189 (1976).

127 Sterkel, M. et al. Tyrosine Detoxification Is an Essential Trait in the Life History of Blood-Feeding Arthropods. Current Biology 26, 2188-2193, doi:10.1016/j.cub.2016.06.025 (2016).

128 Zou, H. et al. Effect of Caloric Restriction on BMI, Gut Microbiota, and Blood Amino Acid Levels in Non-Obese Adults. Nutrients 12, doi:10.3390/nu12030631 (2020).

129 Zheng, Y. et al. Weight-loss diets and 2-y changes in circulating amino acids in 2 randomized intervention trials. Am J Clin Nutr 103, 505-511, doi:10.3945/ajen.115.117689 (2016).

130 Leclerc, E. et al. The effect of caloric restriction on working memory in healthy nonobese adults. Cns Spectrums 25, 2-8, doi:Pii S109285291800156610.1017/S1092852918001566 (2020). 
131 Witte, A. V., Fobker, M., Gellner, R., Knecht, S. \& Floel, A. Caloric restriction improves memory in elderly humans. P Natl Acad Sci USA 106, 1255-1260, doi:10.1073/pnas.0808587106 (2009).

132 Moreno-Villanueva, M. et al. Influence of Acute Exercise on DNA Repair and PARP Activity before and after Irradiation in Lymphocytes from Trained and Untrained Individuals. International Journal of Molecular Sciences 20, doi:ARTN 299910.3390/ijms20122999 (2019).

133 Mascher, H., Andersson, H., Nilsson, P. A., Ekblom, B. \& Blomstrand, E. Changes in signalling pathways regulating protein synthesis in human muscle in the recovery period after endurance exercise. Acta Physiol (Oxf) 191, 67-75, doi:10.1111/j.17481716.2007.01712.x (2007).

134 Cohen-Armon, M. et al. Long-term memory requires polyADP-ribosylation. Science 304, 1820-1822, doi:10.1126/science.1096775 (2004).

135 Goldberg, S., Visochek, L., Giladi, E., Gozes, I. \& Cohen-Armon, M. PolyADPribosylation is required for long-term memory formation in mammals. J Neurochem 111, 72-79, doi:10.1111/j.1471-4159.2009.06296.x (2009).

136 Satchell, M. A. et al. A dual role for poly-ADP-ribosylation in spatial memory acquisition after traumatic brain injury in mice involving NAD+ depletion and ribosylation of 14-3-3gamma. J Neurochem 85, 697-708, doi:10.1046/j.14714159.2003.01707.x (2003).

137 Inaba, H., Tsukagoshi, A. \& Kida, S. PARP-1 activity is required for the reconsolidation and extinction of contextual fear memory. Mol Brain 8, doi:ARTN 6310.1186/s13041015-0153-7 (2015). 
138 Muiras, M. L., Muller, M., Schachter, F. \& Burkle, A. Increased poly(ADP-ribose) polymerase activity in lymphoblastoid cell lines from centenarians. J Mol Med (Berl) 76, 346-354 (1998).

139 Grube, K. \& Burkle, A. Poly(ADP-ribose) polymerase activity in mononuclear leukocytes of 13 mammalian species correlates with species-specific life span. Proc Natl Acad Sci U S A 89, 11759-11763 (1992).

140 Salemi, M. et al. Poly (ADP-ribose) polymerase 1 and Parkinson's disease: A study in post-mortem human brain. Neurochemistry International 144, doi:ARTN 10497810.1016/j.neuint.2021.104978 (2021).

141 Regier, M. et al. Evidence for Decreased Nucleolar PARP-1 as an Early Marker of Cognitive Impairment. Neural Plast 2019, doi:Artn 438325810.1155/2019/4383258 (2019).

142 Zeng, J. Y., Libien, J., Shaik, F., Wolk, J. \& Hernandez, A. I. Nucleolar PARP-1 Expression Is Decreased in Alzheimer's Disease: Consequences for Epigenetic Regulation of rDNA and Cognition. Neural Plast, doi:Artn 898792810.1155/2016/8987928 (2016).

143 Jobin, P. G. et al. Moonlighting matrix metalloproteinase substrates: Enhancement of proinflammatory functions of extracellular tyrosyl-tRNA synthetase upon cleavage. Journal of Biological Chemistry 295, 2186-2202, doi:10.1074/jbc.RA119.010486 (2020).

144 Liu, H. et al. Nuclear cGAS suppresses DNA repair and promotes tumorigenesis. Nature 563, 131-136, doi:10.1038/s41586-018-0629-6 (2018). 
145 Edrey, Y. H. et al. Amyloid beta and the longest-lived rodent: the naked mole-rat as a model for natural protection from Alzheimer's disease. Neurobiol Aging 34, 2352-2360, doi:10.1016/j.neurobiolaging.2013.03.032 (2013).

146 Orr, M. E., Garbarino, V. R., Salinas, A. \& Buffenstein, R. Sustained high levels of neuroprotective, high molecular weight, phosphorylated tau in the longest-lived rodent. Neurobiol Aging 36, 1496-1504, doi:10.1016/j.neurobiolaging.2014.12.004 (2015).

147 Lewis, K. N., Rubinstein, N. D. \& Buffenstein, R. A window into extreme longevity; the circulating metabolomic signature of the naked mole-rat, a mammal that shows negligible senescence. Geroscience 40, 105-121, doi:10.1007/s11357-018-0014-2 (2018).

148 Evdokimov, A. et al. Naked mole rat cells display more efficient excision repair than mouse cells. Aging-Us 10, 1454-1473, doi:10.18632/aging.101482 (2018).

149 Kosova, A. A. et al. Poly(ADP-ribosyl)ation and DNA repair synthesis in the extracts of naked mole rat, mouse, and human cells. Aging-Us 11, 2852-2873, doi:10.18632/aging.101959 (2019).

150 Newgard, C. B. et al. A Branched-Chain Amino Acid-Related Metabolic Signature that Differentiates Obese and Lean Humans and Contributes to Insulin Resistance. Cell Metab 9, 311-326, doi:10.1016/j.cmet.2009.02.002 (2009).

151 Tynkkynen, J. et al. Association of branched-chain amino acids and other circulating metabolites with risk of incident dementia and Alzheimer's disease: A prospective study in eight cohorts. Alzheimers Dement 14, 723-733, doi:10.1016/j.jalz.2018.01.003 (2018).

152 Toledo, J. B. et al. Metabolic network failures in Alzheimer's disease: A biochemical road map. Alzheimers Dement 13, 965-984, doi:10.1016/j.jalz.2017.01.020 (2017). 
153 Novarino, G. et al. Mutations in BCKD-kinase lead to a potentially treatable form of autism with epilepsy. Science 338, 394-397, doi:10.1126/science.1224631 (2012).

154 Tarlungeanu, D. C. et al. Impaired Amino Acid Transport at the Blood Brain Barrier Is a Cause of Autism Spectrum Disorder. Cell 167, 1481-+, doi:10.1016/j.cell.2016.11.013 (2016).

155 Smith, A. M. et al. Amino Acid Dysregulation Metabotypes: Potential Biomarkers for Diagnosis and Individualized Treatment for Subtypes of Autism Spectrum Disorder. Biol Psychiatry 85, 345-354, doi:10.1016/j.biopsych.2018.08.016 (2019).

156 Skalny, A. V. et al. Serum amino acid spectrum in children with autism spectrum disorder (ASD). Res Autism Spect Dis 77, doi:ARTN 10160510.1016/j.rasd.2020.101605 (2020).

157 Zou, M. Y. et al. Identification of Amino Acid Dysregulation as a Potential Biomarker for Autism Spectrum Disorder in China. Neurotoxicity Research, doi:10.1007/s12640020-00242-9 (2020).

158 Rodin, R. E. et al. The landscape of somatic mutation in cerebral cortex of autistic and neurotypical individuals revealed by ultra-deep whole-genome sequencing (vol 24, pg 176, 2021). Nature Neuroscience, doi:10.1038/s41593-021-00830-8 (2021).

159 Gal, R. et al. Resveratrol Improves Heart Function by Moderating Inflammatory Processes in Patients with Systolic Heart Failure. Antioxidants (Basel) 9, doi:10.3390/antiox9111108 (2020).

160 Stryeck, S. et al. Serum Concentrations of Citrate, Tyrosine, 2- and 3- Hydroxybutyrate are Associated with Increased 3-Month Mortality in Acute Heart Failure Patients. Sci Rep 9, 6743, doi:10.1038/s41598-019-42937-w (2019). 
161 Murashige, D. et al. Comprehensive quantification of fuel use by the failing and nonfailing human heart. Science 370, 364-+, doi:10.1126/science.abc8861 (2020).

162 Mankowski, R. T. et al. Higher dose of resveratrol elevated cardiovascular disease risk biomarker levels in overweight older adults - A pilot study. Exp Gerontol 131, 110821, doi:10.1016/j.exger.2019.110821 (2020).

163 Martinet, W., Knaapen, M. W., De Meyer, G. R., Herman, A. G. \& Kockx, M. M. Elevated levels of oxidative DNA damage and DNA repair enzymes in human atherosclerotic plaques. Circulation 106, 927-932, doi:10.1161/01.cir.0000026393.47805.21 (2002).

164 Kono, Y. et al. Elevated levels of oxidative DNA damage in serum and myocardium of patients with heart failure. Circ J 70, 1001-1005, doi:10.1253/circj.70.1001 (2006).

165 Braak, H. \& Braak, E. Neuropathological stageing of Alzheimer-related changes. Acta Neuropathol 82, 239-259, doi:10.1007/BF00308809 (1991).

166 Mirra, S. S. et al. The Consortium to Establish a Registry for Alzheimer's Disease (CERAD). Part II. Standardization of the neuropathologic assessment of Alzheimer's disease. Neurology 41, 479-486, doi:10.1212/wnl.41.4.479 (1991).

167 Ackerson, S. M., Gable, C. I. \& Stewart, J. A. Human CTC1 promotes TopBP1 stability and $\mathrm{CHK} 1$ phosphorylation in response to telomere dysfunction and global replication stress. Cell Cycle 19, 3491-3507, doi:10.1080/15384101.2020.1849979 (2020).

168 Gali, H., Mason-Osann, E. \& Flynn, R. L. Direct Visualization of DNA Replication at Telomeres Using DNA Fiber Combing Combined with Telomere FISH. DNA Repair: Methods and Protocols 1999, 319-325, doi:10.1007/978-1-4939-9500-4_22 (2019). 
169 Jin, M. et al. Soluble amyloid beta-protein dimers isolated from Alzheimer cortex directly induce Tau hyperphosphorylation and neuritic degeneration. Proc Natl Acad Sci U S A 108, 5819-5824, doi:10.1073/pnas.1017033108 (2011).

170 Hernandez, D. E. et al. Axonal degeneration induced by glutamate excitotoxicity is mediated by necroptosis. Journal of Cell Science 131, doi:ARTN jcs21468410.1242/jcs.214684 (2018). 


\section{Figure 1}
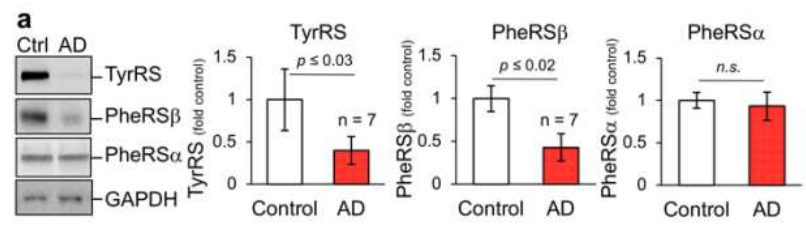

c

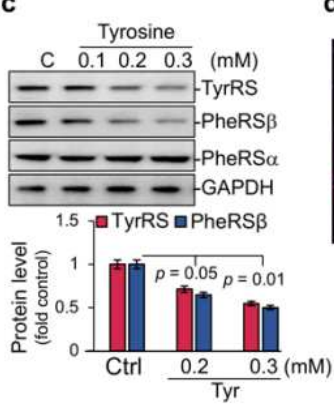

d ${ }_{\text {SiRNA }}{ }^{\mathrm{trI}}$

Control AD
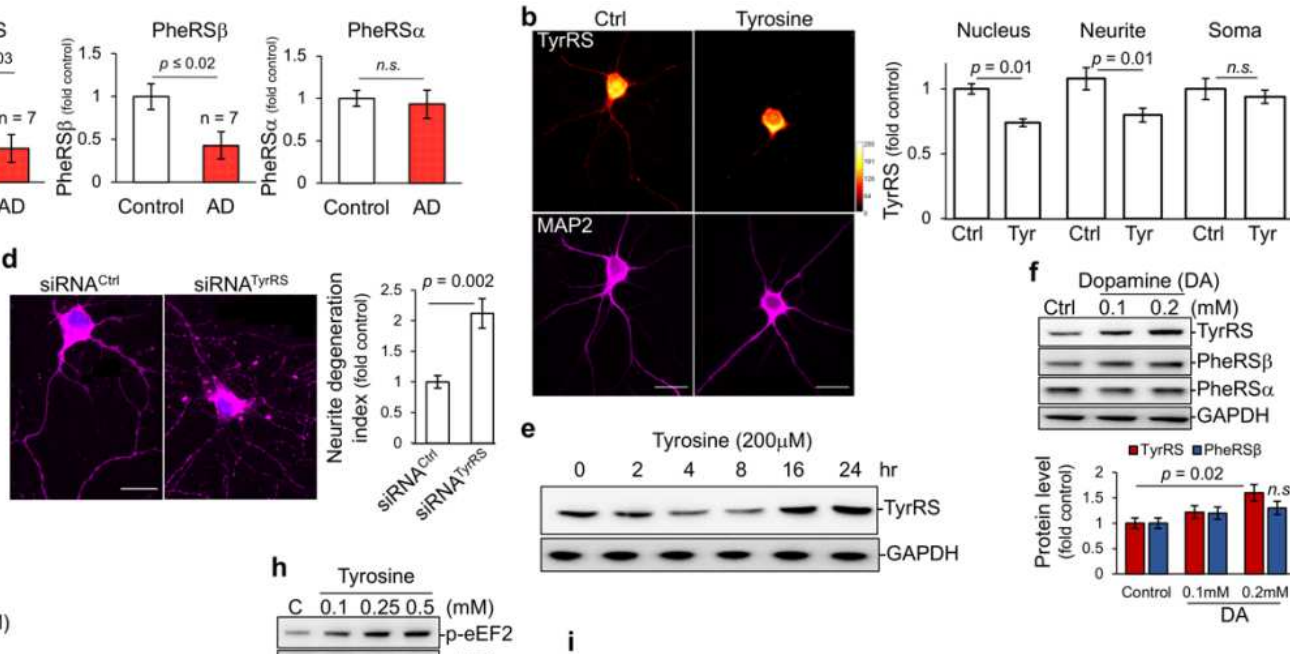

f Dopamine (DA) Ctrl $0.1 \quad 0.2$
- -
$-\quad-\quad-$ TyrRS

e
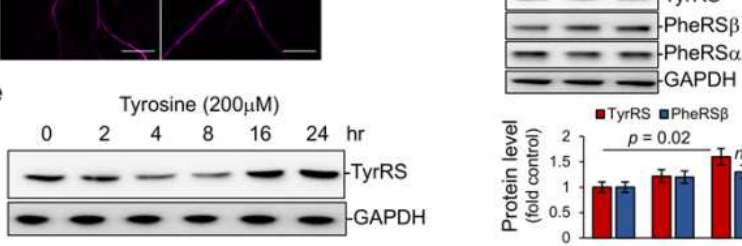

由TyrRS aPheRS

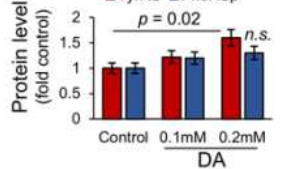

g
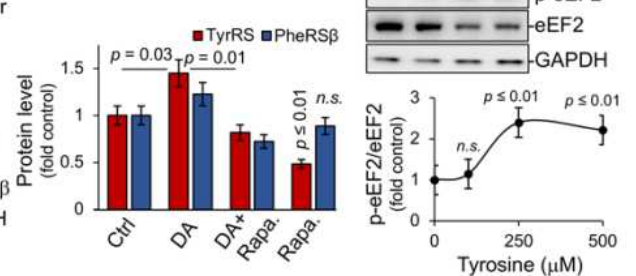

i

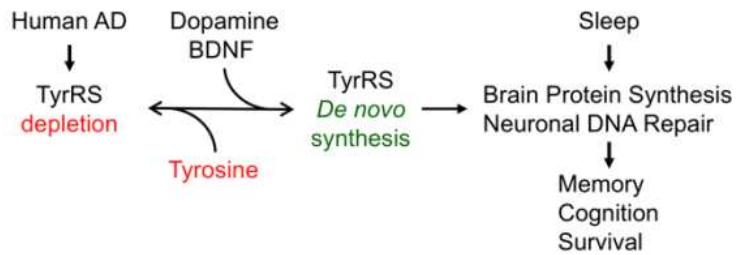

Figure 1. TyrRS protein is decreased in the hippocampal region of AD patients, and

tyrosine decreases nuclear and neurite levels of TyrRS. a. Representative immunoblots and quantification for TyrRS and PheRS $\alpha / \beta$ using anti-TyrRS and PheRS $\alpha / \beta$ antibodies in the hippocampal region of AD patients $(n=7)$ with age and sex-matched controls $(n=7)$. b. Tyrosine preferentially decreases nuclear and neurite levels of TyrRS. Spectral images (scale bar, 20 $\mu \mathrm{m}$ ), and quantitative IF analysis of TyrRS in the nucleus, soma, and neurite of rat cortical neurons (DIV9) using anti-TyrRS antibody after treatment with $\operatorname{Tyr}(250 \mu \mathrm{M})$ for $4 \mathrm{hr}$. c. Tyrosine depletes TyrRS and PheRS $\beta$, but not PheRS $\alpha$. Primary cortical neurons were treated with Tyr $(100-300 \mu \mathrm{M})$ for $4 \mathrm{hr}$, and the levels of PheRS $\beta$ and PheRS $\alpha$ were detected by WB analysis using their specific antibodies. d. TyrRS knockdown using siRNA induces neurite degeneration. Representative images (scale bar, $20 \mu \mathrm{m}$ ) for cortical neurons following siRNA ${ }^{\text {TyrRS }}$ treatment for $72 \mathrm{hr}$ (MAP2 - neurite marker, magenta, and DAPI - nuclear marker, blue). Neurons were 
immunoassayed with anti-MAP2 antibody and quantified for neurite degeneration. e. Tyr effect on TyrRS protein levels is reversible. Primary cortical neurons were treated with Tyr $(200 \mu \mathrm{M})$ for up to $24 \mathrm{hr}$, and TyrRS was detected by WB analysis using anti-TyrRS antibody. $\mathbf{f}$. Dopamine (DA) increases neuronal TyrRS levels. Representative immunoblots for TyrRS and PheRS $\alpha / \beta$ after treatment with DA $(100-200 \mu \mathrm{M})$ for up to $30 \mathrm{~min}$ in rat cortical neurons (DIV9). g. Rapamycin prevents DA-induced increase in TyrRS levels. Representative immunoblots for TyrRS and PheRS $\beta$ after treatment with either DA $(100 \mu \mathrm{M})$ alone or in combination with rapamycin $(100 \mathrm{nM})$ in rat cortical neurons (DIV9). h. Tyrosine induces the phosphorylation of $e E F 2$. Primary cortical neurons were treated with Tyr $(100-500 \mu \mathrm{M})$ for $8 \mathrm{hr}$ and p-eEF2 was detected by WB analysis using anti-p-eEF2 antibody. The data represents mean \pm SEM for $n=3$ experiments with significance measured using Student's paired t-test. i. Schematic representation of the potential mechanism of regulation of the neuronal protein levels of TyrRS. 
Figure 2
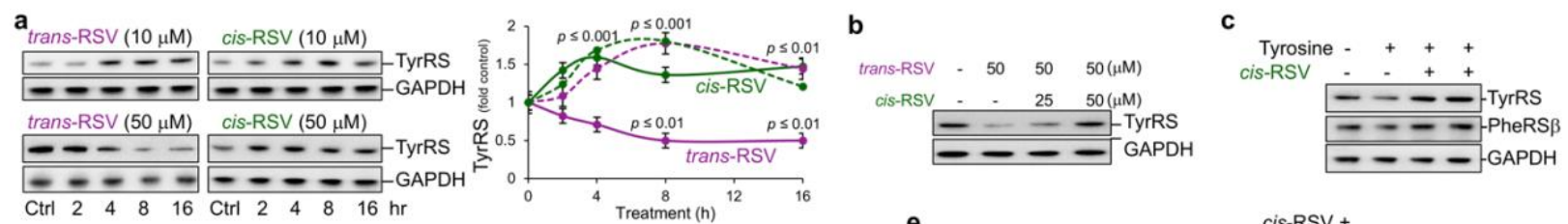

d

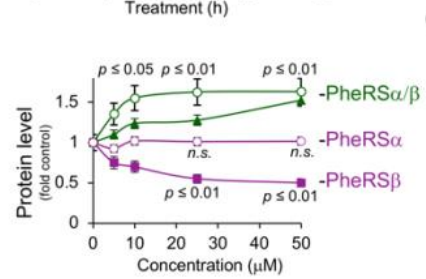

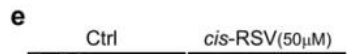

cis-RSV +

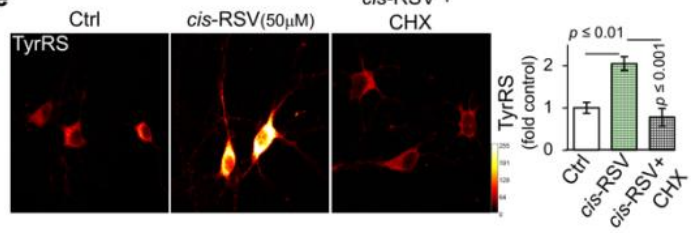

f

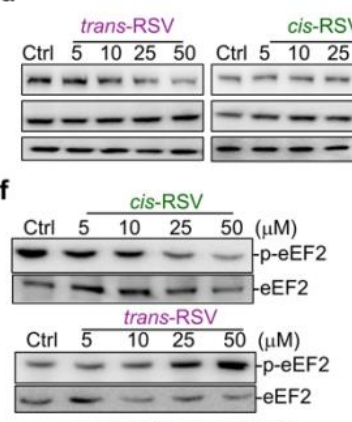

g
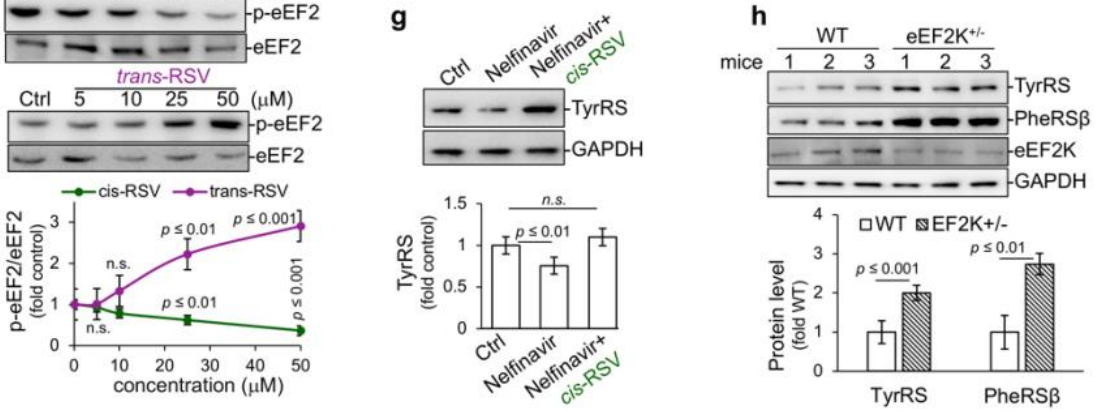

i

IP: $\alpha$-eEF2

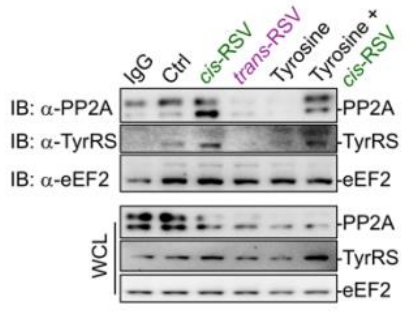

Figure 2. Tyrosine and cis-RSV modulate the de novo synthesis of TyrRS at the elongation

step of protein synthesis. a. Low and high concentrations of trans-RSV (10 and $50 \mu M)$ have

opposite effects on TyrRS, and low concentration trans-RSV mimics cis-RSV to increase the

protein levels of TyrRS. Representative immunoblots and quantification for TyrRS after

treatment with cis-and trans-RSV $(10$ and $50 \mu \mathrm{M})$ for up to $16 \mathrm{hr}$ in rat cortical neurons (DIV9).

b. cis-RSV protects neurons against trans-RSV-mediated decrease in TyrRS levels.

Representative immunoblots showing the protein levels of TyrRS after treatment with trans-RSV

$(50 \mu \mathrm{M})$ alone or in combination with different doses of cis-RSV for $16 \mathrm{hr}$ in rat cortical neurons

(DIV9). c. cis-RSV protects neurons against Tyr-mediated depletion of TyrRS. Primary cortical

neurons were treated with $\operatorname{Tyr}(200 \mu \mathrm{M})$ alone or in combination with cis-RSV for $8 \mathrm{hr}$, and

TyrRS was detected by WB using anti-TyrRS antibody. d. cis-and trans-RSV have opposite

effects on neuronal PheRS $\beta$. Representative immunoblots and quantification for PheRS $\alpha / \beta$ after 
treatment with cis-and trans-RSV $(5-50 \mu \mathrm{M})$ for up to $16 \mathrm{hr}$ in rat cortical neurons (DIV9). e. cis-RSV stimulates the de novo synthesis of neuronal TyrRS. Spectral images (scale bar, 20um) and quantitative IF analysis using anti-TyrRS antibody. Primary cortical neurons were treated

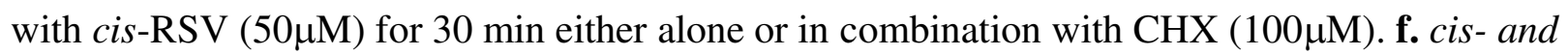
trans-RSV have opposite effects on the phosphorylation of eEF2. Primary cortical neurons were treated with cis- and trans-RSV $(5-50 \mu \mathrm{M})$ for $8 \mathrm{hr}$ and p-eEF2 was detected by WB analysis using anti-p-eEF2 antibody. g. cis-RSV protects neurons against nelfinavir-mediated depletion of TyrRS. Primary cortical neurons were treated with nelfinavir $(20 \mu \mathrm{M})$ alone or in combination with cis-RSV for $8 \mathrm{hr}$, and TyrRS and PheRS $\beta$ were detected by WB analysis using their respective antibodies. h. Genetic reduction of eEF2K increases TyrRS in vivo. Quantitative western blots showing the protein levels of TyrRS and PheRS $\beta$ using anti-TyrRS and PheRS $\beta$ antibodies in the brain tissue samples from eEF $2 \mathrm{~K}^{+/-}$mice. i. cis-RSV facilitates the interaction of PP2A with eEF2. Primary cortical neurons were treated with cis- and trans-RSV $(50 \mu \mathrm{M})$ or Tyr $(200 \mu \mathrm{M})$ either alone or in combination with cis-RSV. Immunoprecipitated eEF2 was probed for its interaction with PP2A and TyrRS using their specific antibodies. The data represents mean \pm SEM for $n=3$ experiments with significance measured using Student's paired t-test. 


\section{Figure 3}

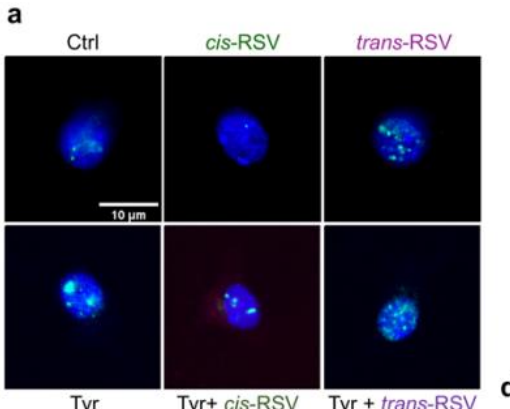

b
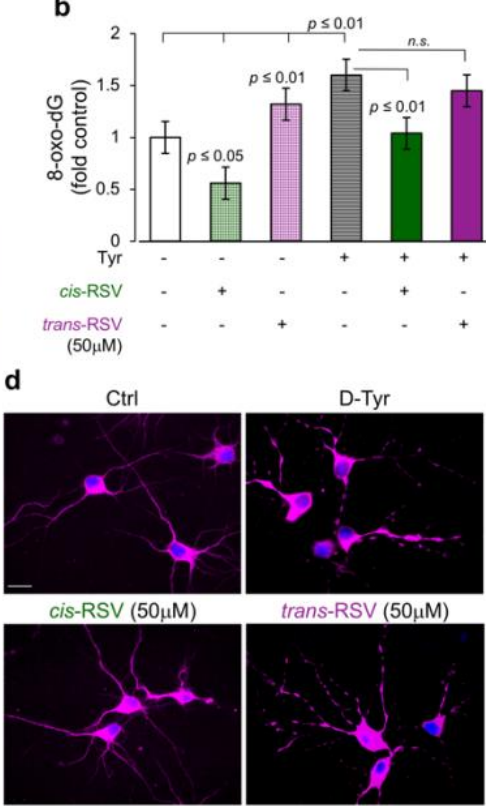

c
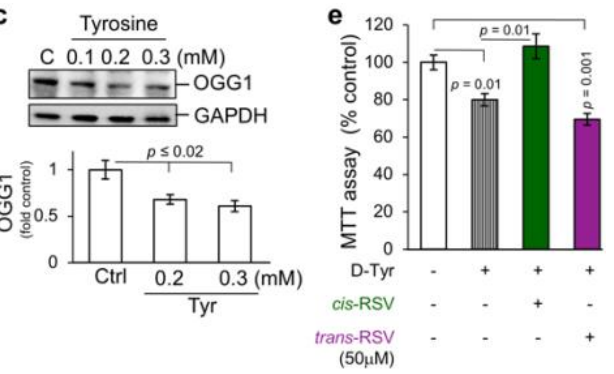

$\mathbf{f}$

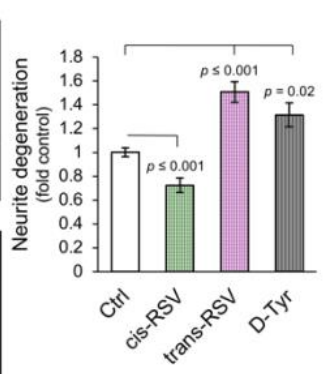

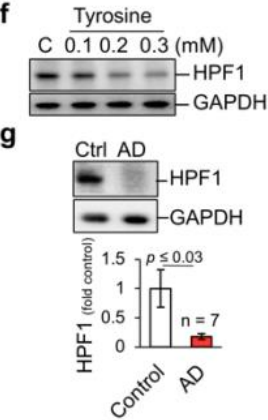

Figure 3. Tyrosine induces oxidative DNA damage in neurons, and cis-RSV protects

neurons against it. a. cis-RSV and trans-RSV have opposite effects on Tyr-mediated accumulation of $\gamma-H 2 A X$. Immunostaining images (scale bar, $10 \mu \mathrm{m}$ ) for DNA damage marker, pSer139-H2AX foci ( $\gamma$-H2AX, green; DAPI - nuclear marker, blue) in cortical neurons (DIV10) after treatment with cis- and trans-RSV $(50 \mu \mathrm{M})$ alone or in combination with Tyr $(250 \mu \mathrm{M})$ for $24 \mathrm{hr}$. The graph represents the average number of $\gamma-\mathrm{H} 2 \mathrm{AX}$ foci per $\mathrm{n}=30$ neurons per treatment condition for $\mathrm{n}=4$ experiments. b. cis- and trans-RSV have opposite effects on Tyr-mediated induction of the oxidation level of neuronal DNA. Quantification of the levels of 8-oxo-2'-dG in rat primary cortical neurons (DIV9/10) after treatment with $\operatorname{Tyr}(500 \mu \mathrm{M})$ either alone or in combination with cis or trans-RSV $(50 \mu \mathrm{M})$ for $16 \mathrm{hr}$. c. Tyr decreases the protein levels of OGG1. Primary cortical neurons were treated with Tyr $(100-300 \mu \mathrm{M})$ for $8 \mathrm{hr}$, and OGG1 was detected by WB analysis using anti-OGG1 antibody. d. D-Tyrosine and trans-RSV induce

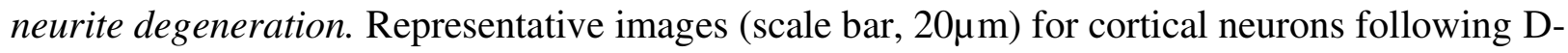


Tyr or cis-RSV and trans-RSV $(50 \mu \mathrm{M})$ for $24 \mathrm{hr}$ treatment (MAP2 - neurite marker, magenta and DAPI - nuclear marker, blue). Neurons were immunoassayed with anti-MAP2 antibody and quantified for neurite degeneration. e. cis-RSV protects neurons against D-Tyrosine-induced toxicity. Rat cortical neurons (DIV9) were treated with either D-Tyr alone or in combination with cis or trans-RSV $(50 \mu \mathrm{M})$ for $48 \mathrm{hr}$, and viability was assessed using MTT assay. f. Tyrosine decreases the protein levels of HPF1. Immunoblots showing the protein levels of HPF1 in rat cortical neurons (DIV9-10) after treatment with Tyr $(\leq 300 \mu \mathrm{M})$ for up to $8 \mathrm{hr}$. g. HPF1 is decreased in the hippocampal region of $A D$ patients. Representative immunoblots and quantification for HPF1 using anti-HPF1 antibody in the hippocampal region of AD patients $(n=7)$ with age and sex-matched controls $(n=7)$. The data represents mean \pm SEM for $n=3$ experiments with significance measured using Student's paired t-test. 


\section{Figure 4}
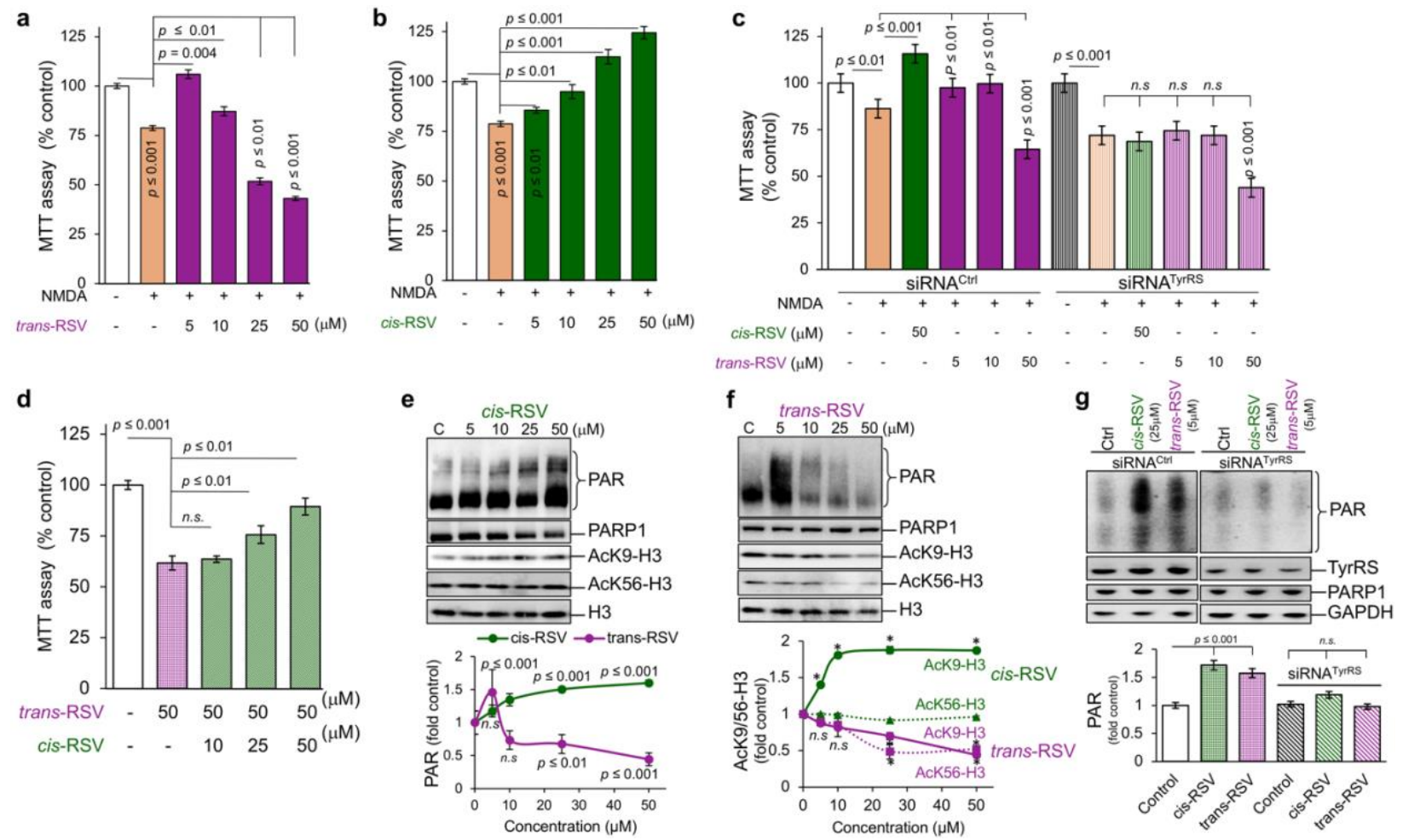

Figure 4. cis- and trans-RSV have opposite effects on neuronal survival under stress. a. trans-RSV has opposite effects on neuronal survival under NMDA-mediated neurotoxicity. Rat cortical neurons (DIV9) were treated with NMDA (50 $\mu \mathrm{M}$ for $5 \mathrm{~min}$ ) and then with trans-RSV $(5-50 \mu \mathrm{M})$ for $24 \mathrm{hr}$. Cells were then exposed to NMDA $(500 \mu \mathrm{M}$ for $5 \mathrm{~min})$ and viability was assessed using MTT assay after $24 \mathrm{hr}$. b. cis-RSV provides dose-dependent neuroprotection against NMDA-mediated neurotoxicity. Rat cortical neurons (DIV9) were treated with NMDA $(50 \mu \mathrm{M}$ for $5 \mathrm{~min})$ and then with $c i s-\mathrm{RSV}(5-50 \mu \mathrm{M})$ for $24 \mathrm{hr}$. Cells were then exposed to NMDA (500 $\mu \mathrm{M}$ for $5 \mathrm{~min}$ ) and viability was assessed using MTT assay after $24 \mathrm{hr}$. c. TyrRS knockdown blunts the neuroprotective effects of cis-RSV and exacerbates the neurotoxicity of trans-RSV. Rat cortical neurons (DIV7) were transfected with TyrRS or control siRNA (75nM) and then treated with cis-RSV $(50 \mu \mathrm{M})$ or trans-RSV $(5,10,50 \mu \mathrm{M})$ for $24 \mathrm{hr}$. Neurons were then exposed to excitotoxic NMDA (500 $\mu \mathrm{M}$ for $5 \mathrm{~min})$, and viability was assessed using MTT assay after $24 \mathrm{hr}$. 
d. cis-RSV protects from trans-RSV-mediated neurotoxicity. Rat cortical neurons (DIV 8) were

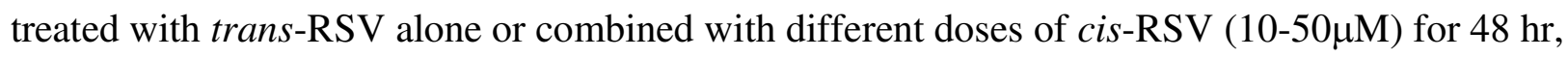
and viability was measured using MTT assay. e, f. cis-RSV and trans-RSV have opposite effects on the auto-PARylation of PARP1. Representative immunoblot images and quantification using specific antibodies for PARylation, PARP1, Ac-K9-H3, Ac-K56-H3 levels after treatment of cortical neurons (DIV9) with cis- and trans-RSV for $15 \min$ (* indicates $p \leq 0.01)$. g. cis-RSV and low dose trans-RSV-dependent auto-PARylation of PARP1 is TyrRS dependent. Rat cortical neurons (DIV7) were transfected with control and TyrRS siRNA followed by treatment with cis$(25 \mu \mathrm{M})$ and trans-RSV $(5 \mu \mathrm{M})$ for $15 \mathrm{~min}$ and immunoblotting and quantification using the specific antibodies for PARylation, PARP1 and TyrRS. The data represents mean \pm SEM for $n=3$ experiments with significance measured using Student's paired t-test. 


\section{Figure 5}
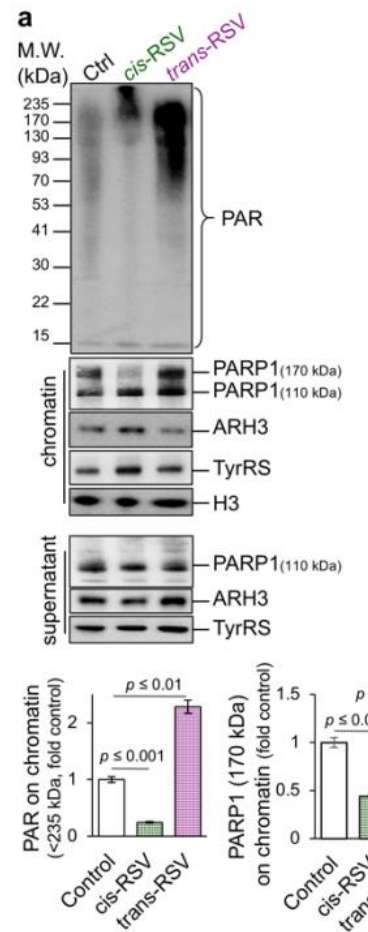

b

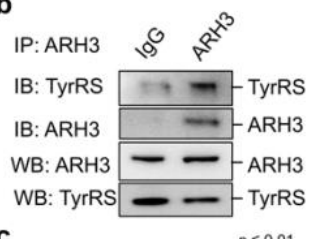

C
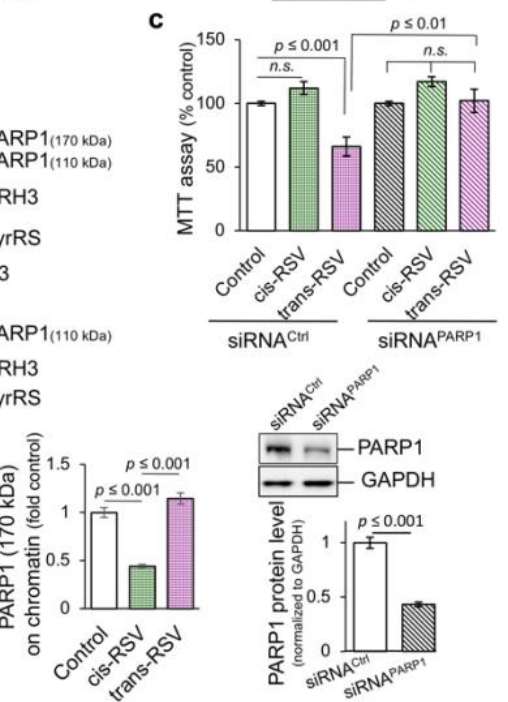

d
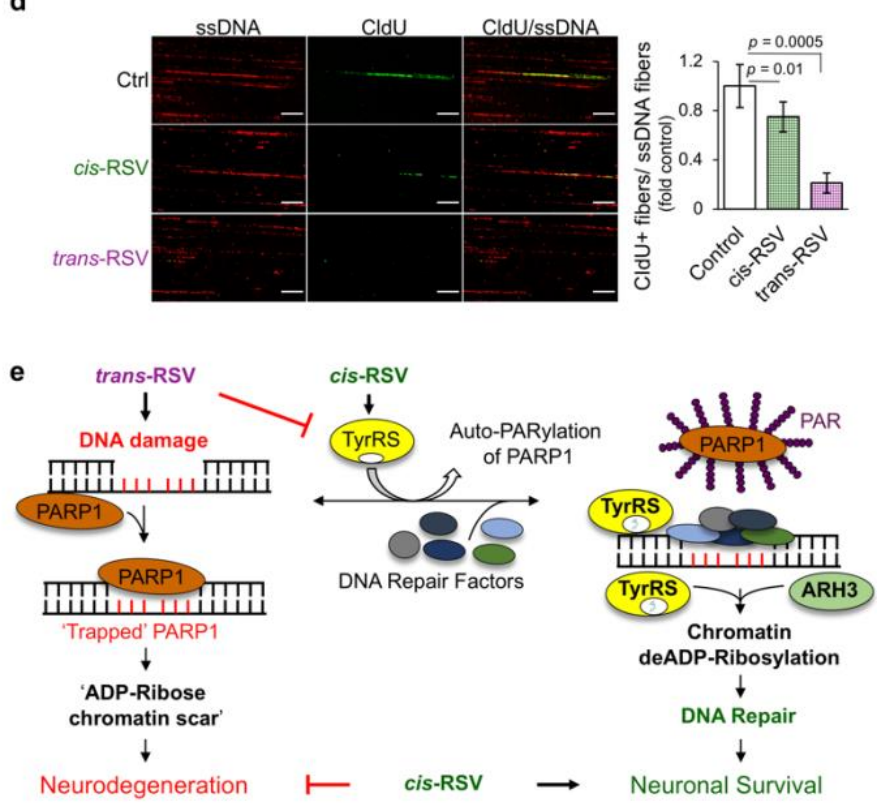

Figure 5. cis- and trans-RSV have opposite effects on auto-PARylation of PARP1 and neuronal DNA repair. a. cis- $R S V$ removes auto-PARylated PARPI from chromatin and trans$R S V$ 'traps' PARPI onto the chromatin. Representative immunoblots and quantification from chromatin fraction of cortical neurons (DIV9) depicting PARP1 and PAR, ARH3, TyrRS after treatment with cis- and trans-RSV $(50 \mu \mathrm{M})$ for $1 \mathrm{hr}$. b. TyrRS interacts with ARH3. Immunoprecipitated (IP) TyrRS from cortical neurons (DIV9) was immunoblotted (IB) using anti-TyrRS and anti-ARH3 antibodies to detect the interaction of TyrRS with ARH3. Total TyrRS and ARH3 were detected by WB. c. siRNA knockdown of PARP1 rescues trans-RSVmediated neurotoxicity. Rat cortical neurons (DIV7) were transfected with siRNA against PARP1 (siRNA ${ }^{\text {PARP1}}$ ) or control siRNA $(75 \mathrm{nM})$ and then treated with cis-RSV $(50 \mu \mathrm{M})$ or transRSV $(50 \mu \mathrm{M})$ for $72 \mathrm{hr}$. Neuronal viability was assessed and quantified using an MTT assay. The knockdown was verified using immunoblot and quantified using specific antibodies for PARP1. 
d. trans-RSV inhibits nucleoside incorporation in a DNA fiber assay. Cortical neurons (DIV9/10) were treated with cis-or trans-RSV $(50 \mu \mathrm{M})$ for $8 \mathrm{hr}$ followed by a $30 \mathrm{~min}$ pulse labeling using $50 \mu \mathrm{M}$ of nucleoside analog, CldU (5-chloro-2'-deoxyuridine). DNA fiber assay was performed according to the published protocol followed by immunostaining for single-stranded (ss) DNA (red) and CldU (green). The incorporation of CldU in DNA during the repair process was assessed using ImageJ by counting the number of CldU positive DNA fibers for a total of 300 fibers per condition. All graphs represent mean \pm SEM with statistical significance calculated using Student's paired t-test. e. Proposed mechanism of cis-RSV-mediated neuroprotection and trans-RSV-mediated neurotoxicity. 


\section{Methods}

\section{Postmortem hippocampal tissue samples}

All human postmortem tissues were obtained from the University of Washington School of Medicine BioRepository and Integrated Neuropathology (BRaIN) Laboratory and Precision Neuropathology Core. AD diagnosis was based on cognitive assessments of dementia and neuropathological verification of AD neuropathologic change using Braak staging (AD stages $\mathrm{V}-$ VI) stage, and Consortium to Establish a Registry for Alzheimer's Disease (CERAD) scores ${ }^{165,166 .}$ Studies were performed using flash frozen hippocampal tissue from male and female patients clinically diagnosed with $\mathrm{AD}(n=7)$ and age-matched controls $(n=7)$. Donor information is presented in Supplementary Table 1. The mean age of death was 89.6 years. Postmortem interval (PMI) ranged between 2 and $11 \mathrm{hr}$, with a mean of $5.3 \mathrm{hr}$.

\section{Cell Culture}

Primary cortical neurons were dissected from E18 Sprague Dawley rats pups in Hibernate E (BrainBits) and dissociated using the Neural Tissue Dissociation kit (Miltenyi Biotec). Minced cortices were incubated in a pre-warmed enzyme mix at $37^{\circ} \mathrm{C}$ for $15 \mathrm{~min}$; tissues were then triturated and strained using a $40 \mu \mathrm{m}$ cell strainer. After washing and centrifugation, neurons were seeded in $50 \mu \mathrm{g} / \mathrm{ml}$ poly-D-Lysine (Sigma Aldrich) coated tissue culture plates. NBActive1 medium (BrainBits) supplemented with $100 \mathrm{U} / \mathrm{ml}$ of Penicillin-Streptomycin (Life Technologies), 2 mM L-Glutamine (Life Technologies), and 1 X N21 supplement (R\&D Systems) was used as culture medium. Control (non-targeting), TyrRS, and PARP1 siRNAs were obtained from Invitrogen (\# AM4635, s443, and s130207, respectively). Rat cortical neurons at 5 DIV were transfected with $75 \mathrm{nM}$ control or TyrRS siRNA using Dharmafect 3 
Transfection Reagent. A second transfection was done two days later using 75nM of TyrRS siRNA, followed by cell collection or assays after another $48 \mathrm{hrs}$. For PARP1 siRNA, neurons at 7 DIV were transfected with 75nM siRNA for both control and PARP1 siRNA.

\section{Western blotting}

Cultured neurons (DIV 9-10) were washed once with cold $1 \times$ PBS and lysed in cell lysis buffer (20 mM Tris- $\mathrm{HCl}$ (pH 7.5), 150 mM NaCl, 1 mM Na2EDTA, 1 mM EGTA, 1\% Triton, $2.5 \mathrm{mM}$ sodium pyrophosphate, $1 \mathrm{mM}$ beta-glycerophosphate, $1 \mathrm{mM} \mathrm{Na} 3 \mathrm{VO}_{4}, 1 \mu \mathrm{g} / \mathrm{ml}$ leupeptin supplemented with protease inhibitor). The lysates were centrifuged at 10,000 RPM for 15 mins at $4^{\circ} \mathrm{C}$ to separate the chromatin-bound and soluble fractions. Lysates were quantified using BioRad Protein Assay, and equal amounts of protein were loaded onto a 4 to $12 \%$ gradient gel (NuPAGE-Invitrogen). Protein was transferred from the gel to $0.2 \mu \mathrm{m} \mathrm{NC}$ membranes at $25 \mathrm{~V}$ for 10 mins using transfer stacks (iBlot 2- Invitrogen) and blocked with 5\% non-fat milk in TBST (10 mM Tris- $\mathrm{HCl} \mathrm{pH} \mathrm{8.0,} 150 \mathrm{mM} \mathrm{NaCl}, 0.01 \%$ Tween-20) for $1 \mathrm{hr}$ before application of primary antibodies. Primary and secondary antibodies were incubated overnight at $4{ }^{\circ} \mathrm{C}$ and for 1 $\mathrm{hr}$ at room temperature, respectively. Immobilon ECL Ultra Western HRP Substrate (WBULS0500, Millipore) and a luminescent image analyzer (ChemiDoc Imaging System, BioRad) were used to detect proteins. Quantification of western blots was done using ImageJ (Version 1.53c).

\section{List of antibodies used for western blotting}

\section{Antibody}

Acetyl-Histone H3 (Lys56)
Company

Cell Signaling Technology 4243

\section{Catalog No. Dilution}

1:1000 (WB) 


\begin{tabular}{|c|c|c|c|}
\hline Acetyl-Histone H3 (Lys9) & Cell Signaling Technology & 9649 & 1:1000 (WB) \\
\hline ARH3 & Proteintech & 16504-1-AP & 1:1000 (WB) \\
\hline eEF2 & Cell Signaling Technology & 2332 & $1: 1000(\mathrm{WB})$ \\
\hline $\operatorname{eIF} 2 \alpha$ & Cell Signaling Technology & 5324 & 1:1000 (WB) \\
\hline Fen1 & Proteintech & 14768-1-AP & $1: 1000(\mathrm{WB})$ \\
\hline GAPDH & Cell Signaling Technology & 2118 & $1: 2000(\mathrm{WB})$ \\
\hline $\mathrm{H} 3$ & Proteintech & 17168-1-AP & $1: 1000(\mathrm{WB})$ \\
\hline HPF1 & Novus Biologicals & NBP1-93973 & $1: 1000(\mathrm{WB})$ \\
\hline OGG1 & Proteintech & 15125-1-AP & $1: 1000(\mathrm{WB})$ \\
\hline PARP1 & Proteintech & 66520-1-Ig & 1:1000 (WB) \\
\hline PARP2 & Abcam & ab177529 & 1:500 (WB) \\
\hline PheRS $\alpha$ & Proteintech & 18121-1-AP & 1:1000 (WB) \\
\hline PheRS $\beta$ & Proteintech & 16341-1-AP & $1: 1000(\mathrm{WB})$ \\
\hline Phospho-eEF2 (Thr56) & Cell Signaling Technology & 2331 & $1: 1000(\mathrm{WB})$ \\
\hline Phospho-eIF2 $\alpha$ (Ser51) & Cell Signaling Technology & 3398 & $1: 1000(\mathrm{WB})$ \\
\hline Poly (ADP-Ribose) Polymer & Abcam & ab14459 & $1: 1000(\mathrm{WB})$ \\
\hline PP2A C & Cell Signaling Technology & 2038 & 1:1000 (WB) \\
\hline TyrRS & Abcam & ab50961 & $1: 1000(\mathrm{WB})$ \\
\hline XRCC1 & Millipore & ABE559 & 1:1000 (WB) \\
\hline
\end{tabular}

\section{DNA Fiber Analysis}

Cultured cortical neurons (DIV9) were treated with cis- and trans-RSV (50 $\mu \mathrm{M})$ for $8 \mathrm{hr}$, followed by the addition of thymidine analog, $50 \mu \mathrm{M}$ CldU (5-Chloro-2'-deoxyuridine) for 30 mins. DNA 
fiber analysis was done according to established protocols ${ }^{167,168}$. Briefly, cells were isolated by trypsinization, embedded in agarose plugs, and subjected to proteinase $\mathrm{K}(0.5 \% \mathrm{SDS}, 0.1 \mathrm{M}$ EDTA, $1 \mathrm{mg} / \mathrm{ml}$ Proteinase $\mathrm{K}$ ) digestion at $50^{\circ} \mathrm{C}$ for $16 \mathrm{hr}$. Plugs were dissolved with agarose (Fisher [NEB], 50-811-726) for 16 hrs. Molecular combing was performed using the FiberComb ${ }^{\circledR}$ Molecular Combing System (Genomic Vision) with a constant stretching factor of $2 \mathrm{~kb} / \mu \mathrm{m}$ using vinylsilane coverslips $(20 \times 20 \mathrm{~mm}$; Genomic Vision), according to the manufacturer's instructions. Combed coverslips were incubated at $60^{\circ} \mathrm{C}$ for $2 \mathrm{hrs}$ in a pre-warmed hybridization oven to minimize photo-breaking, followed by denaturation of the DNA fibers $(0.5 \mathrm{M} \mathrm{NaOH}+1 \mathrm{M}$ $\mathrm{NaCl}$ ) for 8 mins. The coverslips were then washed with PBS, followed by serial ethanol dehydration (70-100\%). Following two 1x PBS washes, the coverslips were blocked in $3 \%$ BSA/1x PBS for 30 mins followed by incubation with $\alpha$-BrdU (for CldU) (BD [347,580]) (1:100) and ssDNA antibody (Millipore MAB3034) (1:100), for $2 \mathrm{hr}$ at $37^{\circ} \mathrm{C}$. After three PBST washes, secondary antibody incubation was done using $\alpha$-mouse AlexaFluor 594 and $\alpha$-rat AlexaFluor 488 (1:500) for $1 \mathrm{hr}$ at $37^{\circ} \mathrm{C}$. Coverslips were washed three times with $1 \mathrm{x}$ PBST, dehydrated and mounted on slides with mounting media. The stained DNA fibers were visualized using a fluorescence microscope (EVOS FL, ThermoFisher Scientific). Analysis was performed in ImageJ by counting the total ssDNA (red) and the CldU labeled fibers (green). For each treatment condition, 300 fibers were counted, and the average ratio of CldU incorporation for ssDNA fibers per condition was used for final representation.

\section{Immunofluorescence (IF)}

Cultured cortical neurons (DIV 9-10) were fixed in $4 \%$ formaldehyde for 15 mins, followed by permeabilization and blocking for 30 mins in 5\% BSA (PBS) and 0.1\% (Tween20) at room 
temperature. Incubation with primary antibodies was done at $4^{\circ} \mathrm{C}$ overnight. The names and dilutions of the primary antibodies used for IF are described below. Secondary antibodies were incubated for $1 \mathrm{hr}$ at room temperature. Secondary antibodies used were: Alexa Fluor 647 (antichicken), Alexa Fluor 555 (anti-mouse), Alexa Fluor 488 (anti-rabbit) from Invitrogen at 1:1000 dilution. Coverslips were then mounted using DAPI (4',6-diamidino-2-phenylindole)supplemented mounting medium, Prolong Gold Antifade (Invitrogen) and imaged with Leica DMI6000 epifluorescent microscope using oil immersion 63x/NA 1.4 objective. The quantification for total protein levels in neurons was done using ImageJ (Version 1.53c), and imaging parameters were matched for exposure, gain, and offset.

\section{List of antibodies used for IF}

$\begin{array}{llll}\text { Antibody } & \text { Company } & \text { Catalog No. } & \text { Dilution } \\ \text { MAP2 } & \text { Abcam } & \text { Ab5392 } & 1: 500 \\ \text { phospho-histone H2AX (Ser139) } & \text { Cell Signaling Technology } & 9178 & 1: 400 \\ \text { TyrRS } & \text { Novus Biologicals } & \text { NBP1-32551 } & 1: 200 \\ \text { 8-hydroxy-2'-deoxyguanosine } & \text { Abcam } & \text { ab48508 } & 1: 200\end{array}$

\section{Drug Treatments}

All drugs/inhibitors stock solutions (1000x) were prepared in DMSO or ethanol and diluted in culture media for final concentration. cis-RSV was purchased from Cayman Chemicals (Item No. $10004235, \geq 98 \%$ purity) and trans-RSV was purchased from Millipore-Sigma (catalog No. $34092, \geq 99 \%$ purity) and the stocks were prepared in ethanol. The various compounds used for treatments and their stock concentrations are listed below. 


\begin{tabular}{|l|l|l|l|l|}
\hline Compound & Catalog & $\begin{array}{l}\text { Stock } \\
\text { Concentration }\end{array}$ & $\begin{array}{l}\text { Final } \\
\text { Concentration }\end{array}$ & Solvent \\
\hline Rapamycin & 53123, Alfa Aesar & $100 \mu \mathrm{M}$ & $5-50 \mathrm{nM}$ & DMSO \\
\hline ISRIB & 5284, Tocris & $250 \mu \mathrm{M}$ & $5-500 \mathrm{nM}$ & DMSO \\
\hline NMDA & 0114, Tocris & $50 \mathrm{mM}$ & $50 \mu \mathrm{M}$ & PBS \\
\hline MPP+ Iodide & D048, Sigma Aldrich & $100 \mathrm{mM}$ & $50 \mu \mathrm{M}$ & DMSO \\
\hline A484594 & 324516, Millipore & $100 \mu \mathrm{M}$ & $100 \mathrm{nM}$ & DMSO \\
\hline $\begin{array}{l}\text { Nelfinavir } \\
\text { mesylate hydrate }\end{array}$ & N0986, TCI & $100 \mu \mathrm{M}$ & $20-40 \mu \mathrm{M}$ & PBS \\
\hline L-Tyr & 194759, MP Biomedicals & $100 \mathrm{mM}$ & $0.1-0.5 \mathrm{mM}$ & PBS \\
\hline Dopamine HCl & H60255, Sigma Aldrich & $100 \mathrm{mM}$ & $0.1-0.5 \mathrm{mM}$ & PBS \\
\hline L-DOPA & A11311, Alfa Aesar & $100 \mathrm{mM}$ & $0.1-0.5 \mathrm{mM}$ & PBS \\
\hline L-Phe & A13238, Alfa Aesar & $100 \mathrm{mM}$ & $0.1-0.5 \mathrm{mM}$ & PBS \\
\hline D-Tyr & 143865, BTC & $100 \mathrm{mM}$ & $0.5-2 \mathrm{mM}$ & PBS \\
\hline D-Trp & 215145, BTC & $100 \mathrm{mM}$ & $0.1-1 \mathrm{mM}$ & PBS \\
\hline D-Phe & 225200, BTC & $100 \mathrm{mM}$ & $0.5-2 \mathrm{mM}$ & PBS \\
\hline $\begin{array}{l}\text { 6-OHDA } \\
\text { hydrobromide) }\end{array}$ & 25330, Cayman Chemical & $100 \mathrm{mM}$ & $0.1-0.3 \mathrm{mM}$ & PBS \\
\hline BDNF & B3795-5UG, Sigma Aldrich & $100 \mu \mathrm{g} / \mathrm{ml}$ & $100 \mathrm{ng} / \mathrm{ml}$ & PBS \\
\hline
\end{tabular}

\section{Neurite Degeneration Index}

The neurite degeneration index was calculated as described previously ${ }^{169,170}$. Samples were imaged using ImageXpress Micro 4 at a magnification of 10x to capture the entire field of interest. The samples analyzed for neurite degeneration were stained using the standard immunofluorescence procedure with MAP2 (Alexa fluor 647) for neurites and DAPI staining for the nucleus. Neurite degeneration was quantified using 5-6 regions of interest of equal sizes from each treatment condition. The analysis of neurite degeneration was done using ImageJ. The fluorescent images for MAP2 staining were binarized, so that pixel intensity of regions corresponding to neurite staining was converted to black, and all other regions were converted to white. Healthy intact neurites show a continuous tract, whereas degenerated axons have a particulate structure due to fragmentation or beading. To detect degenerated neurites, we used 
the particle analyzer module of ImageJ. We calculated the percentage of the area of the small fragments or particles ( $\operatorname{size}=3-10 \mu \mathrm{m}^{2}$ ) to the intact neurites (size $>25 \mu \mathrm{m}^{2}$ ) with information derived from the binary images. A degeneration index (DI) was calculated as the fragmented neurite area ratio over the intact neurite area.

\section{Cell Viability Assays}

Rat cortical neurons (DIV 10-11) were exposed to different treatments (NMDA, ETO, $\mathrm{H}_{2} \mathrm{O}_{2}$, $\mathrm{MPP}^{+}$) after seeding 20,000 cells/well in 96-well plates. Cell viability was then assessed at 48 hrs after the initial exposure to NMDA. 3-[4,5-dimethylthiazole-2-yl]-2,5-diphenyltetrazolium bromide (MTT) assays were used to assess change in cell viability. Rat cortical neurons (DIV 9) were exposed to $5 \mu \mathrm{M}$ etoposide (ETO, 28435 Chem Implex), $400 \mu \mathrm{M} \mathrm{H}_{2} \mathrm{O}_{2}(\mathrm{H} 1009$, Sigma Aldrich) or $10 \mu \mathrm{M} \mathrm{MPP}^{+}$(D048, Sigma Aldrich) for $24 \mathrm{hrs}$ after pre-treatment with cis-RSV or trans-RSV $(50 \mu \mathrm{M})$ for $16 \mathrm{hr}$. Cultured rat cortical neurons were incubated with MTT $(0.5 \mathrm{mg} / \mathrm{mL})$. In the MTT assay, after $2 \mathrm{hr}$ incubation, the insoluble purple product formazan resulting from the reduction of MTT by NAD $(\mathrm{P}) \mathrm{H}$-dependent oxidoreductases present in cells with viable mitochondria was solubilized in dimethyl sulfoxide at room temperature, under agitation, and protected from light. The percentage of MTT reduced as measured by the difference between the absorbances at $570 \mathrm{~nm}$ read in a spectrophotometer (Spectramax 190R Molecular Devices, UK). Results are presented as a percentage of control (wells incubated with the vehicle).

\section{Use of Publicly Available Proteomics Data for the Analysis of TyrRS Levels in Human Brain}

The proteomic data for TyrRS in human brain samples were obtained from the public databases as mentioned below. The graphical representation for biweight midcorrelation (BICOR) score of 
TyrRS protein level in the brain was created by retrieving and analyzing data from a large-scale proteomic database associated with a previously published work in Nat Med 26, 769-780 (2020) 48. The published proteomic analysis ${ }^{48}$ used label-free mass spectrometry to quantitate the protein levels in the clinical samples of dorsolateral prefrontal cortex (DLPFC) regions of patients with or without $\mathrm{AD}$. The parameters used were: disease status, scored as $\mathrm{AD}=2$, Asymptomatic $\mathrm{AD}=1$, Control $=0(\mathrm{n}=419)$, tau neurofibrillary tangle burden (Braak stage, I-VI according to increasing severity, $n=419)$ and cognitive performance assessed by the Cognitive Abilities Screening Instrument (CASI) score $(\mathrm{n}=56)$. Differences in protein levels were assessed by two-sided Welch's t-test and corrected for multiple comparisons to obtain $p$ values. Z-score was measured in terms of standard deviations from the mean.

The region-specific information about TyrRS protein levels was retrieved from a recent public brain proteomic database associated with a previously published work in Commun Biol 2, 43, doi:10.1038/s42003-018-0254-9 (2019) ${ }^{8}$. The log fold change in TyrRS protein levels from six distinct regions from human post-mortem brain of $\mathrm{AD}$ cases versus asymptomatic controls, namely, entorhinal cortex (ERC), hippocampus (Hip), cingulate gyrus (CG), sensory cortex (SCx), the motor cortex (MCx) and cerebellum (CER) were identified using mass spectrometry from donors ( $\mathrm{n}=9$ AD cases, $\mathrm{n}=9$ asymptomatic controls). Statistical significance was determined using a global false discovery rate (FDR) threshold of 5\%, i.e., the largest set of proteins with an average local $\mathrm{FDR} \leq 5 \%$ were deemed significant. 


\section{Acknowledgment}

The authors sincerely appreciate the contributions of Paul Schimmel, Ph.D., Igor Roninson, Ph.D., Jeffery L. Twiss, M.D., Ph.D., and Stephen Cutler, Ph.D. for critically reading the manuscript and making helpful suggestions. The authors thank Amar Kar Ph.D. for his help with the rat primary neuronal cultures and Dr. Erica Melief and Aimee Schantz for administrative support and facilitating brain donor selection and tissue transfer. Authors acknowledge Microscopy Core of the COBRE Center for Targeted Therapeutics (CTT) and the SC SmartState Center for Childhood Neurotherapeutics at the University of South Carolina for assistance with microscopy and funding from NIH COBRE grant (P20GM109091) and NSF (Award Number: 1755670) and American Cancer Society (ACS)- Institutional Research Grant (IRG -17-179-04) (to M.S.), and R01 AG055581, and R01 AG056622 (to T.M.). The authors further appreciate NIH support for the University of Washington Alzheimer's Disease Research Center (P50AG005136 and P30AG066509) and the Adult Changes in Thought (ACT) study (U01006781), the Nancy and Buster Alvord Endowment (to C.D.K.), and research brain donors and their loved ones without whom this research would be impossible.

\section{Author contributions.}

M.J. designed and performed most of the experiments, and analyzed the data, and cowrote the manuscript. X.Z. and T.M. and C.D.K. provided tissue samples. C.N.R. helped with some of the analysis of the data. J.S. performed the DNA fiber assay and helped M.J. with the analysis. M.S. supervised the research, conceived the idea and designed experiments and analyzed the data and wrote the manuscript. All authors reviewed, edited and approved the final draft of the manuscript. 


\section{Competing interest}

The authors declare no competing financial interest associated with this study.

\section{Data availability.}

All data needed to evaluate the conclusions in the paper are present in the paper and/or the Supplementary Materials. Additional data related to this paper may be requested from the authors. Correspondence and requests for materials should be addressed to Mathew Sajish, Email: mathew2@cop.sc.edu 


\section{Supplementary Figure 1}
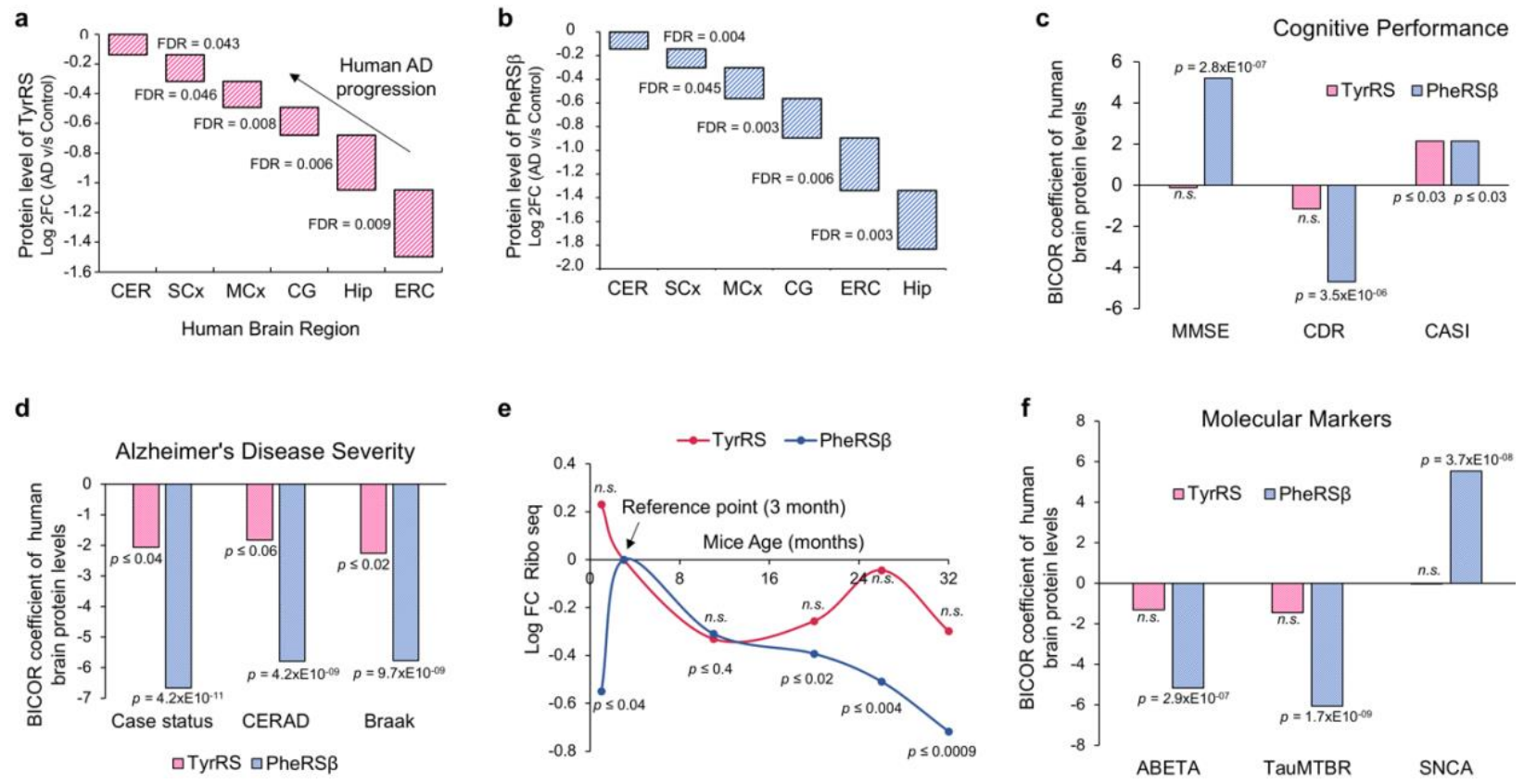

Supplementary Figure 1. Human brain protein levels of TyrRS and PheRS $\beta$ correlate with cognitive performance and AD severity, but TyrRS levels do not correlate with known molecular markers of neurodegeneration. a and b. TyrRS (a) and PheRS $\beta(\boldsymbol{b})$ are decreased in disease-affected brain regions of $A D$ patients. Graph created by the re-analysis of published data from Xu et al. (2019) ${ }^{8}$. Changes in protein levels of TyrRS from six functionally distinct regions of human post-mortem brain of $\mathrm{AD}$ cases versus asymptomatic controls: entorhinal cortex (ERC), hippocampus (Hip), cingulate gyrus (CG), sensory cortex (SCx), motor cortex (MCx) and cerebellum (CER) identified using mass spectrometry. Donors ( $n=9$ AD cases, $n=9$ asymptomatic controls) were well matched for age and post-mortem delay. Proteins with an average local false discovery rate (FDR) $\leq 5 \%$ were deemed significant. $\mathbf{c}$ and d. Brain protein levels of TyrRS and PheRS $\beta$ correlate with human cognitive performance and dementia.

Biweight midcorrelation (BICOR) coefficient of TyrRS and PheRS $\beta$ were created using data published by Johnson et al. $(2020)^{48}$. Increased brain TyrRS and PheRS $\beta$ levels show a positive 
correlation with human cognitive function $(\mathbf{c})$, and its decrease correlates with AD case status and disease severity (d). e. Mouse aging correlates with decreased ribosome occupancy of mRNA of PheRS $\beta$, not TyrRS. Graph created by the re-analysis of published data from

Anisimova, A. S. et al. (2020) ${ }^{51}$. Mouse livers representing six age groups (1-, 3-, 11-, 20-, 26-, and 32-month old) were used. The dynamics of age-related changes in ribosomal coverage of mRNAs were assessed by obtaining a list of nonoverlapping segments with stable footprint coverage and normalized to the mean coverage at three month. f. Brian TyrRS levels do not correlate with known neurodegenerative disease markers. BICOR coefficient of only PheRS $\beta$, not TyrRS shows a significant correlation with known molecular markers of neurodegenerative diseases. 


\section{Supplementary Figure 2}

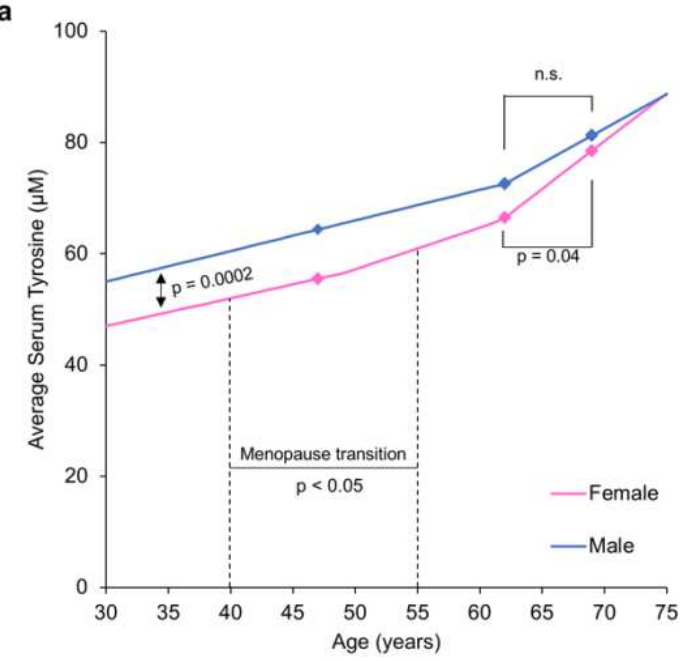

b

b

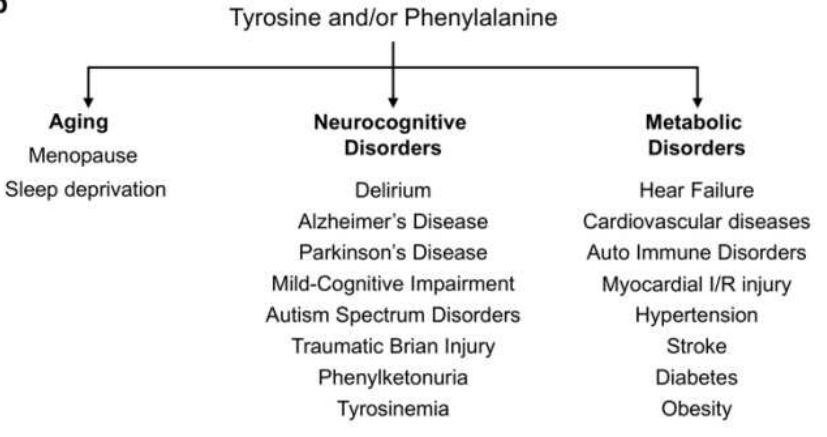

Supplementary Figure 2. Tyrosine is lower in young women but increased during human aging, and in patients with neurocognitive and metabolic disorders. a. A model of agedependent increase in serum tyrosine concentrations. The model graph was built using data obtained from different longitudinal metabolomic studies assessing the effect of aging on metabolic profiles along with their study demographics mentioned in Supplementary Table 2. b. Illustration of various neurocognitive and metabolic disorders with reported increased in serum Tyr and/or Phe as reported in works mentioned in Supplementary Table 3. 


\section{Supplementary Figure 3}

a

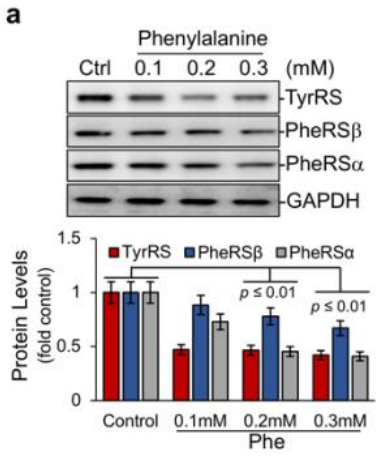

f

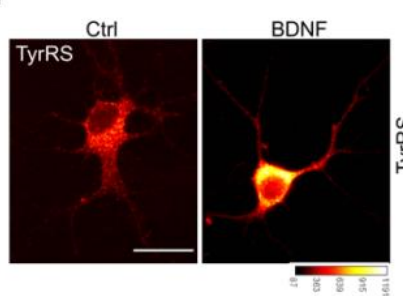

b
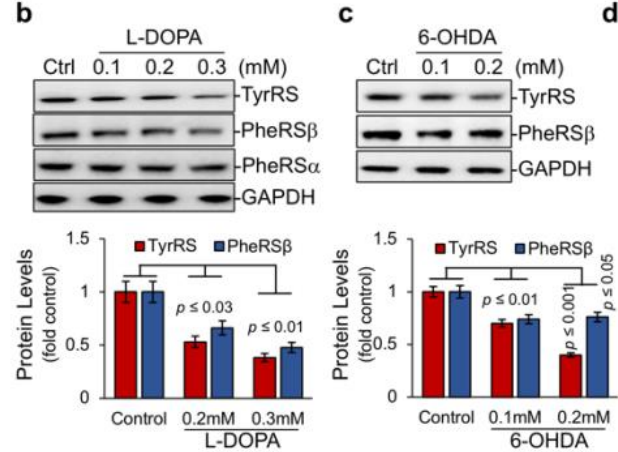

c

C

Ctrl $\frac{6-1}{0.1} 0.2(\mathrm{mM})$
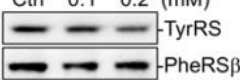

- - - PheRS

- - -GAPDH

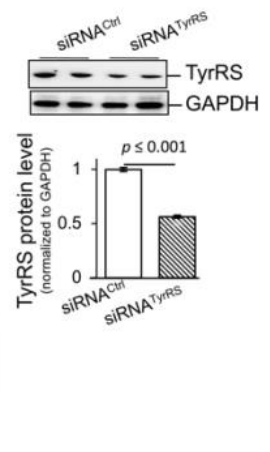

e

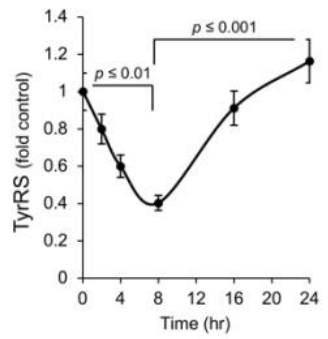

g

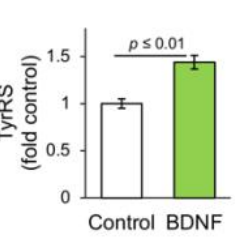

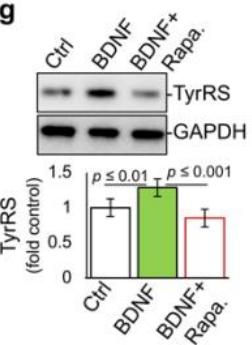

h

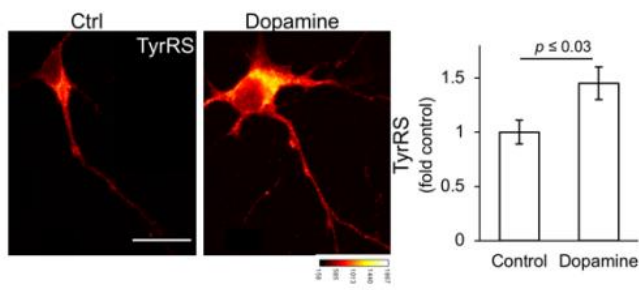

Supplementary Figure 3. BDNF stimulates the de novo synthesis of TyrRS in neurons. a.

Phenylalanine depletes TyrRS and PheRS $\alpha / \beta$. Primary cortical neurons were treated with Phe $(100-300 \mu \mathrm{M})$ for $8 \mathrm{hr}$, and the levels of TyrRS, and PheRS $\alpha / \beta$ were detected by WB analysis using their specific antibodies. b. L-DOPA decreases neuronal TyrRS. Representative immunoblots showing TyrRS, PheRS $\alpha / \beta$ levels after treatment with increasing concentrations of L-DOPA $(100-300 \mu \mathrm{M})$ for $8 \mathrm{hr}$ using their specific antibodies. c. 6-OHDA decreases the levels of TyrRS. Representative immunoblots showing TyrRS, PheRS $\beta$ levels after treatment with increasing concentrations of 6-OHDA (100 and $200 \mu \mathrm{M})$ for $8 \mathrm{hr}$ using their specific antibodies. d. TyrRS knockdown using siRNA in rat cortical neurons. Rat cortical neurons (DIV7) were transfected with siRNA against TyrRS or control siRNA (75nM) for $72 \mathrm{hr}$, and the levels of TyrRS were quantified using anti-TyrRS antibody. e and $\mathbf{f}$. BDNF activates the de novo protein synthesis of TyrRS. Primary cortical neurons were treated with BDNF (50nM) for $1 \mathrm{hr}$ either alone (e) or in combination with rapamycin (rapa,100nM) (f), and subjected to either IF (e) or 
WB (f) analysis using anti-TyrRS antibody to detect changes in the protein levels of TyrRS. All experiments were repeated 3 independent times and quantified for statistical significance. 


\section{Supplementary Figure 4}
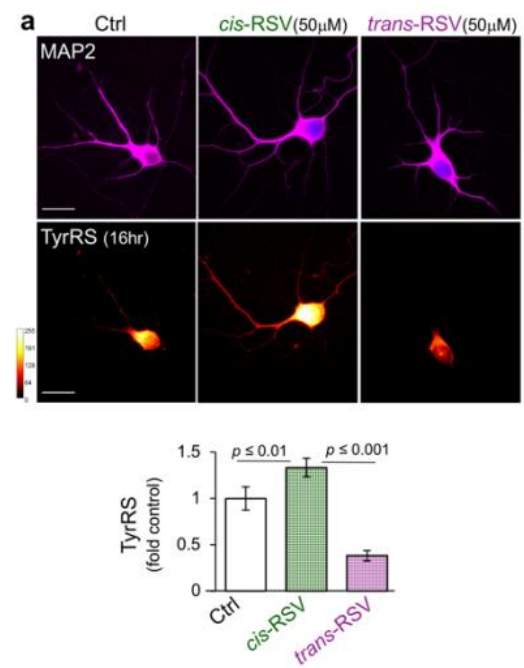

b

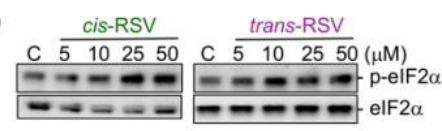

c
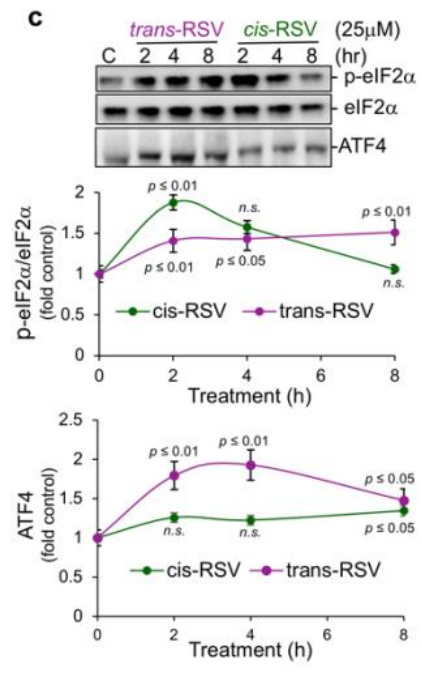

d

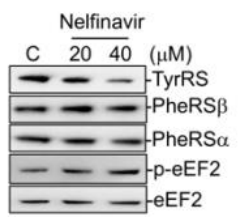

$e, f$
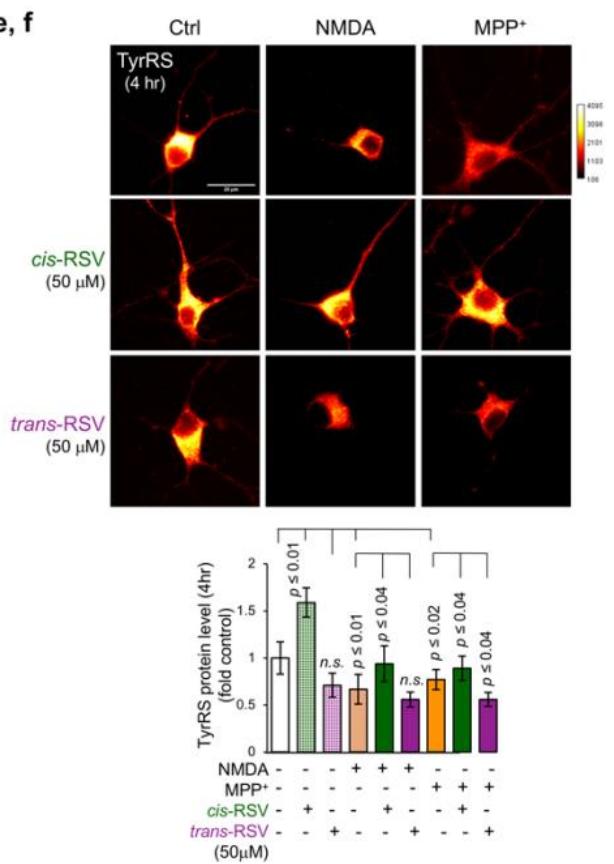

Supplementary Figure 4. Neurotoxic agents decrease TyrRS levels in neurons. a. cis-and trans-RSV have opposite effects on neuronal TyrRS protein. Representative spectral images (scale bar, 20 $\mu \mathrm{m}$ ) the protein level of neuronal TyrRS in rat cortical neurons (DIV10) following treatment with either cis-RSV or trans-RSV for $16 \mathrm{hr}$ (MAP2 - neurite marker, magenta; DAPI nuclear marker, blue; TyrRS - red-yellow spectral image). b. cis- and trans-RSV have differential effects on the phosphorylation of eIF $2 \alpha$. Primary cortical neurons were treated with

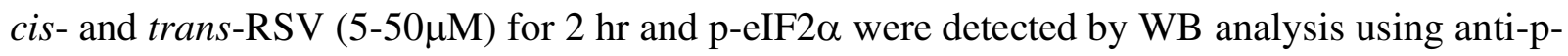
eIF2 $\alpha$ antibody. c. trans-RSV sustains the levels of p-eIF $2 \alpha$ while the effect of cis-RSV is transient. Primary cortical neurons were treated with cis- and trans-RSV $(25 \mu \mathrm{M})$ for up to $8 \mathrm{hr}$ and changes p-eIF2 $\alpha$ were detected by WB analysis using anti-p-eIF $2 \alpha$ antibody. The effect of p-eIF2 $\alpha$ was also measured using the expression levels of ATF4. d. Nelfinavir (eEF2K activator) depletes neuronal TyrRS. Primary cortical neurons were treated with nelfinavir (20- 
$40 \mu \mathrm{M})$ for $8 \mathrm{hr}$ and changes in the levels of TyrRS, PheRS $\beta$ and p-eEF2 were detected by WB analysis using their corresponding antibodies. e and f. cis-RSV prevents, and trans- $R S V$ exacerbates the decrease in the levels of TyrRS by neurotoxic agents. Representative spectral

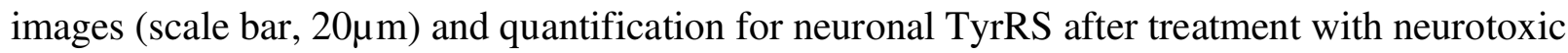
agents $\left(50 \mu \mathrm{M}\right.$ NMDA or $\left.100 \mu \mathrm{M} \mathrm{MPP}^{+}\right)$for $4 \mathrm{hr}$ in combination with cis- and trans-RSV $(50 \mu \mathrm{M})$ in rat cortical neurons (DIV9). The graphical representation is for mean \pm SEM TyrRS protein levels with statistical significance calculated using Student's paired t-test. 


\section{Supplementary Figure 5}

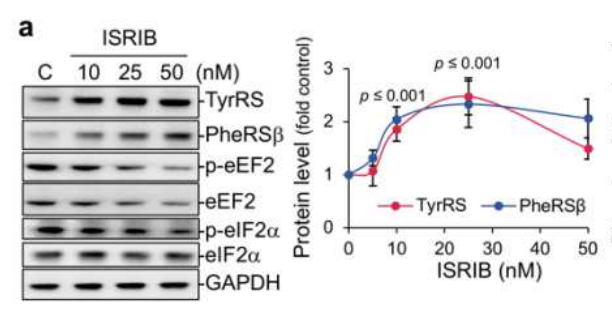

d

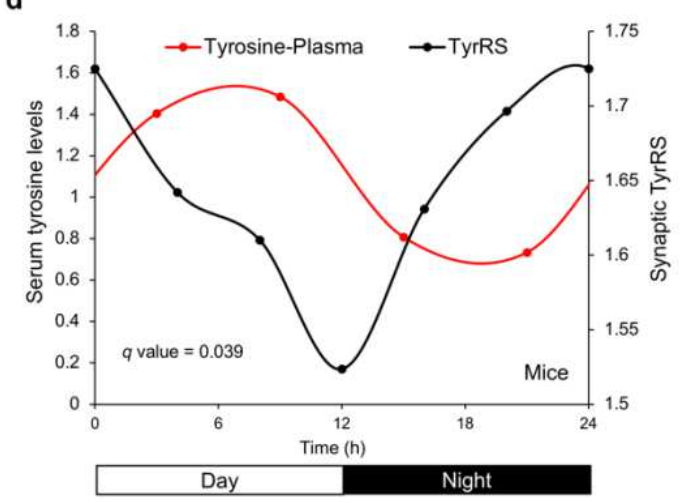

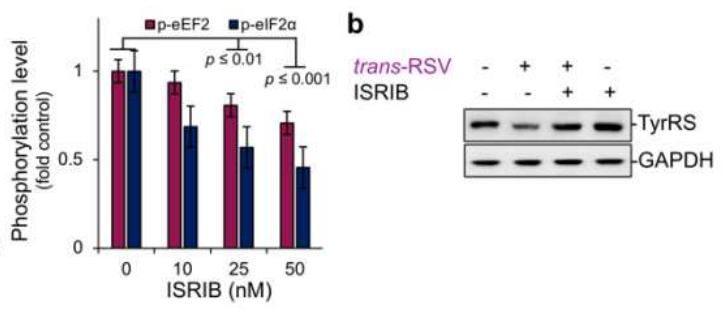

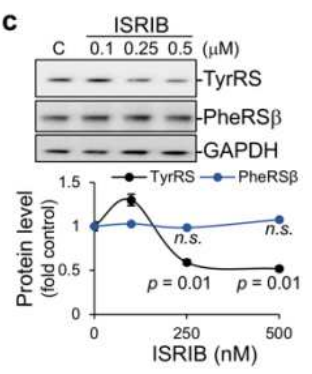

e

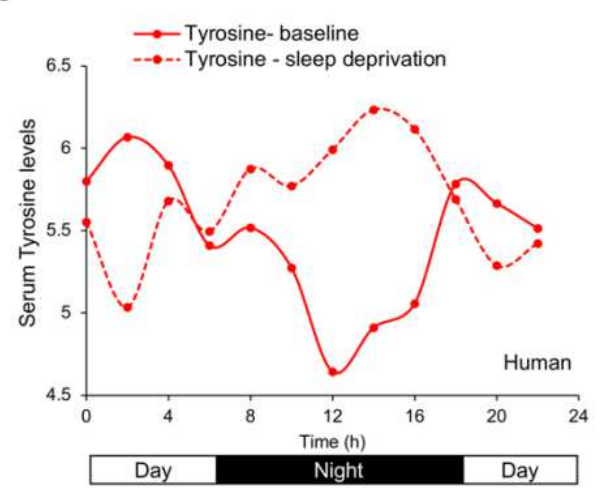

Supplementary Figure 5. Synaptic TyrRS is circadian-regulated, and sleep deprivation

increases serum tyrosine levels in humans. a. ISRIB increases TyrRS levels in neurons.

Primary cortical neurons were treated with ISRIB $(\leq 50 \mathrm{nM})$ for $8 \mathrm{hr}$ and changes in the levels of TyrRS, PheRS $\beta$, p-eEF2, eEF2, p-eIF2 $\alpha$, and eIF2 $\alpha$ were detected and quantified by WB analysis using their respective antibodies. b. ISRIB protects neurons against trans-RSV-mediated depletion of TyrRS. Primary cortical neurons were treated with trans-RSV $(25 \mu \mathrm{M})$ alone or in combination with ISRIB (10nM) for $8 \mathrm{hr}$ and changes in the levels of TyrRS were detected by WB. c. High concentrations of ISRIB decrease the levels of TyrRS in neurons. Primary cortical neurons were treated with ISRIB (100-500nM) for $8 \mathrm{hr}$ and changes in the levels of TyrRS, and PheRS $\beta$ were detected by WB analysis using their respective antibodies. d. Synaptic TyrRS protein is circadian-regulated. Graph depicting the circadian protein levels of synaptic TyrRS and circadian levels of serum tyrosine were generated using data from the re-analysis of the 
mouse circadian proteomic (Noya, S. B. et al. (2019)) $)^{93}$ and metabolomic (Eckel-Mahan, K. L. et al. (2012) $)^{94}$ data. e. Human sleep deprivation disrupts circadian regulation of tyrosine.

Representative graph depicting the circadian levels of serum tyrosine of an individual was generated using data from the re-analysis of the human circadian metabolomic data (Grant, L. K. et al. (2019), and (Kervezee, L. et al. (2019) $)^{95,96 .}$ 


\section{Supplementary Figure 6}

a
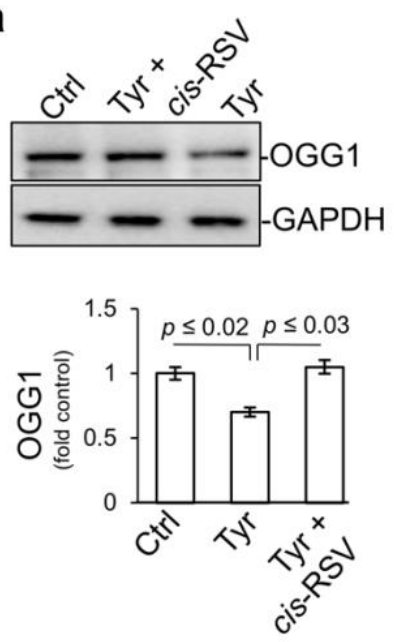

b
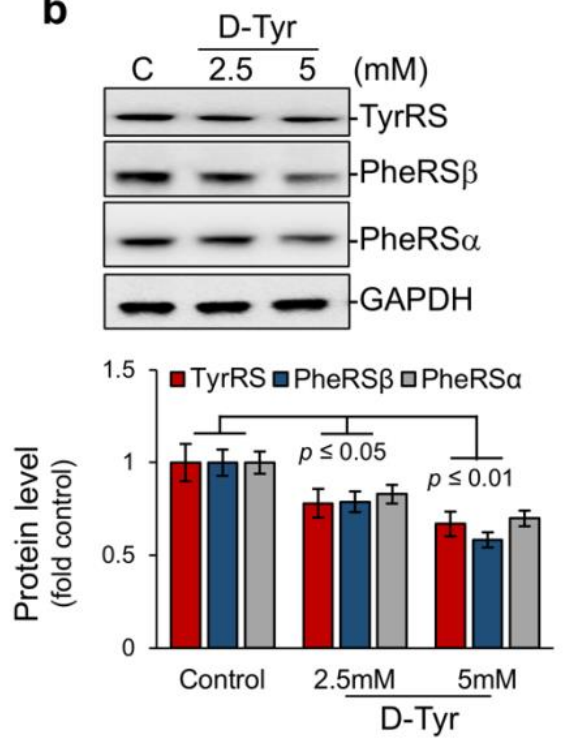

C

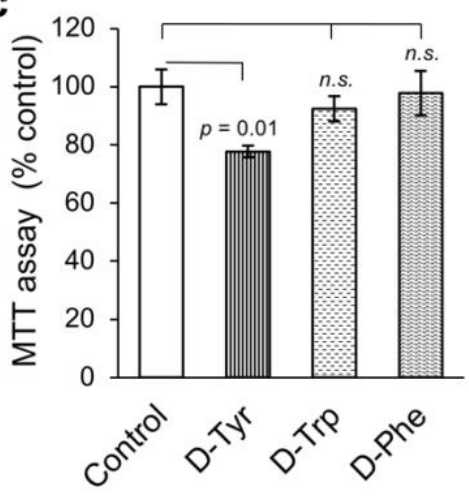

d
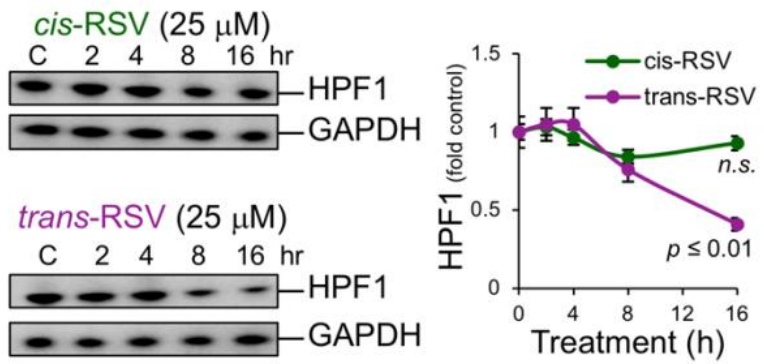

e

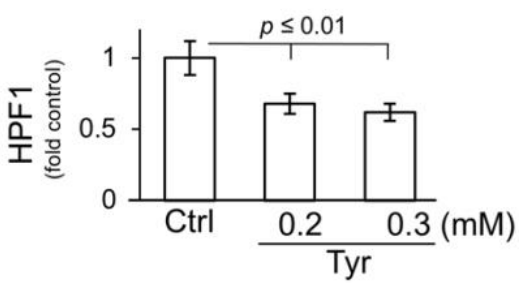

Supplementary Figure 6. D-tyrosine is neurotoxic and trans-RSV decreases HPF1 levels in

neurons. a. cis-RSV rescues Tyr-mediated depletion of OGG1 protein. Primary cortical neurons were treated with either $\operatorname{Tyr}(200 \mu \mathrm{M})$ alone or in combination with cis-RSV $(50 \mu \mathrm{M})$ for $8 \mathrm{hr}$, and the levels of OGG1 was detected by WB analysis using anti-OGG1 antibody. b. D-Tyr decreases both TyrRS and PheRS $\beta$ proteins. Primary cortical neurons were treated with D-Tyr (2.5 and 5mM) for $8 \mathrm{hr}$, and the levels of TyrRS, and PheRS $\beta$ were detected by WB analysis using their specific antibodies. c. D-Tyrosine induces neurotoxicity. Rat cortical neurons (DIV9) were treated with either D-Tyr or D-Phe or D-Trp (2mM) for $48 \mathrm{hr}$, and viability was assessed using MTT assay. d. trans-RSV decreases HPF1 levels. Immunoblots showing the protein levels of HPF1 in rat cortical neurons (DIV9/10) after treatment with cis- and trans-RSV for up to 16 
hr. Graphs represents mean \pm SEM from $n=4$ experiments with statistical significance calculated using Student's paired t-test. e. Quantification of Tyr-mediated decrease in the levels of HPF1 as shown in Fig. 3f. 


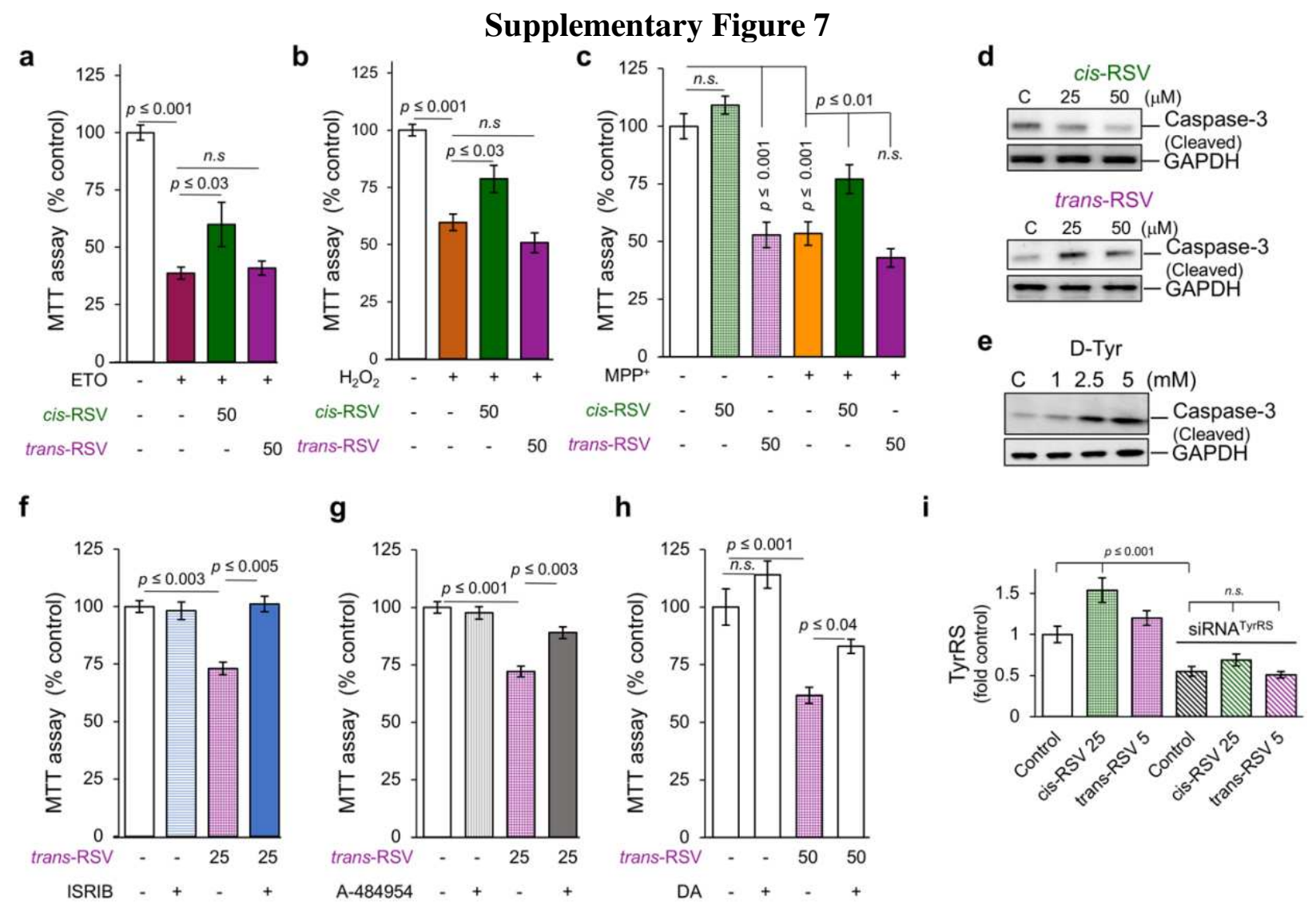

Supplementary Figure 7. Pharmacological activation of protein synthesis protects neurons

against trans-RSV-mediated toxicity. a-c. Only cis-RSV protects neurons against etoposide (a), $\mathrm{H}_{2} \mathrm{O}_{2}$ (b) and $\mathrm{MPP}^{+}(\boldsymbol{c})$ toxicity. Rat cortical neurons (DIV9) were exposed to $5 \mu \mathrm{M}$ etoposide (ETO), $400 \mu \mathrm{M} \mathrm{H}_{2} \mathrm{O}_{2}$ or $10 \mu \mathrm{M} \mathrm{MPP}{ }^{+}$for $24 \mathrm{hr}$ after pre-treatment with cis-RSV or trans-RSV $(50 \mu \mathrm{M})$ for $16 \mathrm{hr}$. Cell viability was assessed using MTT assay. d. trans-RSV induces neuronal apoptosis. Immunoblots showing the levels of cleaved caspase-3 in rat cortical neurons (DIV9/10) after the treatment with cis- and trans-RSV $(25$ and $50 \mu \mathrm{M})$ for $24 \mathrm{hr}$. e. D-Tyr induces neuronal apoptosis. Immunoblots showing the levels of cleaved caspase-3 in rat cortical neurons (DIV 9/10) after the treatment with D-Tyr $(2 \mathrm{mM})$ for $16 \mathrm{hr}$. f. ISRIB protects neurons from trans- $R S V$ mediated neurotoxicity. Rat cortical neurons (DIV8) were treated with trans-RSV alone or in combination with ISRIB (10nM) for 48 hrs and viability was measured using MTT assay. g. $A$ - 
484954 (eEF2K inhibitor) protects neurons from trans-RSV-mediated toxicity. Rat cortical neurons (DIV8) were treated with trans-RSV alone or in combination with A484954 (100nM) for $48 \mathrm{hr}$ and viability was measured using MTT assay. h. DA protects neurons from trans-RSVmediated toxicity. Rat cortical neurons (DIV8) were treated with trans-RSV alone or in combination with DA $(100 \mu \mathrm{M})$ for $72 \mathrm{hr}$ and viability was measured using MTT assay. i. Quantification of TyrRS protein levels in Fig. $4 g$. 


\section{Supplementary Figure 8}
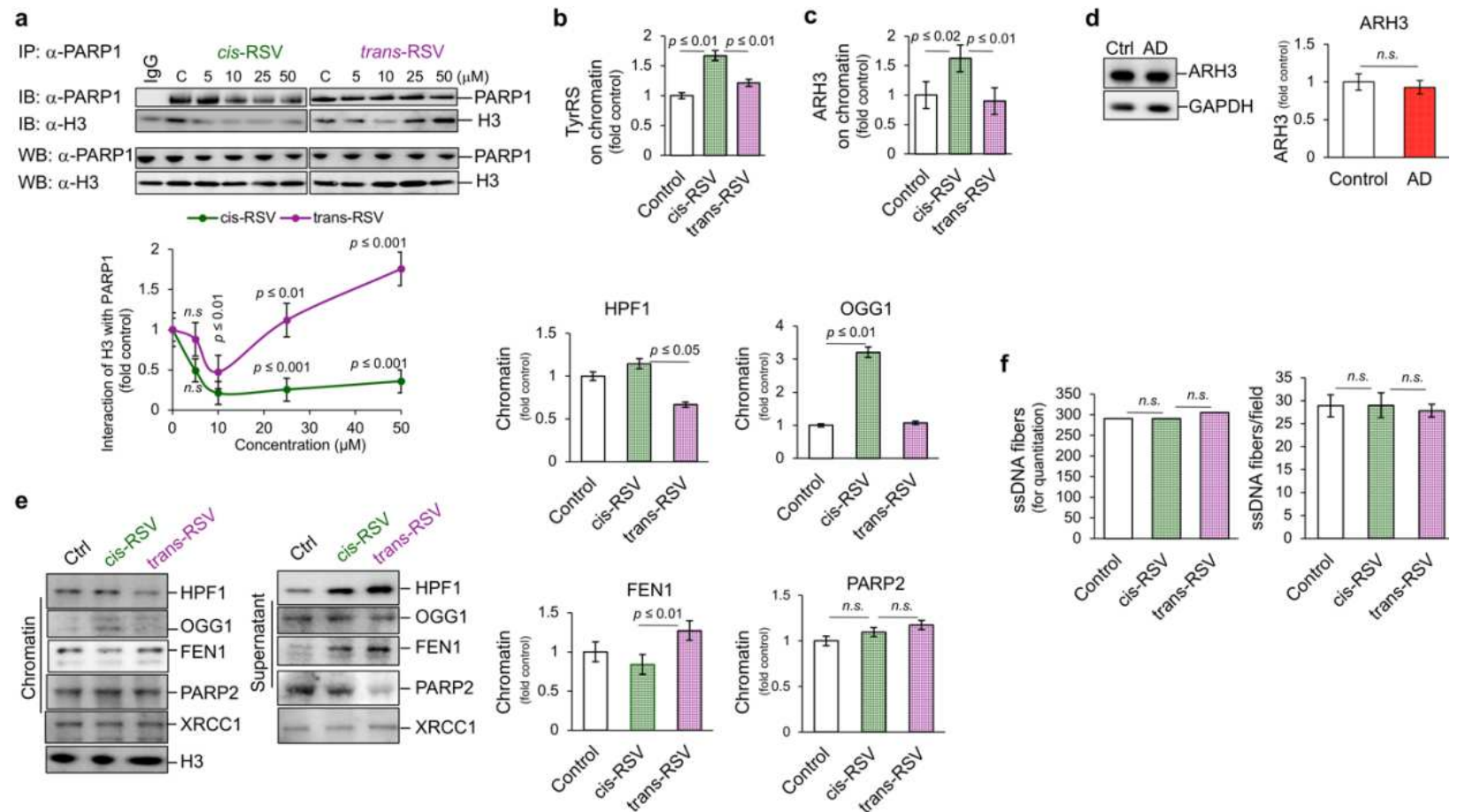

Supplementary Figure 8. cis-and trans-RSV have opposite effects on the recruitment of DNA

repair factors to the chromatin. a. cis-RSV prevents and trans-RSV increases the interaction of PARP1 with histone H3. Representative immunoblots and quantification of the interaction of $\mathrm{H} 3$

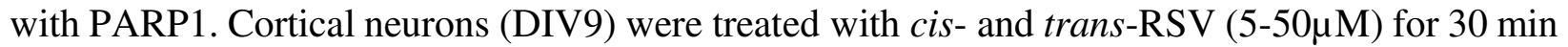
and PARP1 was immunoprecipitated (IP) using antibody against PARP1. The interaction of PARP1 with $\mathrm{H} 3$ was determined using anti-H3 antibody. b. Quantification of TyrRS in the chromatin fraction in Fig. 5a. c. Quantification of ARH3 in the chromatin fraction in Fig. 5A. d. ARH3 levels are not affected in the hippocampal tissues of human AD patients. Representative immunoblots and quantification for ARH3 using anti-ARH3 antibody in the hippocampal region of $\mathrm{AD}$ patients $(\mathrm{n}=7)$ with age and sex-matched controls $(\mathrm{n}=7)$. e. cis-RSV and trans-RSV have differential effects on chromatin recruitment of DNA repair proteins. Representative immunoblots using specific antibodies, and quantification from chromatin fraction of cortical neurons (DIV9) 
depicting HPF1, OGG1, FEN1, XRCC1, and PARP2 after treatment with cis- and trans-RSV $(50 \mu \mathrm{M})$ for $1 \mathrm{hr} . \mathbf{f}$. Quantification of neuronal DNA fibers for fig. $5 \mathrm{~d}$. 


\section{Extended Data Figure 9}

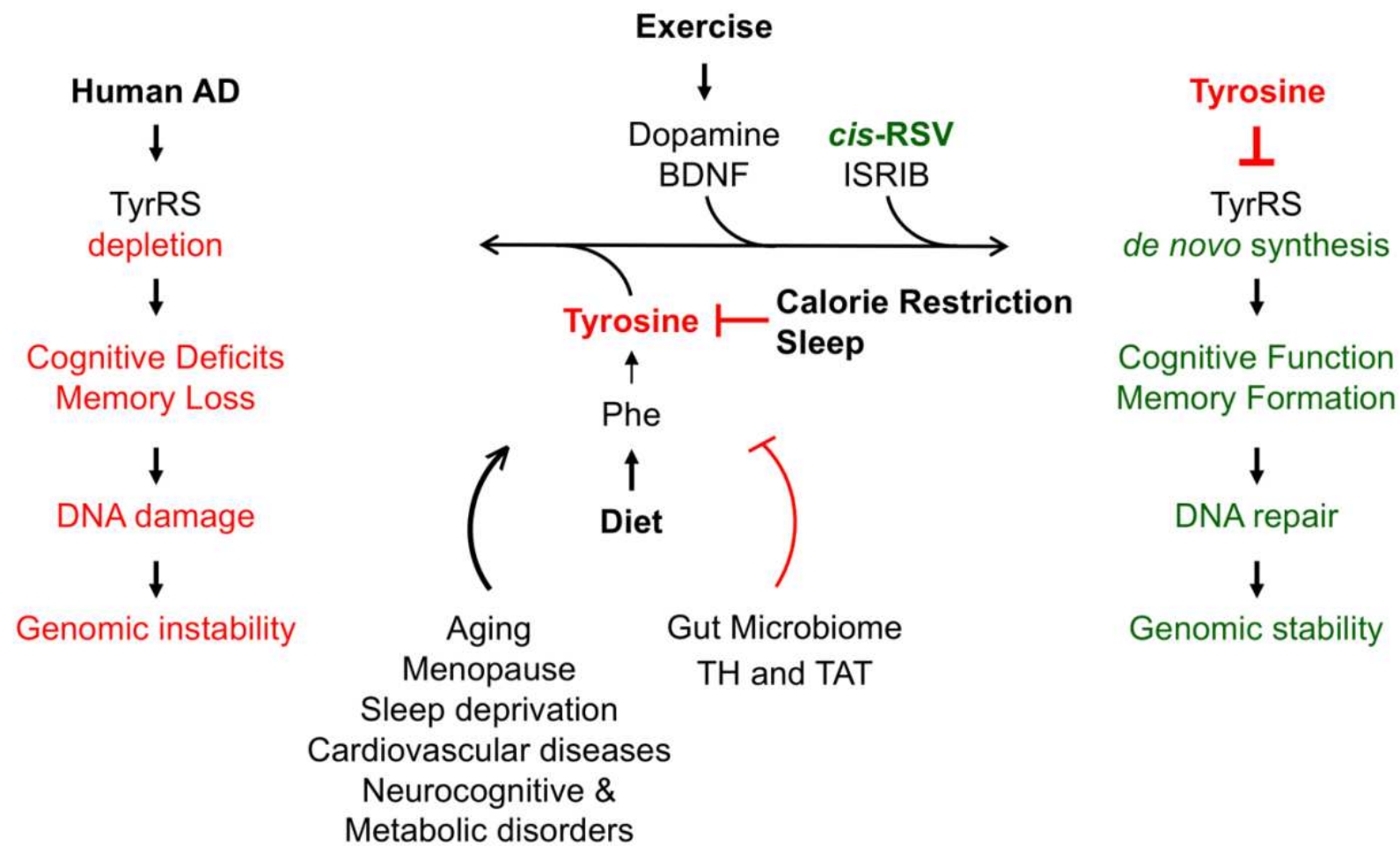

Supplementary Figure 9. Potential mechanism of Tyr-mediated induction of age-associated neurocognitive disorders, DNA damage, and genomic instability. 


\section{Supplementary Table 1}

Patient demographics

\begin{tabular}{|ccccccc|}
\hline Diagnosis & Sex & Age & PMI (hr) & APOE & $\begin{array}{c}\text { Braak } \\
\text { Stage }\end{array}$ & $\begin{array}{c}\text { CERAD } \\
\text { Score }\end{array}$ \\
No dementia & F & 92 & $06: 00$ & $3 / 3$ & III & Sparse \\
No dementia & M & 86 & $03: 15$ & $3 / 3$ & III & Absent \\
No dementia & F & 95 & $03: 05$ & $3 / 4$ & III & Absent \\
No dementia & F & 92 & $06: 00$ & $3 / 3$ & III & Sparse \\
No dementia & M & 78 & $06: 00$ & $3 / 3$ & II & Sparse \\
No dementia & M & 86 & $03: 15$ & $3 / 3$ & III & Absent \\
No dementia & F & 91 & $11: 00$ & $4 / 3$ & III & Absent \\
AD & M & 88 & $04: 40$ & $4 / 3$ & VI & Moderate \\
AD & M & 91 & $07: 00$ & $3 / 4$ & V & Moderate \\
AD & F & 96 & $04: 45$ & $3 / 3$ & VI & Frequent \\
AD & F & 98 & $02: 30$ & $3 / 3$ & IV & Frequent \\
AD & M & 88 & $04: 40$ & $4 / 3$ & VI & Moderate \\
AD & M & 91 & $07: 00$ & $3 / 4$ & V & Moderate \\
AD & F & 90 & $03: 51$ & $3 / 3$ & V & Frequent \\
\hline
\end{tabular}

PMI: post-mortem interval; APOE: Apolipoprotein E allele status; M: Male; F: Female 


\section{Supplementary Table 2}

\begin{tabular}{|l|l|l|}
\hline Plasma Tyrosine concentration & Age (mean) & Reference \\
\hline $64.1 \pm 15.1 \mu \mathrm{M}$ & $46.2 \pm 6.4(\mathrm{n}=174, \mathrm{M})$ & Andraos, et al., $2021^{1}$ \\
$59.8 \pm 16.8 \mu \mathrm{M}$ & $43.6 \pm 4.8(\mathrm{n}=1150, \mathrm{~F})$ & \\
\hline $61(54-70) \mu \mathrm{M}$ & $26 \pm 4(\mathrm{n}=68, \mathrm{M})$ & Caballero, et al., $1991^{2}$ \\
$52(47-61) \mu \mathrm{M}$ & $25 \pm 5(\mathrm{n}=72, \mathrm{~F})$ & \\
$63(55-69) \mu \mathrm{M}$ & $71 \pm 7(\mathrm{n}=32, \mathrm{M})$ & \\
$59(50-75) \mu \mathrm{M}$ & $72 \pm 8(\mathrm{n}=42, \mathrm{~F})$ & \\
\hline $66.48 \pm 17.29 \mu \mathrm{M}$ & $62.71(55-74, \mathrm{n}=317, \mathrm{~F})$ & Chak, et al., $2019^{3}$ \\
$78.4 \pm 15.24 \mu \mathrm{M}$ & $69.71(62-81, \mathrm{n}=317, \mathrm{~F})$ & \\
$72.59 \pm 17.04 \mu \mathrm{M}$ & $62.69(55-74, \mathrm{n}=273, \mathrm{M})$ & \\
$81.7 \pm 17.69 \mu \mathrm{M}$ & $69.69(62-81, \mathrm{n}=273, \mathrm{M})$ & \\
\hline
\end{tabular}

\section{References}

1 Andraos, S. et al. Population epidemiology and concordance for plasma amino acids and precursors in 11-12-year-old children and their parents. Sci Rep-Uk 11, doi:ARTN 361910.1038/s41598-020-80923-9 (2021).

2 Caballero, B., Gleason, R. E. \& Wurtman, R. J. Plasma amino acid concentrations in healthy elderly men and women. Am J Clin Nutr 53, 1249-1252, doi:10.1093/ajen/53.5.1249 (1991).

3 Chak, C. M. et al. Ageing Investigation Using Two-Time-Point Metabolomics Data from KORA and CARLA Studies. Metabolites 9, doi:ARTN 4410.3390/metabo9030044 (2019). 


\section{Supplementary Table 3}

\begin{tabular}{|c|c|c|}
\hline Condition/Disease & Elevated Amino Acids & References \\
\hline Aging & $\begin{array}{l}\text { Tyr, Val, Gly, Leu, Ile, } \\
\text { Gln }\end{array}$ & $\begin{array}{l}\text { Chak, C.M, et al. } 2019^{1} \\
\text { Darst BF, et al. } 2019^{2} \\
\text { Hwangbo, N. et al. } 2021^{3} \\
\text { Andraos, et al. } 2021^{4} \\
\text { van de Rest, O., et al. } 2017^{5} \\
\text { Ravaglia, G. et al. } 2002^{6} \\
\text { Kochhar, S. et al. } 2006^{7} \\
\text { Kouchiwa, T. et al. } 2012^{8} \\
\text { Rist, M. J. et al. } 2017^{9}\end{array}$ \\
\hline Menopause & Tyr, Val, Glu, Ile, Gly & Auro, K. et al. $2014^{10}$ \\
\hline Sleep Deprivation & $\begin{array}{l}\text { Tyr, Phe, Trp, Ile, Thr, } \\
\text { Pro, Lys }\end{array}$ & $\begin{array}{l}\text { Grant, L. K. et al. } 2019^{11} \\
\text { Gehrman, P. et al. } 2018^{12}\end{array}$ \\
\hline Delirium & $\begin{array}{l}\text { Tyr, Trp } \\
\text { Tyr, Phe, Trp }\end{array}$ & $\begin{array}{l}\text { Pandharipande, P. P. et al. } 2009^{13} \\
\text { Watne, L. O. et al. } 2016^{14}\end{array}$ \\
\hline $\begin{array}{l}\text { Alzheimer's Disease } \\
\text { (AD) } \\
\text { and } \\
\text { Mild Cognitive } \\
\text { Impairment (MCI) }\end{array}$ & $\begin{array}{l}\text { Tyr, Phe, Trp, Asp, Thr, } \\
\text { Glu, Gln, Met, His, Pro, } \\
\text { Val and Ala (elevated in } \\
\text { brain of AD patients) } \\
\text { Tyr, Phe (plasma for } \\
\text { MCI) }\end{array}$ & $\begin{array}{l}\text { Storga, D., et al. } 1996^{15} \\
\text { Fekkes, D. et al. } 1998^{16} \\
\text { Kim, Y. H. et al. } 2019^{17} \\
\text { Huo, Z. et al. } 2020^{18} \\
\text { Ravaglia, G. et al. } 2004^{19} \\
\text { Ravaglia, G. et al. } 2002^{6}\end{array}$ \\
\hline $\begin{array}{l}\text { Parkinson's Disease } \\
\text { (PD) }\end{array}$ & Tyr, Phe & $\begin{array}{l}\text { Jimenez-Jimenez, F. J. et al. } 2020^{20} \\
\text { Vascellari, S. et al. } 2020^{21} \\
\text { Zhao, H. et al. } 2018^{22} \\
\text { Wu, J.F. et al. } 2016^{23} \\
\text { T. Hatano, et al. } 2016^{24}\end{array}$ \\
\hline $\begin{array}{l}\text { Autism Spectrum } \\
\text { Disorders (ASD) }\end{array}$ & $\begin{array}{l}\text { Tyr, Phe, Glu, Asn, } \\
\text { Ala, Lys, Arg, Cys, His, } \\
\text { Met, Ser, Val }\end{array}$ & $\begin{array}{l}\text { Skalny, A. V. et al. } 2020^{25} \\
\text { Zou, M. Y. et al. } 2020^{26} \\
\text { Aldred, S. et al. } 2003^{27}\end{array}$ \\
\hline $\begin{array}{l}\text { Traumatic brain injury } \\
\text { (TBI) }\end{array}$ & Tyr, Phe & Vuille-Dit-Bille, et al. $2012^{28}$ \\
\hline Tyrosinemia I & Tyr & Bendadi, F. et al. $2014^{29}$ \\
\hline Tyrosinemia II & Tyr & R. Huhn, H. et al. $1998^{30}$ \\
\hline Tyrosinemia III & Tyr & Ellaway, C. J. et al. $2001^{31}$ \\
\hline Phenylketonuria (PKU) & Phe & Blau, N., et al. $2010^{32}$ \\
\hline $\begin{array}{l}\text { Diabetes, } \\
\text { Obesity, and Insulin } \\
\text { Resistance }\end{array}$ & Tyr, Phe, Leu, Ile, Val & $\begin{array}{l}\text { Felig, P., et al. } 1969^{33} \\
\text { Newgard, C. B., et al. } 2009^{34} \\
\text { Wang, T. J. et al. } 2011^{35} \\
\text { R. Yang, et al. } 2014^{36} \\
\text { P. Wurtz, et al. } 2014^{37} \\
\text { Hellmuth et al, } 2016^{38}\end{array}$ \\
\hline $\begin{array}{l}\text { Cardiovascular Disease } \\
\text { (CVD) }\end{array}$ & Tyr, Phe & $\begin{array}{l}\text { Wurtz, P. et al. } 2015^{39} \\
\text { P. Welsh, et al. } 2018^{40}\end{array}$ \\
\hline Hypertension & Tyr, Phe, Leu, Ile, Val & $\begin{array}{l}\text { Altorf-van der Kuil, W. et al. } 2013^{41} \\
\text { F. Teymoori, et al. } 2018^{42}\end{array}$ \\
\hline
\end{tabular}




\begin{tabular}{|c|c|c|}
\hline $\begin{array}{l}\text { Myocardial Ischemia- } \\
\text { Reperfusion injury }\end{array}$ & Tyr, Phe & A. Surendran, et al. $2019^{43}$ \\
\hline Heart failure & Tyr, Phe Met, His & $\begin{array}{l}\text { Stryeck, S. et al. } 2019^{44} \\
\text { Murashige, D. et al. } 2020^{45} \\
\text { Hakuno, D., et al. } 2015^{46} \\
\text { Cheng, M. L. et al. } 2015^{47}\end{array}$ \\
\hline Stroke & Phe, His & Vojinovic, D. et al. $2020^{48}$ \\
\hline $\begin{array}{l}\text { Liver Diseases } \\
\text { (Cirrhosis } \\
\text { Hepatitis) }\end{array}$ & Tyr, Phe, Trp & $\begin{array}{l}\text { S. J. O'Keefe, et al. } 1981^{49} \\
\text { C. H. Dejong, et al. } 2007^{50} \\
\text { M. Y. Morgan, et al. } 1982^{51} \\
\text { A. J. McCullough, et al. } 1981^{52}\end{array}$ \\
\hline $\begin{array}{l}\text { Auto-Immune } \\
\text { Disorders }\end{array}$ & Tyr, Phe & D. Blackmore, L. Li, et al. $2020^{53}$ \\
\hline Sepsis & $\begin{array}{l}\text { Tyr, Phe, Cys, Met, } \\
\text { Ala, Asp, Glu, Pro }\end{array}$ & $\begin{array}{l}\text { H. R. Freund, et al. } 1978^{54} \\
\text { H. Freund, et al. } 1979^{55}\end{array}$ \\
\hline
\end{tabular}

\section{References}

1 Chak, C. M. et al. Ageing Investigation Using Two-Time-Point Metabolomics Data from KORA and CARLA Studies. Metabolites 9, doi:ARTN 4410.3390/metabo9030044 (2019).

2 Darst, B. F., Koscik, R. L., Hogan, K. J., Johnson, S. C. \& Engelman, C. D. Longitudinal plasma metabolomics of aging and sex. Aging (Albany NY) 11, 1262-1282, doi:10.18632/aging.101837 (2019).

3 Hwangbo, N. et al. An aging clock using metabolomic CSF. bioRxiv, 2021.2004.2004.438397, doi:10.1101/2021.04.04.438397 (2021).

4 Andraos, S. et al. Population epidemiology and concordance for plasma amino acids and precursors in 11-12-year-old children and their parents. Sci Rep-Uk 11, doi:ARTN 361910.1038/s41598-020-80923-9 (2021).

5 van de Rest, O., Bloemendaal, M., de Heus, R. \& Aarts, E. Dose-Dependent Effects of Oral Tyrosine Administration on Plasma Tyrosine Levels and Cognition in Aging. Nutrients 9, doi:10.3390/nu9121279 (2017). 
6 Ravaglia, G. et al. Plasma amino acid concentrations in healthy and cognitively impaired oldest-old individuals: associations with anthropometric parameters of body composition and functional disability. Br J Nutr 88, 563-572, doi:10.1079/BJN2002700 (2002).

7 Kochhar, S. et al. Probing gender-specific metabolism differences in humans by nuclear magnetic resonance-based metabonomics. Anal Biochem 352, 274-281, doi:10.1016/j.ab.2006.02.033 (2006).

8 Kouchiwa, T. et al. Age-related changes in serum amino acids concentrations in healthy individuals. Clin Chem Lab Med 50, 861-870, doi:10.1515/cclm-2011-0846 (2012).

9 Rist, M. J. et al. Metabolite patterns predicting sex and age in participants of the Karlsruhe Metabolomics and Nutrition (KarMeN) study. Plos One 12, e0183228, doi:10.1371/journal.pone.0183228 (2017).

10 Auro, K. et al. A metabolic view on menopause and ageing. Nat Commun 5, 4708, doi:10.1038/ncomms5708 (2014).

11 Grant, L. K. et al. Circadian and wake-dependent changes in human plasma polar metabolites during prolonged wakefulness: A preliminary analysis. Sci Rep 9, 4428, doi:10.1038/s41598-019-40353-8 (2019).

12 Gehrman, P. et al. Altered diurnal states in insomnia reflect peripheral hyperarousal and metabolic desynchrony: a preliminary study. Sleep 41, doi:10.1093/sleep/zsy043 (2018).

13 Pandharipande, P. P. et al. Plasma tryptophan and tyrosine levels are independent risk factors for delirium in critically ill patients. Intens Care Med 35, 1886-1892, doi:10.1007/s00134-009-1573-6 (2009). 
14 Watne, L. O. et al. Increased CSF levels of aromatic amino acids in hip fracture patients with delirium suggests higher monoaminergic activity. Bmc Geriatr 16, 149, doi:10.1186/s12877-016-0324-0 (2016).

15 Storga, D., Vrecko, K., Birkmayer, J. G. D. \& Reibnegger, G. Monoaminergic neurotransmitters, their precursors and metabolites in brains of Alzheimer patients. Neuroscience Letters 203, 29-32, doi:Doi 10.1016/0304-3940(95)12256-7 (1996).

16 Fekkes, D. et al. Abnormal amino acid metabolism in patients with early stage Alzheimer dementia. J Neural Transm (Vienna) 105, 287-294, doi:10.1007/s007020050058 (1998).

17 Kim, Y. H. et al. Metabolomic Analysis Identifies Alterations of Amino Acid Metabolome Signatures in the Postmortem Brain of Alzheimer's Disease. Exp Neurobiol 28, 376-389, doi:10.5607/en.2019.28.3.376 (2019).

18 Huo, Z. et al. Brain and blood metabolome for Alzheimer's dementia: findings from a targeted metabolomics analysis. Neurobiol Aging 86, 123-133, doi:10.1016/j.neurobiolaging.2019.10.014 (2020).

19 Ravaglia, G. et al. Plasma amino acid concentrations in patients with amnestic mild cognitive impairment or Alzheimer disease. Am J Clin Nutr 80, 483-488, doi:10.1093/ajen/80.2.483 (2004).

20 Jimenez-Jimenez, F. J., Alonso-Navarro, H., Garcia-Martin, E. \& Agundez, J. A. G. Cerebrospinal and blood levels of amino acids as potential biomarkers for Parkinson's disease: review and meta-analysis. Eur J Neurol 27, 2336-2347, doi:10.1111/ene.14470 (2020).

21 Vascellari, S. et al. Gut Microbiota and Metabolome Alterations Associated with Parkinson's Disease. mSystems 5, doi:10.1128/mSystems.00561-20 (2020). 
22 Zhao, H. et al. Potential biomarkers of Parkinson's disease revealed by plasma metabolic profiling. J Chromatogr B Analyt Technol Biomed Life Sci 1081-1082, 101-108, doi:10.1016/j.jchromb.2018.01.025 (2018).

23 Wu, J. F. et al. NMR analysis of the CSF and plasma metabolome of rigorously matched amyotrophic lateral sclerosis, Parkinson's disease and control subjects. Metabolomics 12, doi:ARTN 10110.1007/s11306-016-1041-6 (2016).

24 Hatano, T., Saiki, S., Okuzumi, A., Mohney, R. P. \& Hattori, N. Identification of novel biomarkers for Parkinson's disease by metabolomic technologies. J Neurol Neurosurg Psychiatry 87, 295-301, doi:10.1136/jnnp-2014-309676 (2016).

25 Skalny, A. V. et al. Serum amino acid spectrum in children with autism spectrum disorder (ASD). Res Autism Spect Dis 77, doi:ARTN 10160510.1016/j.rasd.2020.101605 (2020).

26 Zou, M. Y. et al. Identification of Amino Acid Dysregulation as a Potential Biomarker for Autism Spectrum Disorder in China. Neurotoxicity Research, doi:10.1007/s12640020-00242-9 (2020).

27 Aldred, S., Moore, K. M., Fitzgerald, M. \& Waring, R. H. Plasma amino acid levels in children with autism and their families. Journal of Autism and Developmental Disorders 33, 93-97, doi:Doi 10.1023/A:1022238706604 (2003).

28 Vuille-Dit-Bille, R. N., Ha-Huy, R. \& Stover, J. F. Changes in plasma phenylalanine, isoleucine, leucine, and valine are associated with significant changes in intracranial pressure and jugular venous oxygen saturation in patients with severe traumatic brain injury. Amino Acids 43, 1287-1296, doi:10.1007/s00726-011-1202-x (2012). 
29 Bendadi, F. et al. Impaired cognitive functioning in patients with tyrosinemia type I receiving nitisinone. J Pediatr 164, 398-401, doi:10.1016/j.jpeds.2013.10.001 (2014).

30 Huhn, R. et al. Novel and recurrent tyrosine aminotransferase gene mutations in tyrosinemia type II. Human Genetics 102, 305-313, doi:DOI 10.1007/s004390050696 (1998).

31 Ellaway, C. J. et al. Outcome of tyrosinaemia type III. Journal of Inherited Metabolic Disease 24, 824-832, doi:Doi 10.1023/A:1013936107064 (2001).

32 Blau, N., van Spronsen, F. J. \& Levy, H. L. Phenylketonuria. Lancet 376, 1417-1427, doi:Doi 10.1016/S0140-6736(10)60961-0 (2010).

33 Felig, P., Marliss, E. \& Cahill, G. F. Plasma Amino Acid Levels and Insulin Secretion in Obesity. New Engl J Med 281, 811-+, doi:Doi 10.1056/Nejm196910092811503 (1969).

34 Newgard, C. B. et al. A Branched-Chain Amino Acid-Related Metabolic Signature that Differentiates Obese and Lean Humans and Contributes to Insulin Resistance. Cell Metab 9, 311-326, doi:10.1016/j.cmet.2009.02.002 (2009).

35 Wang, T. J. et al. Metabolite profiles and the risk of developing diabetes. Nat Med 17, 448-453, doi:10.1038/nm.2307 (2011).

36 Yang, R. et al. Association of branched-chain amino acids with carotid intima-media thickness and coronary artery disease risk factors. Plos One 9, e99598, doi:10.1371/journal.pone.0099598 (2014).

37 Wurtz, P. et al. Metabolic signatures of adiposity in young adults: Mendelian randomization analysis and effects of weight change. PLoS Med 11, e1001765, doi:10.1371/journal.pmed.1001765 (2014). 
38 Hellmuth, C. et al. Tyrosine Is Associated with Insulin Resistance in Longitudinal Metabolomic Profiling of Obese Children. J Diabetes Res, doi:Artn 210890910.1155/2016/2108909 (2016).

39 Wurtz, P. et al. Metabolite profiling and cardiovascular event risk: a prospective study of 3 population-based cohorts. Circulation 131, 774-785, doi:10.1161/CIRCULATIONAHA.114.013116 (2015).

40 Welsh, P. et al. Circulating amino acids and the risk of macrovascular, microvascular and mortality outcomes in individuals with type 2 diabetes: results from the ADVANCE trial. Diabetologia 61, 1581-1591, doi:10.1007/s00125-018-4619-х (2018).

41 Altorf-van der Kuil, W. et al. Dietary amino acids and the risk of hypertension in a Dutch older population: the Rotterdam Study. Am J Clin Nutr 97, 403-410, doi:10.3945/ajcn.112.038737 (2013).

42 Teymoori, F., Asghari, G., Mirmiran, P. \& Azizi, F. High dietary intake of aromatic amino acids increases risk of hypertension. J Am Soc Hypertens 12, 25-33, doi:10.1016/j.jash.2017.11.004 (2018).

43 Surendran, A., Aliani, M. \& Ravandi, A. Metabolomic characterization of myocardial ischemia-reperfusion injury in ST-segment elevation myocardial infarction patients undergoing percutaneous coronary intervention. Sci Rep 9, 11742, doi:10.1038/s41598019-48227-9 (2019).

44 Stryeck, S. et al. Serum Concentrations of Citrate, Tyrosine, 2- and 3- Hydroxybutyrate are Associated with Increased 3-Month Mortality in Acute Heart Failure Patients. Sci Rep 9, 6743, doi:10.1038/s41598-019-42937-w (2019). 
45 Murashige, D. et al. Comprehensive quantification of fuel use by the failing and nonfailing human heart. Science 370, 364-+, doi:10.1126/science.abc8861 (2020).

46 Hakuno, D., Hamba, Y., Toya, T. \& Adachi, T. Plasma amino acid profiling identifies specific amino acid associations with cardiovascular function in patients with systolic heart failure. Plos One 10, e0117325, doi:10.1371/journal.pone.0117325 (2015).

47 Cheng, M. L. et al. Metabolic disturbances identified in plasma are associated with outcomes in patients with heart failure: diagnostic and prognostic value of metabolomics. J Am Coll Cardiol 65, 1509-1520, doi:10.1016/j.jacc.2015.02.018 (2015).

48 Vojinovic, D. et al. Association of circulating metabolites in plasma or serum and risk of stroke: Meta-analysis from seven prospective cohorts. Neurology, doi:10.1212/WNL.0000000000011236 (2020).

49 O'Keefe, S. J. et al. Increased plasma tyrosine concentrations in patients with cirrhosis and fulminant hepatic failure associated with increased plasma tyrosine flux and reduced hepatic oxidation capacity. Gastroenterology 81, 1017-1024 (1981).

50 Dejong, C. H., van de Poll, M. C., Soeters, P. B., Jalan, R. \& Olde Damink, S. W. Aromatic amino acid metabolism during liver failure. J Nutr 137, 1579S-1585S; discussion 1597S-1598S, doi:10.1093/jn/137.6.1579S (2007).

51 Morgan, M. Y., Marshall, A. W., Milsom, J. P. \& Sherlock, S. Plasma amino-acid patterns in liver disease. Gut 23, 362-370, doi:10.1136/gut.23.5.362 (1982).

52 McCullough, A. J., Czaja, A. J., Jones, J. D. \& Go, V. L. The nature and prognostic significance of serial amino acid determinations in severe chronic active liver disease. Gastroenterology 81, 645-652 (1981). 
53 Blackmore, D. et al. Metabolomic profile overlap in prototypical autoimmune humoral disease: a comparison of myasthenia gravis and rheumatoid arthritis. Metabolomics 16, 10, doi:10.1007/s11306-019-1625-z (2020).

54 Freund, H. R., Ryan, J. A., Jr. \& Fischer, J. E. Amino acid derangements in patients with sepsis: treatment with branched chain amino acid rich infusions. Ann Surg 188, 423-430, doi:10.1097/00000658-197809000-00017 (1978).

55 Freund, H., Atamian, S., Holroyde, J. \& Fischer, J. E. Plasma Amino-Acids as Predictors of the Severity and Outcome of Sepsis. Annals of Surgery 190, 571-576, doi:Doi 10.1097/00000658-197911000-00003 (1979). 